\title{
Measurements of Benzene Destruction Efficiency in a Lab-Scale Flare
}

\author{
by
}

\section{Nicholas Thomas Brooker}

\begin{abstract}
A thesis submitted to The Faculty of Graduate Studies and Research
in partial fulfilment of the degree requirements of

\section{Master of Applied Science in Mechanical Engineering}

\author{
Ottawa-Carleton Institute for \\ Mechanical and Aerospace Engineering \\ Department of Mechanical and Aerospace Engineering \\ Carleton University \\ Ottawa, Ontario, Canada
}

October 2019

Copyright (C) 2019 - Nicholas Thomas Brooker 


\section{Abstract}

Benzene is a known human carcinogen that is commonly encountered during upstream oil and gas production. When raw natural gas is produced, it is saturated with water vapour that must be removed. This is generally done using a glycol dehydrator, which uses liquid glycol to absorb water vapour. However, the liquid glycol also absorbs trace amounts of hydrocarbons including benzene, which are eventually removed in a still prior to the glycol being cycled back through the dehydrator. This benzene-laden still gas is commonly vented directly to atmosphere. The objective of this research is to investigate the benzene destruction removal efficiency (DRE) and black carbon (BC) emissions when using flaring as an emissions control mechanism for glycol dehydrators. Experiments were performed at the Carleton University Flare Facility (CUFF) in which fuel mixtures representative of glycol dehydrator still vent gas were combusted in a $50.8 \mathrm{~mm}$ diameter flare. Additional fuel mixtures were also tested to investigate the effects of heating value, methane and carbon dioxide dilution, and benzene addition on benzene DRE and BC yield. In all cases the DRE of benzene in a laboratory flare in quiescent conditions was nearly $100 \%$, but the presence of benzene in the fuel increased the BC yield above similar results for alkaneonly fuels. Considering reported data for Alberta, Canada in 2017, the results of this work suggest that flaring glycol dehydrator still gases could potentially reduce benzene emissions by a factor of 1000, but increase yearly black carbon emissions produced by flaring in Alberta by up to $66 \%$. The increase in BC could be partially mitigated by adding methane to the still gas mixture prior to flaring. Further work is recommended to investigate the effects of crosswinds on the benzene DRE in a flare. 


\section{Table of Contents}

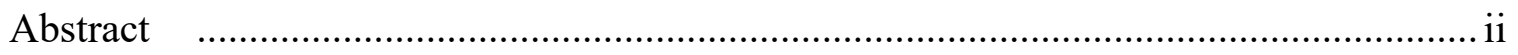

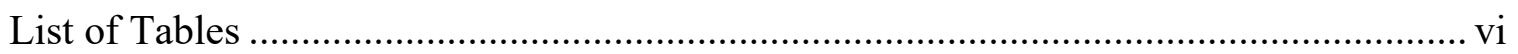

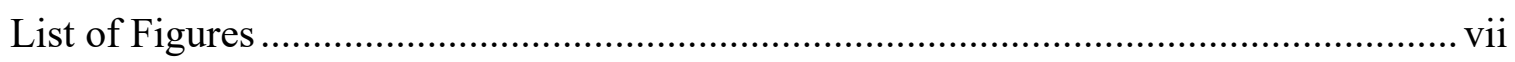

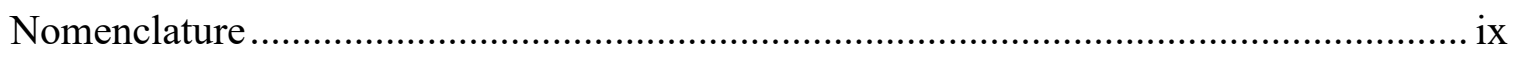

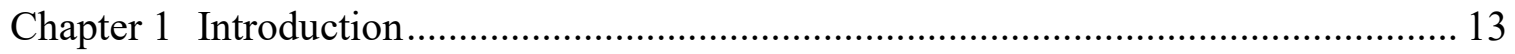

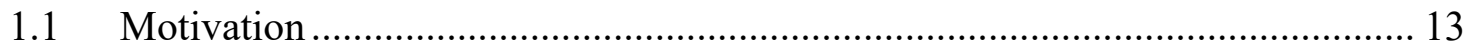

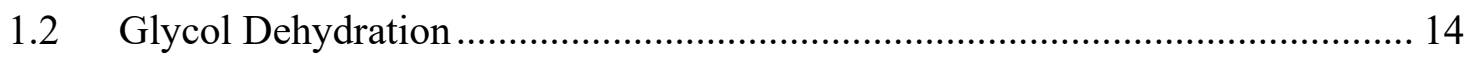

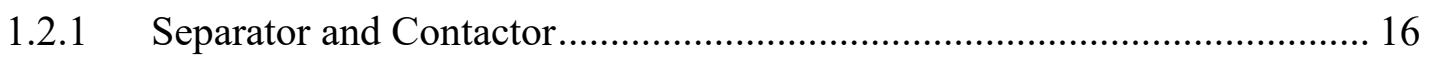

1.2.2 Still, reboiler, and surge drum............................................................ 17

1.2.3 Optional Flash Tank ........................................................................... 17

1.3 Benzene Reporting Guidelines and Emission Regulations ............................... 18

1.3.1 Benzene Reporting in the National Pollutant Release Inventory (NPRI) ... 19

1.4 Review of Currently Used Benzene DRE Values for Flares ............................ 20

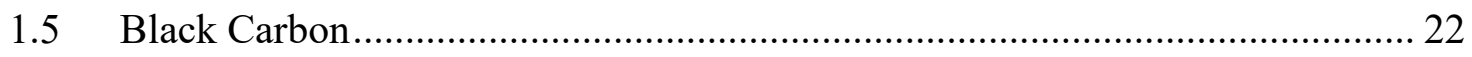

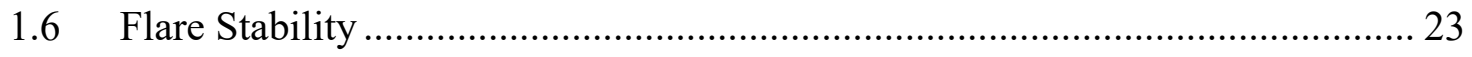

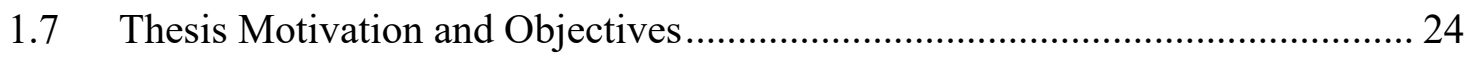

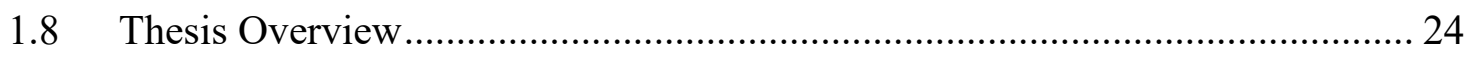

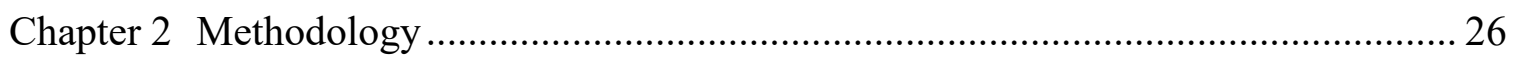

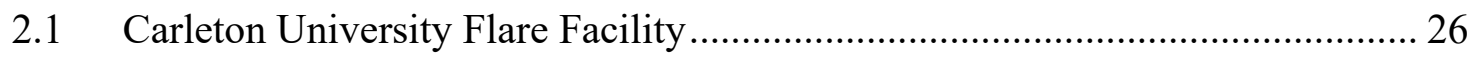

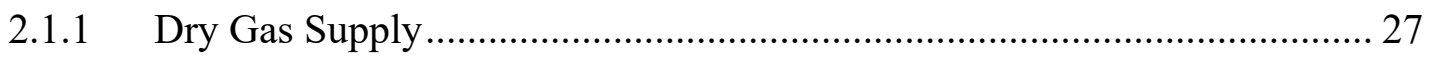

2.1.2 Liquid Fuel Vaporization ....................................................................... 27

2.2 Benzene Measurements with Gas Chromatography ......................................... 29

2.2.1 Baseline-Mocon Series 9100 GC Separation................................................. 30 
2.2.2 Baseline-Mocon Series 9100 GC Detection ................................................ 31

2.2.3 Chromatograph and Calibration............................................................... 33

2.3 Organic Carbon and Elemental Carbon ………………………....................... 34

2.4 Glycol Dehydrator Still Gas Compositions...................................................... 35

2.4.1 Test Matrix Development Based on Higher Heating Value ........................ 36

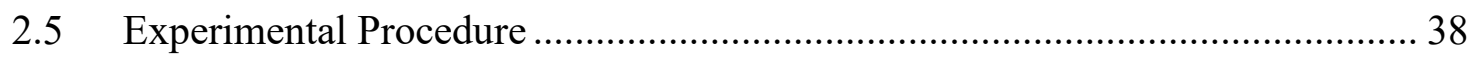

Chapter 3 System Verification, Test Matrix, and Calculation Procedures........................ 39

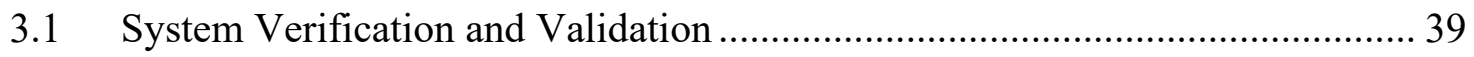

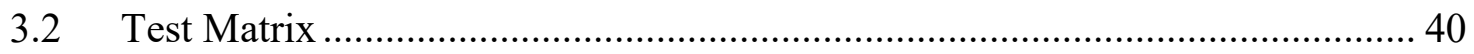

3.3 Calculation of Destruction and Removal Efficiency.......................................... 43

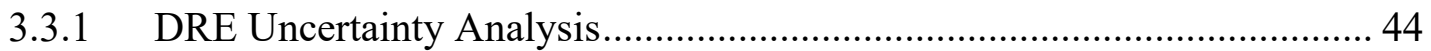

3.3.2 Benzene Yield Calculation and Uncertainty Analysis................................ 46

3.3.3 Repeatability Experiments and Sample Calculations .................................. 47

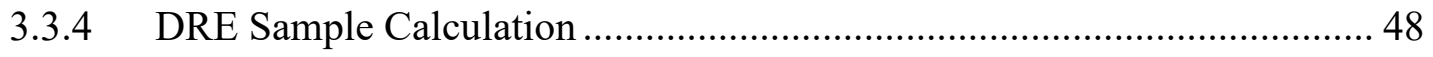

3.3.5 DRE Uncertainty Sample Calculation ......................................................... 49

3.3.6 Benzene Yield and Uncertainty Sample Calculation..................................... 51

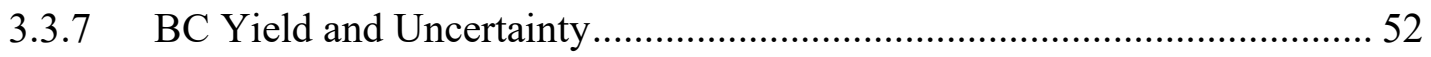

Chapter 4 Results and Discussion ......................................................................... 54

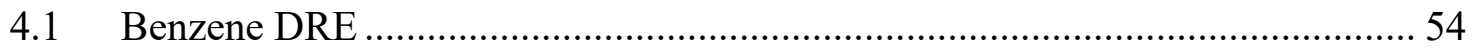

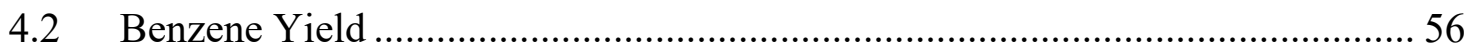

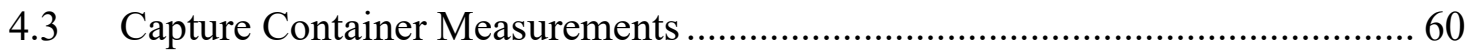

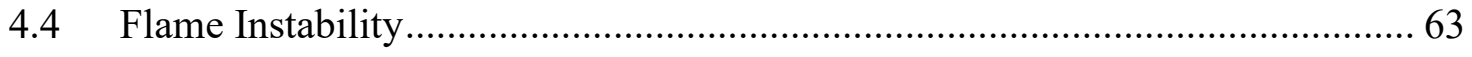

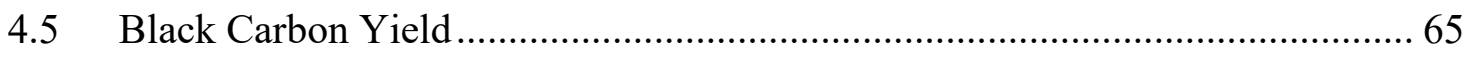

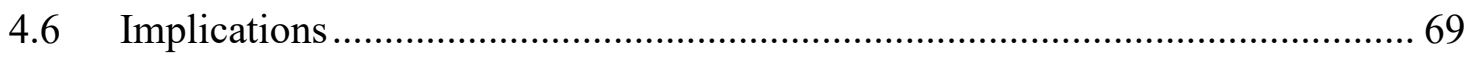

Chapter 5 Final Comments and Future Work.............................................................. 71 
5.1 Future Recommendations.................................................................... 72

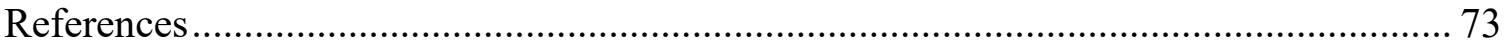




\section{List of Tables}

Table 1.1: Benzene emission requirements from AER ............................................... 19

Table 1.2: Summary of DRE values from literature ................................................ 22

Table 2.1: Composition and flow rate data from glycol dehydrator still vents operating in

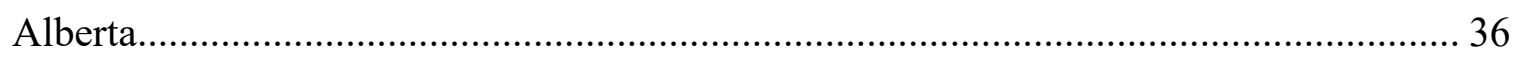

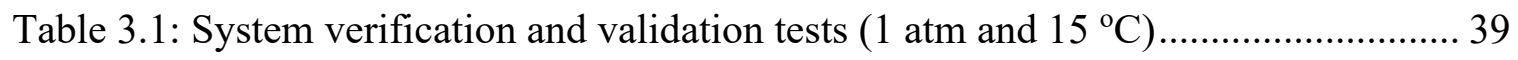

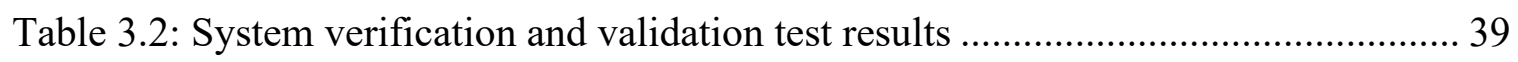

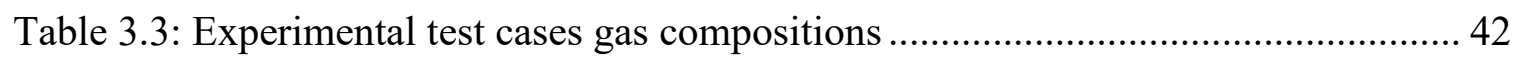

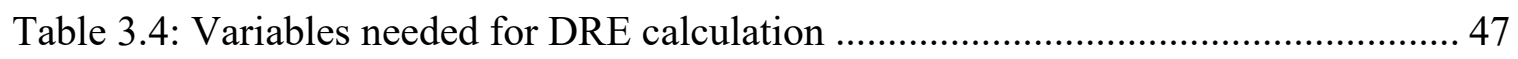

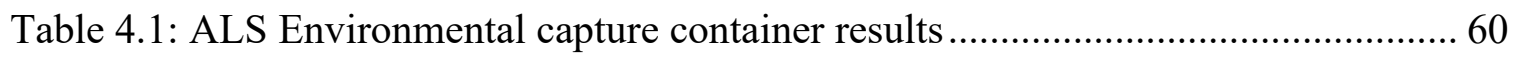

Table A.1: Results summary for repeats of the M11 test ...................................... 77

Table A.2: Experimental results summary, with precision error from repeated M11 measurements applied to DRE and benzene yield to estimate total uncertainty ............. 78

Table A.3: Simulated glycol dehydrator still gas compositions .................................. 79 


\section{List of Figures}

Figure 1.1: Glycol dehydrator at a facility in Alberta.................................................... 15

Figure 1.2: Glycol dehydrator simplified schematic.................................................. 15

Figure 1.3: Bubble cap tray simplified schematic …………….................................... 16

Figure 1.4: Glycol dehydrator simplified schematic with optional flash tank................. 18

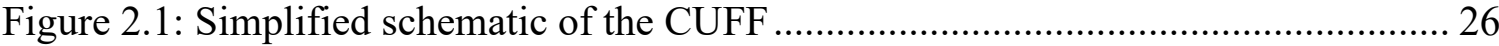

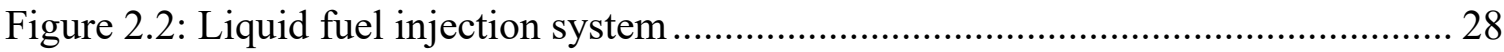

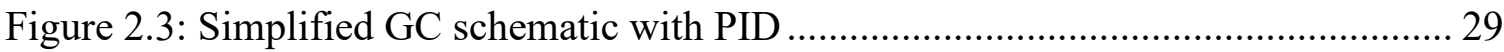

Figure 2.4: Baseline-Mocon Series 9100 GC column oven simplified schematic ........... 31

Figure 2.5: Ionization potentials of gases expected to be present in combustion products.

Figure 2.6: Simplified schematic of PID operation ........................................................ 33

Figure 2.7: Baseline-Mocon series 9100 GC calibration peak ………………………..... 33

Figure 3.1: M11 DRE repeatability measurements......................................................... 51

Figure 4.1: Benzene DRE in 50.8-mm diameter vertical flares burning a broad range of multicomponent fuel mixtures. (a) Plot including data for all performed experiments; (b) Same data as (a) but excluding the two low flowrate cases with the highest uncertainties.

Figure 4.2: Benzene yield as a function of benzene flare gas mole fraction (a) including all tests performed with an exponential fit (b) excluding the S-M11+ $\mathrm{C}_{6} \mathrm{H}_{6}$ case such that remaining data are for flare gas benzene mole fraction $\leq 3.4 \% \ldots \ldots \ldots \ldots \ldots \ldots \ldots \ldots \ldots \ldots \ldots \ldots \ldots \ldots . . .57$

Figure 4.3: Benzene yield for compositions with zero benzene in fuel stream ................ 59

Figure 4.4: (a) DRE measured from GC and capture container (b) benzene yield measured from $\mathrm{GC}$ and capture container

Figure 4.5: Flame lift from $\mathrm{CO}_{2}$ instability (a) flame is partially lifted (b) and (c) flame is fully lifted (d) flame is attached. 
Figure 4.6: BC yield for all compositions measured with Sunset Labs Model 4 OCEC analyzer (a) as a function of HHV with alkane fuel BC yield model and (b) as a function

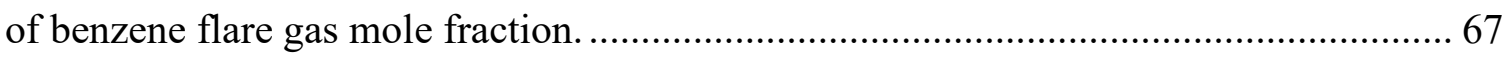




\section{Nomenclature}

Latin

Symbol Description

$B_{D R E_{C_{6} H_{6}}}$ Bias error on the destruction and removal efficiency $\%$ of benzene

$B_{\dot{m}_{B C}} \quad$ Bias error on the mass flow rate of black carbon $\quad \%$ produced from the flare

$B_{x_{i}} \quad$ Bias error on the measurement of species $i$

$B_{Y_{C_{6} H_{6}}}$

$B_{\Delta X_{C_{6} H_{6}}}$

Bias error on benzene yield

Bias error on difference in benzene measured in the $\%$ plume and ambient lab air

$M_{\infty} \quad$ Molar mass of the ambient lab air

$\dot{m}_{B C}$

Mass flare

$M_{C_{6} H_{6}} \quad$ Molar mass of benzene

$M_{F G} \quad$ Molar mass of the flare gas

$\dot{m}_{F G} \quad$ Mass flow rate of the flare gas

$\dot{n}_{C_{6} H_{6}, p} \quad$ Molar flow rate of benzene in the plume of the flare

$\dot{n}_{F G}$

$\dot{n}_{p}$

$N$

$P_{D R E}$

$P_{p}$

$P_{Y_{C_{6} H_{6}}}$

$Q_{F G}$

$R_{u}$

$t$

$T_{\text {sample }}$

$X_{C_{6} H_{6}, \infty}$

$X_{C_{6} H_{6}, F G}$

$X_{C_{6} H_{6}, p}$

$X_{C_{x} H_{y}, F G}$

$\mathrm{X}_{\mathrm{CH}_{4}, \infty}$

$\mathrm{X}_{\mathrm{CH}_{4}, \mathrm{p}}$

$X_{C O, \infty}$
Molar flow rate of the flare gas

Molar flow rate of the plume of the flare

Number of measurements made of destruction and removal efficiency of benzene for one test case

Precision error on the measurement of destruction and removal efficiency of benzene

Pressure of the sample inside the OCEC

Precision error on the benzene yield

Volumetric flow rate of the flare gas at standard conditions $\left(15^{\circ} \mathrm{C}\right.$ and $\left.101325 \mathrm{~Pa}\right)$

Universal gas constant

Student t-value corresponding to the number of measurements

Temperature of the sample inside the OCEC

Mole fraction of benzene in the ambient lab air

Mole fraction of benzene in flare gas

Mole fraction of benzene in the plume of the flare gas

Mole fraction of hydrocarbons in the flare gas

Mole fraction of methane in the ambient lab air

Mole fraction of methane in the plume of the flare gas

Mole fraction of carbon monoxide in the ambient lab air
First Use

Units Eqn. Page

(3.6) 45

(3.15) 53

(3.6) 45

(3.13) 47

(3.13) 47

$\mathrm{kg} / \mathrm{kmol} \quad$ (3.2) 44

$\mathrm{kg} / \mathrm{s} \quad$ (3.14) 53

$\mathrm{kg} / \mathrm{kmol} \quad$ (3.12) 46

$\mathrm{kg} / \mathrm{kmol} \quad$ (3.8) 45

$\mathrm{kg} / \mathrm{s} \quad(3.2) \quad 44$

$\mathrm{kmol} / \mathrm{s} \quad$ (3.1) 43

$\mathrm{kmol} / \mathrm{s} \quad$ (3.1) 43

$\mathrm{kmol} / \mathrm{s} \quad(3.7) \quad 45$

(3.11) 46

(3.11) 46

$\mathrm{Pa} \quad$ (3.14) 53

$\begin{array}{lll}\% & \text { (3.13) }\end{array}$

SLPM (3.12) 46

(3.14) 53

(3.11) 46

(3.14) 53

(3.2) 44

(3.1) 43

(3.2) 44

(3.2) 44

(3.3) 44

(3.3) 44

(3.3) 44 
Latin

Symbol Description

$X_{C O, p} \quad$ Mole fraction of carbon monoxide in the plume of $\%$ the flare gas

$X_{\mathrm{CO}_{2} . \infty} \quad$ Mole fraction of carbon dioxide in the ambient lab $\%$ air

$X_{\mathrm{CO}_{2} . \mathrm{FG}} \quad$ Mole fraction of carbon dioxide in the flare gas $\quad \%$

$X_{\mathrm{CO}_{2} \cdot p} \quad$ Mole fraction of carbon dioxide in the plume of the $\%$ flare gas

$X_{i} \quad$ Mole fraction of each species $I$ in fuel mixture $\quad \%$

$\Delta X_{C_{6} H_{6}} \quad$ Difference in mole fraction of benzene measured in $\%$ plume and ambient lab air

$Y_{C_{6} H_{6}} \quad$ Yield of benzene produced per cubic meter of flare $\mathrm{mg} / \mathrm{m}^{3}$ gas
First Use

Eqn. Page

(3.3) $\quad 44$

(3.2) 44

(3.2) 44

(3.2) 44

(2.1) $\quad 37$

(3.13) 47

(3.12) 46
Greek

Symbol

$f_{\mathcal{v}, \text { measured }}$

$\rho_{B C}$

$\sigma$

$\theta_{D R E_{C_{6} H_{6}}, i}$

$\Theta_{\dot{m}_{B C}, i}$

$\Theta_{\dot{n}_{p, i}}$
Description

Measured soot volume fraction

Density of black carbon

Standard deviation on the mean of the measurement of destruction and removal efficiency of benzene

Sensitivity indices for destruction and removal efficiency of benzene for species $i$

Sensitivity indices for the mass flow rate of black carbon for species $i$

Sensitivity indices for the molar flow rate of the plume for species $i$

Variable Description

$\# C_{C_{6} H_{6}} \quad$ Number of carbon atoms in benzene

$\# C_{F G} \quad$ Number of carbon atoms in flare gas

$D R E_{C_{6} H_{6}}$

$H H V_{\text {mixture }}$

$H H V_{i}$

$U N C_{\dot{n}_{p}}$

$U N C_{Q_{F G}}$

$U N C_{X_{C_{6} H_{6}, \infty}}$
Destruction and removal efficiency of benzene

Higher heating value of overall fuel mixture

Higher heating value of each species $I$ in fuel mixture

Relative uncertainty on the molar flow rate of the plume of the flare

Relative uncertainty on the volumetric flow rate of the flare gas

Absolute uncertainty on the mole fraction of benzene in the ambient lab air
First Use

Unit Eqn. Page

$\begin{array}{ccc}- & (3.14) & 53 \\ \mathrm{~kg} / \mathrm{m}^{3} & (3.14) & 53 \\ \% & (3.11) & 46 \\ - & (3.6) & 45 \\ - & (3.15) & 53 \\ - & (3.7) & 45\end{array}$

First Use

Units Eqn. Page

- (3.3) 44

- (3.2) 44

$\% \quad(3.1) \quad 43$

$\mathrm{MJ} / \mathrm{m}^{3} \quad(2.1) \quad 37$

$\mathrm{MJ} / \mathrm{m}^{3} \quad$ (2.1) $\quad 37$

$\% \quad(3.13) \quad 47$

$\% \quad(3.13) \quad 47$

ppb (3.13) 47 


\begin{tabular}{|c|c|c|c|c|}
\hline \multirow[b]{2}{*}{ Variable } & \multirow[b]{2}{*}{ Description } & \multirow[b]{2}{*}{ Units } & \multicolumn{2}{|c|}{ First Use } \\
\hline & & & Eqn. & Page \\
\hline$U N C_{X_{C_{6} H_{6}, p}}$ & $\begin{array}{l}\text { Absolute uncertainty on the mole fraction of } \\
\text { benzene in the plume of the flare }\end{array}$ & $\mathrm{ppb}$ & (3.13) & 47 \\
\hline$U N C_{Y_{C_{6} H_{6}}}$ & $\begin{array}{l}\text { Uncertainty on the yield of benzene produced per } \\
\text { cubic meter of flare gas }\end{array}$ & $\mathrm{mg} / \mathrm{m}^{3}$ & (3.13) & 47 \\
\hline
\end{tabular}

Acronym Description

First Use

AAAQO Alberta Ambient Air Quality Objectives 14

$\begin{array}{lll}\text { AER } & \text { Alberta Energy Regulator } & 18\end{array}$

CAC Criteria Air Contaminant 20

CAPP Canadian Association of Petroleum Producers 21

ccm Cubic Centimeters per Minutes 30

CCME Canadian Council of Ministers of the Environment 13

$\begin{array}{lll}\text { CEM } & \text { Controlled Evaporator Mixer } & 28\end{array}$

CUFF Carleton University Flare Facility 26

DRE Destruction and Removal Efficiency 14

EERL Energy \& Emissions Research Laboratory 52

EPEA Alberta Environment Protection and Enhancement 14

Act

$\begin{array}{lll}\mathrm{eV} & \text { Electron Volts } & 31\end{array}$

GC Gas Chromatograph 29

H11 Heavy $95^{\text {th }}$ percentile fuel mixtures with 11 fuels 36

HHV Higher Heating Value $\quad 37$

L11 Light $5^{\text {th }}$ percentile fuel mixtures with 11 fuels 36

M11 Medium 50 ${ }^{\text {th }}$ percentile fuel mixtures with 11 fuel 36

MFC Mass Flow Controller $\quad 27$

MSD $\quad$ Mass Selective Detector $\quad 60$

NDIR Non-Dispersive Infrared $\quad 34$

NIOSH National Institute of Occupational Safety and Heath 34

$\begin{array}{ll}\text { NPRI National Pollutant Release Inventory } & 13\end{array}$

PAH Polycyclic Aromatic Hydrocarbons 23

PID Photo-Ionization Detector $\quad 29$

$\begin{array}{ll}\text { ppb Parts Per Billion } & 27\end{array}$

SLPM Standard Liters Per Minute 26

UOG Upstream Oil and Gas $\quad 13$

U.S. EPA United States Environmental Protection Agency 21

$\begin{array}{lll}\text { VOC } & \text { Volatile Organic Compound } & 14\end{array}$ 


$\begin{array}{llr}\begin{array}{l}\text { Chemical } \\ \text { Formula }\end{array} & \text { Description } & \text { First Use } \\ \text { PC } & \text { Black Carbon } & 14 \\ \mathrm{C} 1 & \text { Methane } & 37 \\ \mathrm{C} 7 & \text { Heptanes } & 37 \\ \mathrm{C} 8 & \text { Octanes } & 37 \\ \mathrm{CH}_{4} & \text { Methane } & 39 \\ \mathrm{C}_{6} \mathrm{H}_{6} & \text { Benzene } & 35 \\ \mathrm{CO}_{2} & \text { Carbon Dioxide } & 21 \\ \mathrm{EC} & \text { Elemental Carbon } & 34 \\ \mathrm{H}_{2} \mathrm{O} & \text { Water vapour } & 41 \\ \mathrm{~N}_{2} & \text { Nitrogen gas } & 37 \\ \mathrm{OC} & \text { Organic Carbon } & 34\end{array}$




\section{Chapter 1 Introduction}

\subsection{Motivation}

In the upstream oil and gas (UOG) sector, raw natural gas extracted from the ground is generally saturated with water vapour. The water content must be reduced to an acceptable level for this gas to be marketable and/or compressed into pipelines. This is usually achieved using a dehydrator in which water vapour is absorbed by a working fluid commonly triethylene glycol. Although the primary goal of a glycol dehydrator is to remove water vapour, trace amounts of benzene and other hydrocarbons are absorbed by the working fluid. When the fluid is regenerated to be cycled back through the dehydrator, these absorbed vapours are released. The regeneration process involves heating the glycol to release water and other vapours in a still column, which is frequently vented, untreated, to the atmosphere. This makes glycol dehydrators a dominant source of benzene emissions in the upstream oil and gas sector [1], [2].

In 2017, there were 1528 glycol dehydrators operating in Alberta, which are estimated to have released 399 tonnes of benzene into the atmosphere after any emissions controls [3]. This is roughly half of the benzene emissions reported to the Canadian National Pollutant Release Inventory (NPRI) in 2017, although as elaborated in Section 1.3.1 not all glycol dehydrator emissions are included in the NPRI inventory. In a 2010 report [4], the Canadian Council of Ministers of the Environment (CCME) estimated that total benzene emissions from glycol dehydrators was 1800 tonnes in 2008. This was thought to be the third largest source (12.4\%) of benzene emissions in Canada in 2008 (14,560 tonnes), following transportation (45.7\%), and residential wood burning (30.4\%) [4].

Benzene is a dangerous substance that has been classified as a human carcinogen for all forms of exposure with supporting evidence from animal and human studies [5]. There have been documented incidents where the standardized mortality ratio (i.e. the ratio

of the number of deaths observed to the number of deaths expected in general population) has been significantly increased due to exposure to benzene [5]. Alberta Ambient Air 
Quality Objectives (AAAQO) limit annual ambient air benzene concentrations to $3 \mu \mathrm{g} / \mathrm{m}^{3}$ and hourly concentrations to $30 \mu \mathrm{g} / \mathrm{m}^{3}$, which corresponds to $0.9 \mathrm{ppb}_{\mathrm{v}}$ and $9.0 \mathrm{ppb}_{\mathrm{v}}$ respectively. These limits were developed for the Alberta Environment Protection and Enhancement Act (EPEA), which is intended to ensure that all industrial facilities operate under the benzene ambient air concentration [6].

Flaring is one potential control method to reduce or eliminate benzene emissions from dehydrator still columns. However, benzene destruction efficiencies in flares are highly uncertain as further elaborated in Section 1.4 below. Flaring can also produce other undesirable emissions such as volatile organic compounds (VOCs) and black carbon (BC, also known as soot). The primary motivation of this thesis is to better understand the suitability of flaring as a control mechanism for glycol dehydrator benzene emissions, considering both benzene destruction and removal efficiency (DRE) in flares.

\subsection{Glycol Dehydration}

In a typical dehydration system, raw natural gas that is saturated with water vapour is sent through a glycol dehydrator that uses liquid glycol (typically triethylene glycol) which has the capability of absorbing water vapour. The dehydrator system is designed so that after

the natural gas meets the glycol, the water content is reduced to approximately 4-7 $\mathrm{lb} / \mathrm{MMscf}\left(64-112 \mathrm{~kg} / \mathrm{m}^{3}\right)$ of gas [7], making the dried gas fit for market. Unfortunately, the triethylene glycol can also absorb hydrocarbons, which most notably include benzene. The water vapour and absorbed hydrocarbons must be removed to regenerate and reuse the glycol in the dehydrator. An example photo of a glycol dehydrator at a natural gas production site in Alberta is shown in Figure 1.1. This dehydrator vents the waste gases produced from the glycol regeneration process, as is common practice. 


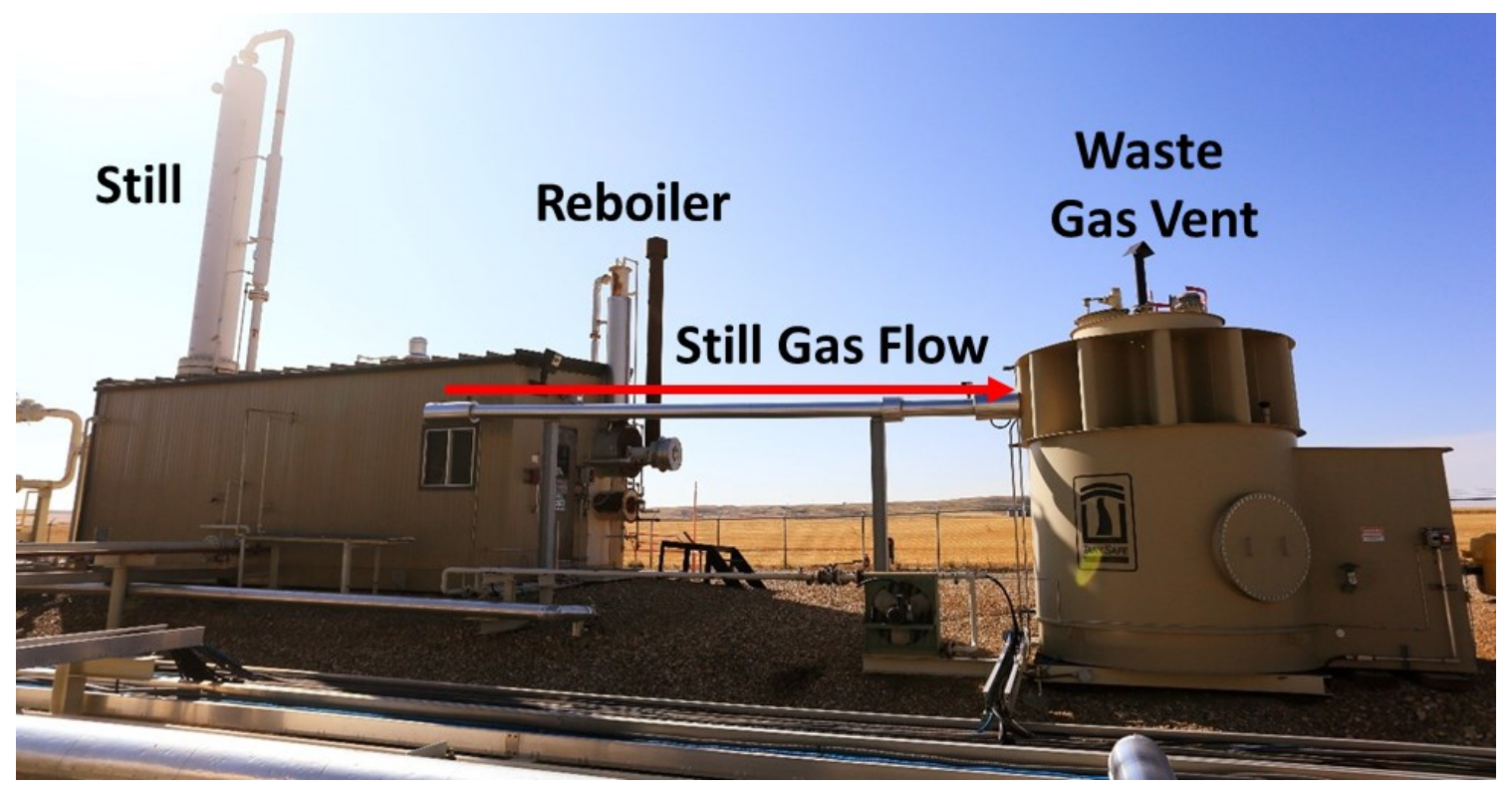

Figure 1.1: Glycol dehydrator at a facility in Alberta

The main components of a glycol dehydrator are the contactor, still, reboiler, surge drum, and separator, which are shown in a simplified schematic in Figure 1.2. The full process of how benzene enters the dehydrator, is absorbed by the liquid glycol, and is then released into the atmosphere is detailed in Sections 1.2.1 through 1.2.3.

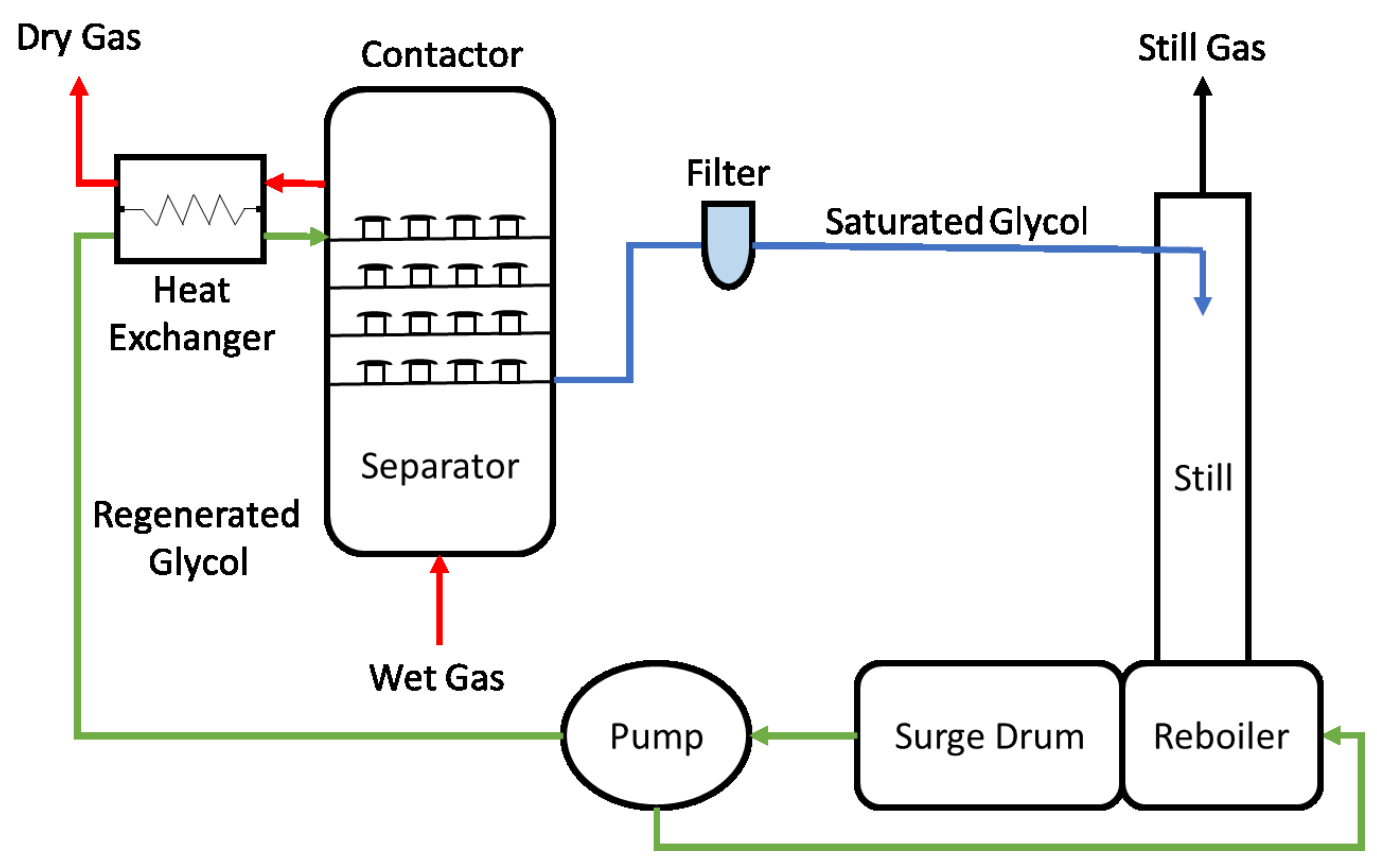

Figure 1.2: Glycol dehydrator simplified schematic 


\subsubsection{Separator and Contactor}

Raw natural gas entering the dehydrator first passes through a separator which removes particulates and liquids before entering the contactor. The separator may be a standalone unit or built into the contactor and typically works by having the wet gas flow through a mist eliminator. Water or liquid fuel droplets in the wet gas will coalesce, be captured by a wire mesh, and drip out of the separator [8].

The contactor is where the liquid glycol is brought into contact with the wet natural gas so that water vapour can be absorbed. Contactors typically use what are called bubble cap trays, illustrated in Figure 1.3. Liquid glycol flows into the contactor above the uppermost tray, flooding the first tray and overflowing into the subsequent trays below it. As the gas flows upward through the cap, it goes through slots inside of the cap and into the glycol, forming bubbles that generate a large surface area for the absorption of water vapour. After exiting the contactor, the sales-grade dehydrated natural gas passes through a heat exchanger to cool down the stream of regenerated glycol before leaving the system [8]. Not shown in Figure 1.2 and Figure 1.4 are various other heat exchangers and cooling devices which may be used to ensure the regenerated glycol is sufficiently cool before reentering the contactor.

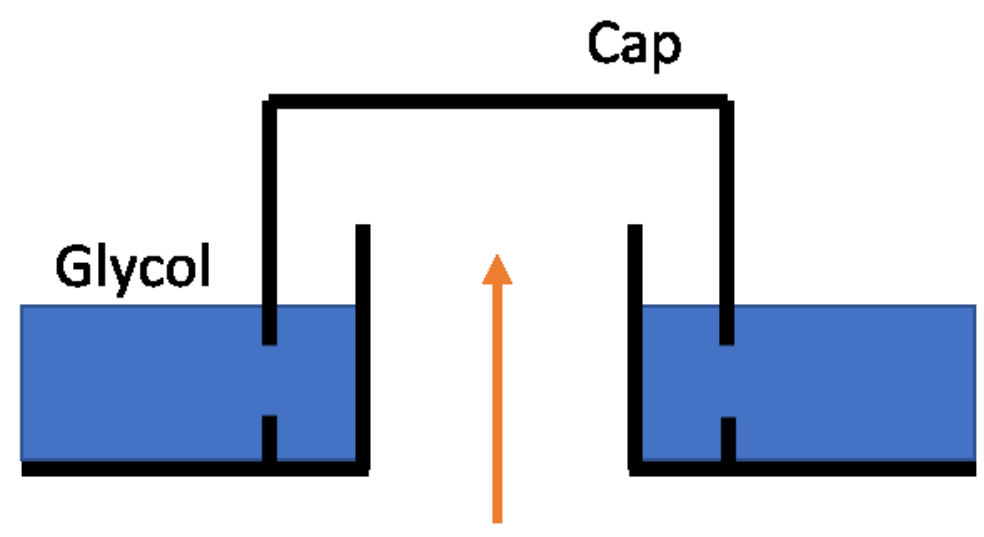

Natural Gas

Figure 1.3: Bubble cap tray simplified schematic 


\subsubsection{Still, reboiler, and surge drum}

After absorbing the water vapour and trace hydrocarbons, the saturated glycol needs to be regenerated so that it can be reused in the contactor. The saturated glycol exits the bottom of the contactor, is filtered, and may exchange heat with the regenerated glycol before entering the top of the still. Upon entering the still, the glycol drops through a section packed with ceramic, which improves the contact area between the liquid phase and the vapour phase, and into the reboiler [8]. The reboiler heats the liquid glycol to near its boiling temperature, releasing both the absorbed water and any absorbed hydrocarbons. This happens because glycol loses its ability to retain water and hydrocarbons at high temperature [8]. This waste gas (hydrocarbons and water vapour) then rises out of the still where it can be vented or otherwise controlled. The waste gas leaving the still is the focus of this research as it is the primary source of benzene released into the atmosphere. An emissions control mechanism such as a flare may be installed on the exhaust, though this is not necessarily required.

Dehydrated liquid glycol then flows to the surge drum, which is a large reservoir used to ensure there is enough glycol in the system while preventing surges in the flow. The surge drum is required to maintain a nearly constant amount of glycol inside of the contactor as well as keep a nearly steady flow throughout the system [8].

\subsubsection{Optional Flash Tank}

Figure 1.4 shows a schematic of a glycol dehydrator with an optional component called a flash tank (as seen on the centre of the Figure 1.4). The flash tank serves as a preliminary step before the still and the reboiler. The saturated glycol first passes through the still which acts as a heat exchanger that heats the glycol to near boiling where it enters the flash tank and experiences a pressure drop. This pressure drop causes the glycol to release some of the absorbed hydrocarbons, which then may be sent to a flare or are sometimes used to power the reboiler [8]. Although flash tanks are not commonly seen in industry, if they are included in the system benzene can be found in the flash tank off-gas. 


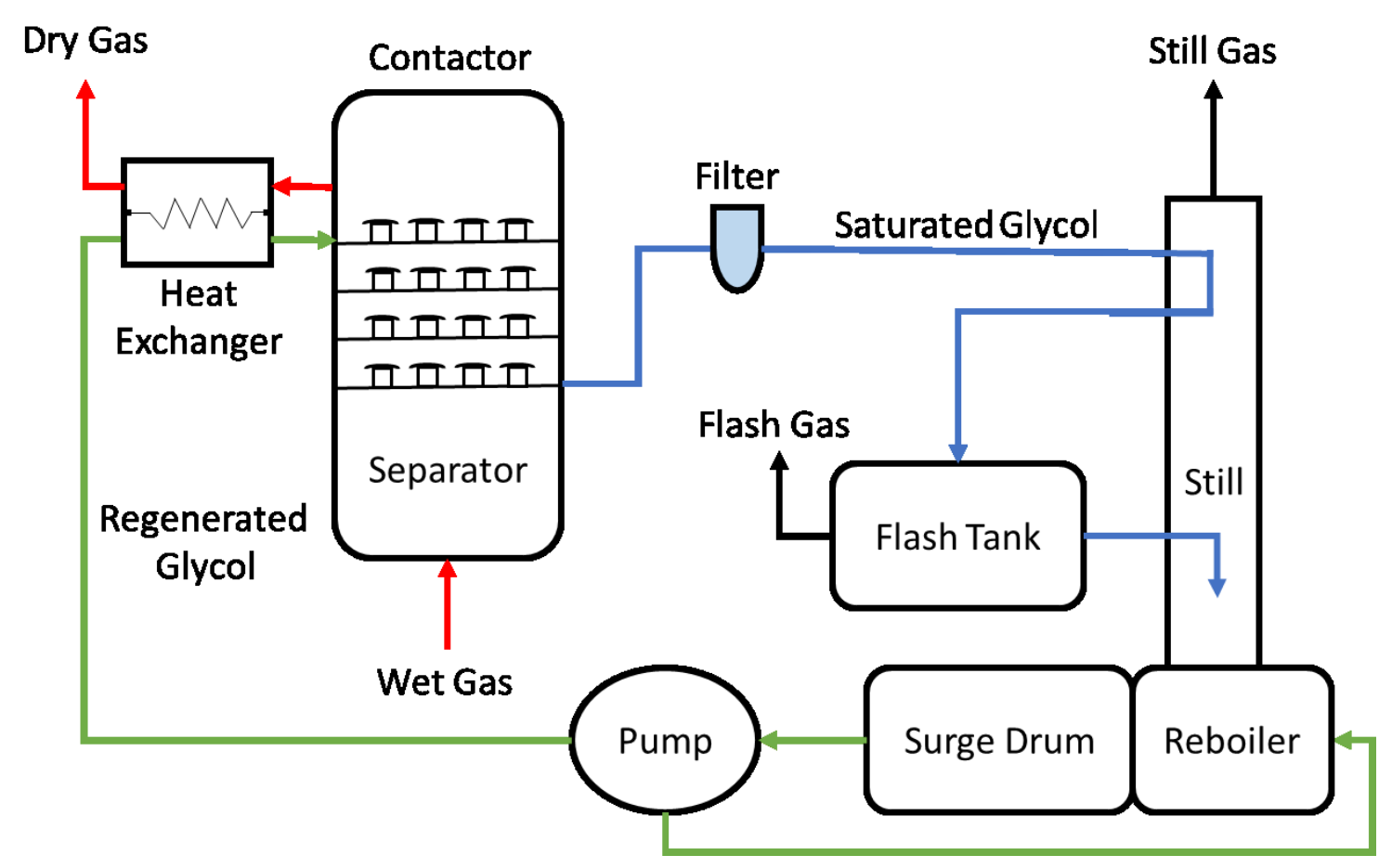

Figure 1.4: Glycol dehydrator simplified schematic with optional flash tank

\subsection{Benzene Reporting Guidelines and Emission Regulations}

Alberta Energy Regulator (AER) Directive 060 [9] governs flaring, incinerating, and venting at upstream wells and facilities in Alberta, including specific requirements on when a gas stream must be flared. Glycol dehydrators are regulated in the directive, but only from the perspective of reducing methane emissions from the dehydrators by the year 2022 . Directive 60 refers to Directive 039 [2] for emission reduction and reporting of benzene.

AER's Directive 039 sets limits and reporting requirements for benzene emissions from glycol dehydrators based on the distance from permanent residences as summarized in Table 1.1 (reproduced from Table 1 in [2]). The main purpose of this directive is to reduce benzene emissions such that the requirements for the AAAQO are met for the onehour average and annual average. The directive states that all glycol dehydrator sites must determine the shortest distance to the nearest development. For developments within close proximity to a benzene emissions source (defined as $\leq 750 \mathrm{~m}$ ), the operators must inform all occupants of the nearby development about benzene, its dangers, and site-specific information. Benzene emissions from glycol dehydrators on sites may be estimated 
through simulation using GRI-GLYCalc or by sampling. To reduce benzene emissions, the directive authorizes optimizing glycol dehydrator operation or implementing control methods such as a flare, incinerator, vapour recovery, reboiler burner, or reciprocating engine. The maximum DRE that the directive allows to be assumed for a flare is $90 \%$ [2]. However, as discussed in Section 1.4, there are little to no data supporting this $90 \%$ DRE value in a flare.

Table 1.1: Benzene emission requirements from AER

\begin{tabular}{|l|c|c|}
\hline \multicolumn{1}{|c|}{ Type of Emissions Control } & $\begin{array}{c}\text { Distance from } \\
\text { development }(\mathbf{m})\end{array}$ & $\begin{array}{c}\text { Emission limit } \\
\text { in tonnes }(\mathbf{t})\end{array}$ \\
\hline \multirow{2}{*}{$\begin{array}{l}\text { Without a control device or a control device other than an } \\
\text { "appropriately designed flare, incinerator or reciprocating } \\
\text { engine" }\end{array}$} & 10100 & 0.0 \\
\cline { 2 - 3 } & $251-750$ & 0.1 \\
\cline { 2 - 3 } & $>750$ & 0.5 \\
\hline $\begin{array}{l}\text { With control device "appropriately designed flare, } \\
\text { incinerator or reciprocating engine" }\end{array}$ & $\leq 750$ & 1.0 \\
\cline { 2 - 3 } & $>750$ & 1.0 \\
\hline
\end{tabular}

The definition of an "appropriately designed flare or incinerator" in Table 1.1 is one that complies with the basic performance requirements laid out in Directive 060. From Directive 060, all flares and incinerators must be designed, operated, and maintained such that resulting emissions do not exceed the AAAQO or produce $\mathrm{H}_{2} \mathrm{~S}$ odours. If a flare or incinerator produces odours or visible smoke, it must be modified or replaced. The heating value of gases being flared or incinerated must not be lower than $20 \mathrm{MJ} / \mathrm{m}^{3}$, though this may go as low as $12 \mathrm{MJ} / \mathrm{m}^{3}$ if the flame is stable and does not exceed the AAAQO. Flare and incinerator stacks must be designed such that the ground radiant heat does not exceed $4.73 \mathrm{~kW} / \mathrm{m}^{2}$. Flares or incinerators that are a distance of less than five times the height the nearest building must be at least 2.5 times as tall as the highest building in the vicinity. Flares or incinerators must also be high enough to ensure proper plume dispersion [9]. Notably, there are no specific requirements for flare efficiencies or associated species emission rates in Directive 060 [9].

\subsubsection{Benzene Reporting in the National Pollutant Release Inventory (NPRI)}

The NPRI is Canada's publicly available inventory of emissions for over 320 pollutants from sites across the country. However, the NPRI only includes a fraction of all emissions sources and reporting requirements vary depending on the substance in question. UOG 
facilities may need to report to the NPRI if employees or contractors work more than 20,000 per year at the facility or operate stationary combustion equipment. If either or both of these criteria are met, then reporting is only required if emissions thresholds for NPRI designated substances are exceeded [10]. The NPRI classifies benzene as a Part 5 substance and emissions must be reported if the following criteria are met (values in tonnes/year):

- The total quantity of the Part 5 substance (benzene in this case) released to air is $\geq$ 1 tonne, and

- Part 4 total VOCs released to air are $\geq 10$ tonnes.

From all sources captured by the NPRI, there were 457 tonnes of reportable benzene emissions into the air in 2011, 657 tonnes in 2015, and 802 tonnes in 2017 [11]. However, an Environment Canada Criteria Air Contaminant (CAC) emissions inventory prepared by Clearstone Engineering Ltd. suggests that in 2011 there were 3560 tonnes of benzene emissions from the Canadian oil and gas sector alone [12]. About 2600 tonnes of these emissions were attributed to the UOG sector in Alberta [12]. The 2018 AER report ST60B [3] suggests that in 2011 glycol dehydrators in Alberta accounted for 849 tonnes of benzene emissions. This is roughly $33 \%$ of the total benzene emissions released in the Alberta UOG sector as estimated in the Clearstone Engineering Ltd. report, and 86\% larger than the reported emissions of all sources captured by NPRI. The 2018 AER report ST60B reports that there were 399 tonnes of benzene emitted from glycol dehydrators in Alberta in 2017 [3].

\subsection{Review of Currently Used Benzene DRE Values for Flares}

To the author's knowledge there are no publicly available, published data on the DRE of benzene in industrial flares representative of those that could be produced using glycol dehydrator still vent gas. The literature does contain measurements of DRE for non-premixed flames, but reported values cited conflict, lack supporting data, or lack references to determine if the data accurately represent benzene flaring scenarios. Only three reports directly reference the DRE of benzene in a flare as summarized in Table 1.2. 
A report from the Canadian Association of Petroleum Producers (CAPP) called "Control of Benzene Emissions from Glycol Dehydrators" recommends use of a 90\% DRE for benzene is for flaring [1] and references the "University of Alberta Flare Research Project" final report [13] as the source of this value. The objective of the research presented in [13] was to use a wind tunnel to determine the effects of nozzle diameter, exit velocity, and wind speed on the overall combustion efficiency for flaring models [13]. Benzene emissions were not directly considered. In the report the only mention of measuring benzene appears on page 149, where BTEX samples were taken during a limited number of tests in the wind tunnel. According to the report BTEX concentrations were below the detectable limits for all test cases, making the calculation of a nominal DRE impossible. Perhaps coincidentally, one of the experiments performed was to measure the carbon conversion efficiency (percentage of fuel that had been fully converted into $\mathrm{CO}_{2}$ ). Under certain conditions, the result of this test was a carbon conversion efficiency of $90.4 \%$. It is possible that the CAPP report was referencing carbon conversion efficiency as a surrogate for benzene DRE, but without further knowledge to what the CAPP report was referencing it appears that their statement of a $90 \%$ benzene DRE is unsubstantiated.

The other two benzene DRE values are from reports by the United States Environmental Protection Agency (U.S. EPA). The first document, "Locating and Estimating Air Emission Sources of Benzene," [14] reports 89.5\% as the DRE of benzene in a flare. Unfortunately, there is no reference or supporting data to substantiate this value. The second report of interest, "Evaluation of The Efficiency of Industrial Flares: Flare Head Design and Gas Composition" states that the DRE of benzene in a flare is $99.59 \%$ [15]. This DRE was determined experimentally on a flare with a nozzle diameter of $1 / 16$ " burning $98.5 \%$ propane [15]. To determine whether or not the behaviour of such a flame should be considered applicable to flares in the upstream oil and gas industry it is useful to consider the non-premixed flame regimes described in Delichatsios [16] and further discussed by McEwen [17]. In the context of flares typical of Alberta, the flame described in the EPA report [15] would fall in Delichatsios's "turbulent buoyant - near top" regime, while upstream oil and gas flares more typically fall in the "turbulent buoyant - transition shear" and "turbulent buoyant - transition buoyant" regimes. A flare from a glycol dehydrator still vent would be smaller than a flare from a typical well, and thus would most 
likely be in the "turbulent buoyant - transition buoyant" regime. The "turbulent buoyant - near top" regime would not necessarily represent a flare from a glycol dehydrator still vent as this regime would only be transitioning to turbulent around the flame tip. A "turbulent buoyant - transition buoyant" flame would be mostly turbulent with vortices created near the nozzle and thus would be different from a "turbulent buoyant - transition buoyant" flame. The flare described in [15] is thus questionably relevant to a typical flare in the upstream oil and gas sector and would not necessarily give a result representative of the DRE of benzene that could be applied to UOG industry flaring.

Table 1.2: Summary of DRE values from literature

\begin{tabular}{|l|c|c|l|}
\hline \multicolumn{1}{|c|}{ Report Title } & Publisher & DRE Value [\%] & \multicolumn{1}{|c|}{ Reason for Invalidity } \\
\hline $\begin{array}{l}\text { Control of Benzene Emissions } \\
\text { from Glycol Dehydrators }\end{array}$ & CAPP [1] & 90 & $\begin{array}{l}\text { Source is a report with no mention } \\
\text { of benzene DRE measurements }\end{array}$ \\
\hline $\begin{array}{l}\text { Locating and Estimating Air } \\
\text { Emission Sources of Benzene }\end{array}$ & $\begin{array}{c}\text { U.S. EPA } \\
{[14]}\end{array}$ & 89.5 & $\begin{array}{l}\text { No reference or data to validate the } \\
\text { DRE value }\end{array}$ \\
\hline $\begin{array}{l}\text { Evaluation of The Efficiency of } \\
\text { Industrial Flare Head Design and } \\
\text { Gas Composition }\end{array}$ & $\begin{array}{c}\text { U.S. EPA } \\
\text { [15] }\end{array}$ & 99.59 & $\begin{array}{l}1 / 16 \text {-inch (1.6-mm) diameter } \\
\text { burner used for experiments not } \\
\text { representative of a typical } \\
\text { industrial flare }\end{array}$ \\
\hline
\end{tabular}

\subsection{Black Carbon}

Black carbon, commonly known as soot, is a pollutant that is formed through combustion. $\mathrm{BC}$ is made up of many aggregated carbon-rich spherules, formed primarily from polyaromatic hydrocarbons. $\mathrm{BC}$ is a known climate force [18]-[21], and may be the second-most important positive anthropogenic climate forcer after $\mathrm{CO}_{2}$ [19]. In the air, $\mathrm{BC}$ absorbs radiation from the sun which has a direct heating effect on the atmosphere. When $\mathrm{BC}$ mixes with atmospheric aerosols and eventually deposits on snow or ice on the ground it changes the surface albedo, causing the radiation that would normally be reflected to be absorbed, thus promoting melting. $\mathrm{BC}$ also has known negative health effects and has been found to be "causally involved in all-cause, lung cancer, and cardiovascular mortality, morbidity, and perhaps adverse birth and nervous system effects" [22]. A significant source of BC production is industrial flaring, and it is estimated that more than 140 billion cubic meters of gas is flared each year [23]-[25]. 
Polycyclic aromatic hydrocarbons (PAH) are a key part in the formation of $\mathrm{BC}$. PAHs are non-polar hydrocarbons that are formed from multiple aromatic rings that have aggregated. Groups of PAHs will aggregate, forming high carbon spherules that lead to $\mathrm{BC}$ being formed. Benzene is part of that process as it builds into PAHs, making benzene a known precursor to soot [26]. Because benzene is a critical step in the formation of soot, introducing significant quantities of benzene into a typical flare is expected to increase $\mathrm{BC}$ production. Though flaring glycol dehydrator still vent gas may reduce benzene emissions, it would almost certainly increase $\mathrm{BC}$ emissions in the process. Since BC is a dangerous emission on its own, it is important to understand this potential trade-off.

\subsection{Flare Stability}

Flare stability is an issue that arises when proposing flaring as an emissions reduction strategy. To ensure that unburnt gases are not vented into the atmosphere, the flare needs to be stable. In a study from 1986, it was found that when flares are near their stability limit there is a sudden drop in combustion efficiency [27]. One factor that can push a flare toward its stability limit is a low heating value of the flare gas. If the heating value of the flare drops too low the flame can emit some unburnt fuel (known as fuel stripping) and potentially blow out completely [28]. A sudden drop in combustion efficiency is especially concerning if there is a significant amount of benzene present in the fuel stream.

Even with a stable flare, emissions may be affected by flame liftoff, which occurs when the flow rate of the fuel is high enough that the flame separates from the burner. Though difficult to predict exactly, Kalghatgi [29] modeled the height of a lifted flame above the burner as a function of the flame speed, gas velocity at the burner exit, fuel and air density, and fuel viscosity. As the flow rate of the fuel is increased further, the liftoff height will increase until the flare becomes unstable and blowout occurs.

Given the possibility or liftoff or flare instability, there is a risk that when dehydrator waste gas is flared combustion may be incomplete and fuel stripping could occur. If fuel stripping happens with benzene present in the flare, benzene concentrations in the combustion products would rise, causing the effective DRE to decrease. The DRE of benzene in a flare may thus follow the trends in combustion efficiency near the limits of 
stability observed by Pohl [27]. In his study of vertical flares burning propane-nitrogen mixtures, Pohl concluded that flares operating within the stability limit have combustion efficiencies greater than $98 \%$, while defining flame instability as the point where "the jet velocity exceeds the flame velocity". However, when the propane fraction was reduced to point where the flame became unstable at low heating values, combustion efficiency dropped dramatically [27]. Reproducing a case similar to this with benzene in the flare may cause benzene DRE to decrease drastically and increase benzene emissions.

\subsection{Thesis Motivation and Objectives}

Overall there is a lack of available data on benzene DRE in industrial flares. The primary motivation of this thesis is to determine if flaring glycol dehydrator waste gas is an effective control mechanism for benzene emissions, while considering potential increases in $\mathrm{BC}$ production. The specific objectives of this thesis are to:

- Quantify the DRE of benzene in a flare that is representative of the case of flaring glycol dehydrator waste gas;

- Investigate the effects of flare gas composition (fuel chemistry) on benzene DRE and $\mathrm{BC}$ yield;

- Investigate the effects of water in the fuel stream on benzene DRE and BC yield; and

- Look for changes to the benzene DRE occurring during liftoff and near the lowheating-value stability limit.

\subsection{Thesis Overview}

Chapter 2 gives a summary of the methods and equipment used to perform the experiments necessary for this thesis along with a basic theory of gas chromatography and methods used for test case generation.

Chapter 3 provides a detailed description of the theory behind determining DRE, BC yield, and their corresponding uncertainties, including examples. 
Chapter 4 consists of a summary of all obtained results and plots of DRE, BC yield, and benzene yield all with the varying fuel compositions as well as a discussion of the obtained results and observed trends in the data.

Chapter 5 summarizes the thesis contributions and briefly discusses future work that could be performed to extend this project. 


\section{Chapter 2 Methodology}

\subsection{Carleton University Flare Facility}

All experiments were performed at the Carleton University Flare Facility (CUFF). The CUFF consists of a fuel supply system, burner, an exhaust hood that collects and dilutes combustion products, as well as gas and particulate phase analyzers. The CUFF is capable of producing a flare up to three meters tall at flow rates up to 600 SLPM (standard liters per minute, $288.15 \mathrm{~K}$ and $1 \mathrm{~atm})$. The CUFF is operated from a single computer using LabVIEW to monitor and control the fuel supply, temperature probes, and analyzers. Figure 2.1 shows a simplified schematic of the CUFF.
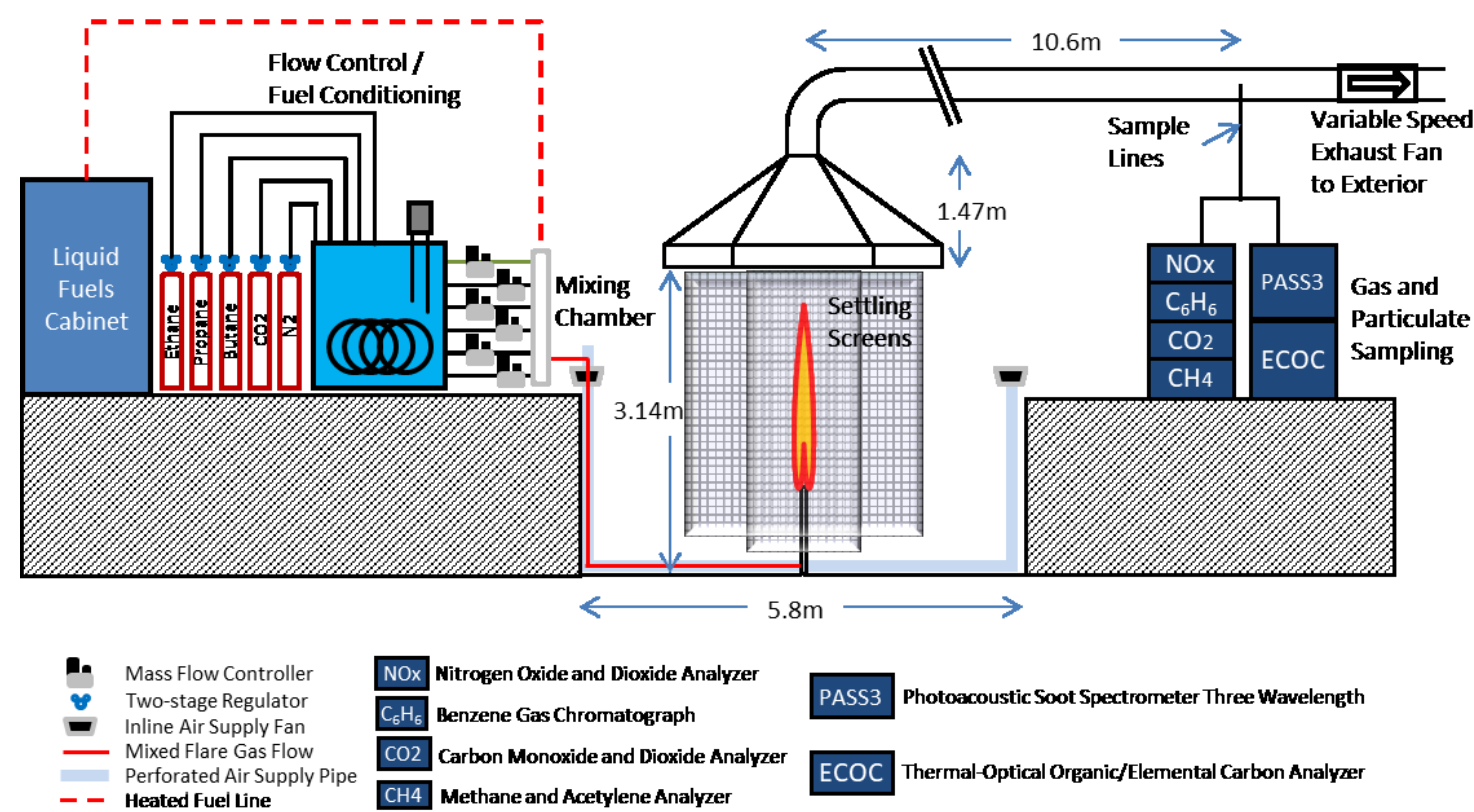

Figure 2.1: Simplified schematic of the CUFF

Controllable fuel mixtures composed of as many as eleven components are metered and mixed in a mixing header and directed to the flare to be combusted. The flare burner is in the center of a $1.88 \mathrm{~m}$ deep pit and surrounded by two sets of circular mesh screens, which help dissipate any room air currents to ensure flare stability. Supplemental ventilation air through a perforated air supply pipe at the periphery of the pit ensures the flame behaviour is not influenced by the pit walls. All combustion products and additional room air are drawn into a hexagonal exhaust hood (1.56 m included diameter) that feeds 
into a $40.6 \mathrm{~cm}$ diameter duct. The exhaust system is powered by a $3.7 \mathrm{~kW}$ IAP Vane Axial 180 fan that exhausts the combustion products to the exterior of the building. Samples are drawn $10.6 \mathrm{~m}$ downstream from the duct inlet from two separate ports, one for the gas analyzers and another for the particulate analyzers.

\subsubsection{Dry Gas Supply}

The CUFF can flare fuel mixtures with methane ( $>99 \%$ purity, compressed), ethane ( $>99 \%$ purity, compressed), propane ( $>99 \%$ purity, compressed), n-butane ( $>99 \%$ purity, compressed), isopentane (2-methylbutane, liquid), hexane (mixture of hexanes, liquid), heptane (mixture of heptanes, liquid), benzene ( $>99 \%$ purity, liquid), nitrogen ( $>99.998 \%$ purity, compressed), carbon dioxide (>99.9\% purity, compressed), and distilled water. Fuel components supplied in gaseous form (i.e. methane, ethane, propane, butane, nitrogen, and carbon dioxide) flow from pressurized gas cylinders (shown in red in Figure 2.1) through 7.5-m long coils of copper tubing immersed in a heated water bath (shown as light blue rectangle in Figure 2.1) that is held at a constant temperature. The heated water bath ensures the gases are re-warmed to ambient conditions following Joule-Thomson cooling as the pressure is reduced through regulators prior to being metered. The gas flows are controlled using thermal mass flow controllers (MFC).

\subsubsection{Liquid Fuel Vaporization}

Fuel components supplied as liquids (i.e. pentane, hexane, heptane, benzene, and water) are vaporized and connected to the mixing header via a heated line to prevent condensation. A schematic of the liquid fuel injection system is shown in Figure 2.2. It is housed in a ventilated cabinet for safety purposes and to avoid contaminating the laboratory air with trace parts per billion ( $\mathrm{ppb}$ ) levels of benzene which could theoretically be drawn into the flare exhaust hood and into the benzene analyzer. 


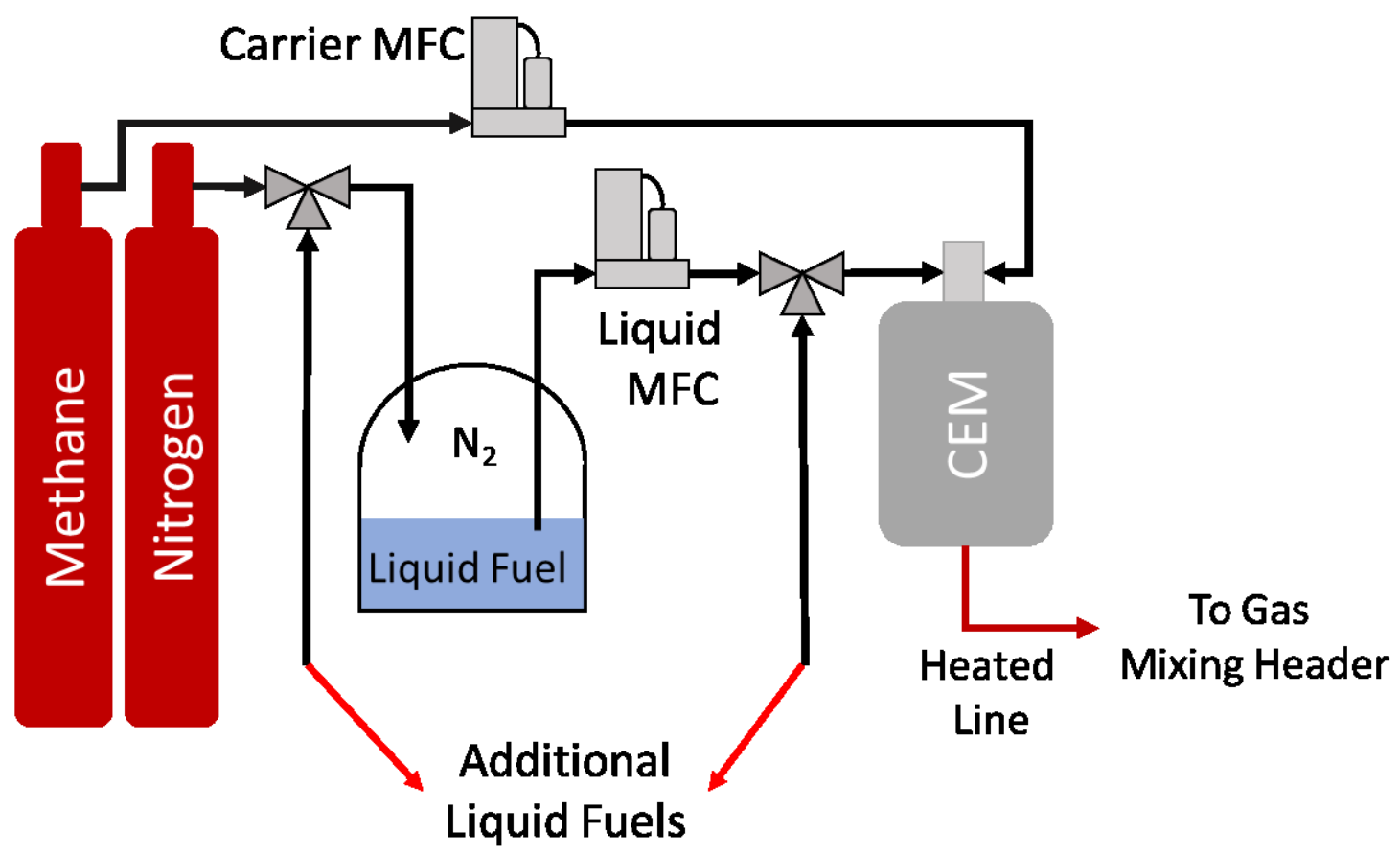

Figure 2.2: Liquid fuel injection system

Starting at the left side of Figure 2.2, nitrogen is used to pressurize the liquid fuels inside of pressure vessels. The liquid fuels are then pushed through $1 / 4$ " Kynar tubing and metered using Bronkhorst Mini Cori-Flow (models M12-M14) Coriolis MFCs (with flows ranging from $0.1 \mathrm{~g} / \mathrm{h}$ up to $6.875 \mathrm{~kg} / \mathrm{h}$ ). The liquid fuels are mixed in a $1-\mathrm{m}$ long length of tubing prior to entering the Bronkhorst W-303B Controlled Evaporator Mixer (CEM). Inside the CEM the liquid fuels flow through a heated perforated plate that creates heated droplets. For the liquid fuels to be completely vaporized, they must be picked up by a carrier gas, which in this case is methane. The carrier gas flow is controlled using a Bronkhorst EL-Flow Select thermal MFC, with a maximum flow rate of 40 SLPM. This vaporized fuel mixture is then sent through a heated line, held at approximately $110^{\circ} \mathrm{C}$ to prevent condensation, to the mixing header and mixed with the dry gases to achieve the desired fuel composition.

A Bronkhorst E8000 Readout/Controller with an added FLOW-BUS module is used to power and control the Coriolis MFCs, carrier gas MFC, and CEM. The E8000 connects to the main CUFF computer using an RS232 serial to USB connection, enabling 
the MFCs and CEM to be controlled remotely via a desktop computer running National Instruments' LabVIEW software.

\subsection{Benzene Measurements with Gas Chromatography}

Benzene emissions were measured using a Baseline-Mocon Series 9100 online Gas Chromatograph (GC). Gas chromatography is a scientific technique that is used to separate and identify gas mixtures. A typical gas chromatograph utilizes a carrier gas, column, column oven, injector, detector, and a data processor to measure the concentration of a chemical species in a gas sample. A simplified schematic of a typical GC is shown in Figure 2.3. The sample is injected into the carrier gas flow, which flows through a tubular column that separates the species in the mixture. After flowing through the column, the sample is analyzed by the detector and processed on the data processor. The BaselineMocon Series 9100 GC utilizes two columns in series to separate the sample, and it uses a photo-ionization detector (PID) to measure the benzene levels.

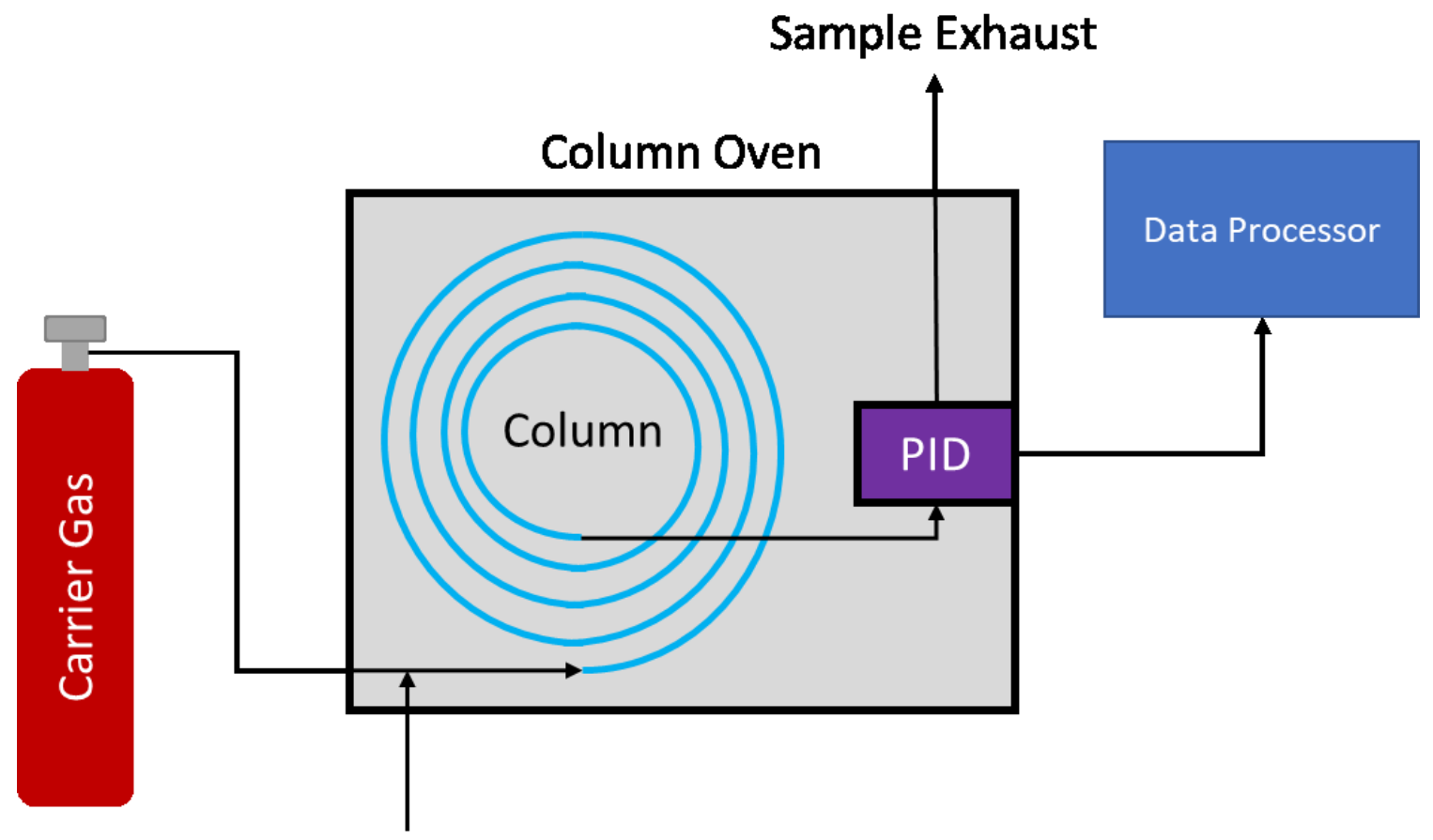

Sample Injection

Figure 2.3: Simplified GC schematic with PID 


\subsubsection{Baseline-Mocon Series 9100 GC Separation}

The sample is drawn into the Baseline-Mocon GC with a sample pump operating at 250 cubic centimeters per minute $(\mathrm{ccm})$. The sample injection method used is called elution chromatography, where a discrete volume of sample gas is injected into the high purity nitrogen carrier gas flow. The carrier gas may also be referred to as the "mobile phase", as its purpose is to move the volume of sample gas through the GC column. The column is a long length of tubing that houses the "stationary phase", which is of proprietary composition in the Baseline-Mocon GC. As the two phases come into contact, the sample will begin to be adsorbed into the stationary phase. Different species of gases elute along the column at different rates, causing the separation of species [30]. This causes each species to exit the GC column at distinct times separating the gases, thus allowing species of interest to be measured in the detector.

The Baseline-Mocon GC utilizes two columns connected in series to separate the gas sample: a 10-m long column with a highly polar stationary phase and a $20-\mathrm{m}$ long column with a non-polar stationary phase. A simplified schematic of the GC showing the two columns can be seen in Figure 2.4. The sample is drawn into the GC by the sample pump at a flow of $250 \mathrm{~cm}^{3} / \mathrm{min}$. The pump operates continuously to ensure fresh sample is always available, but the flow bypasses the analyzer until a new gas volume is needed (approximately every $5 \mathrm{~min}$ ). The diaphragm valve shown on the diagram and located between the first and second columns has multiple ports allowing it to direct multiple flows. The sample enters the diaphragm valve and is injected into the carrier gas (mobile phase) flow of $6 \mathrm{~cm}^{3} / \mathrm{min}$. The sample then flows into the $10 \mathrm{~m}$ highly polar column, which causes non-polar substances such as benzene to have a lower retention time and thus a faster migration rate. Essentially all non-polar species (such as the species of interest benzene) present in the combustion products will exit the first column before the polar species. The retained polar substances are subsequently vented from the GC after the non-polar substances pass through the diaphragm valve. The predominantly non-polar substances, including benzene are diverted by the diaphragm valve into the $20 \mathrm{~m}$ long non-polar column to be further separated. This second column separates the remaining species which flow sequentially through the PID lamp. This process was designed to ensure that only benzene and carrier gas will flow through the PID at the time the measurement is made. 


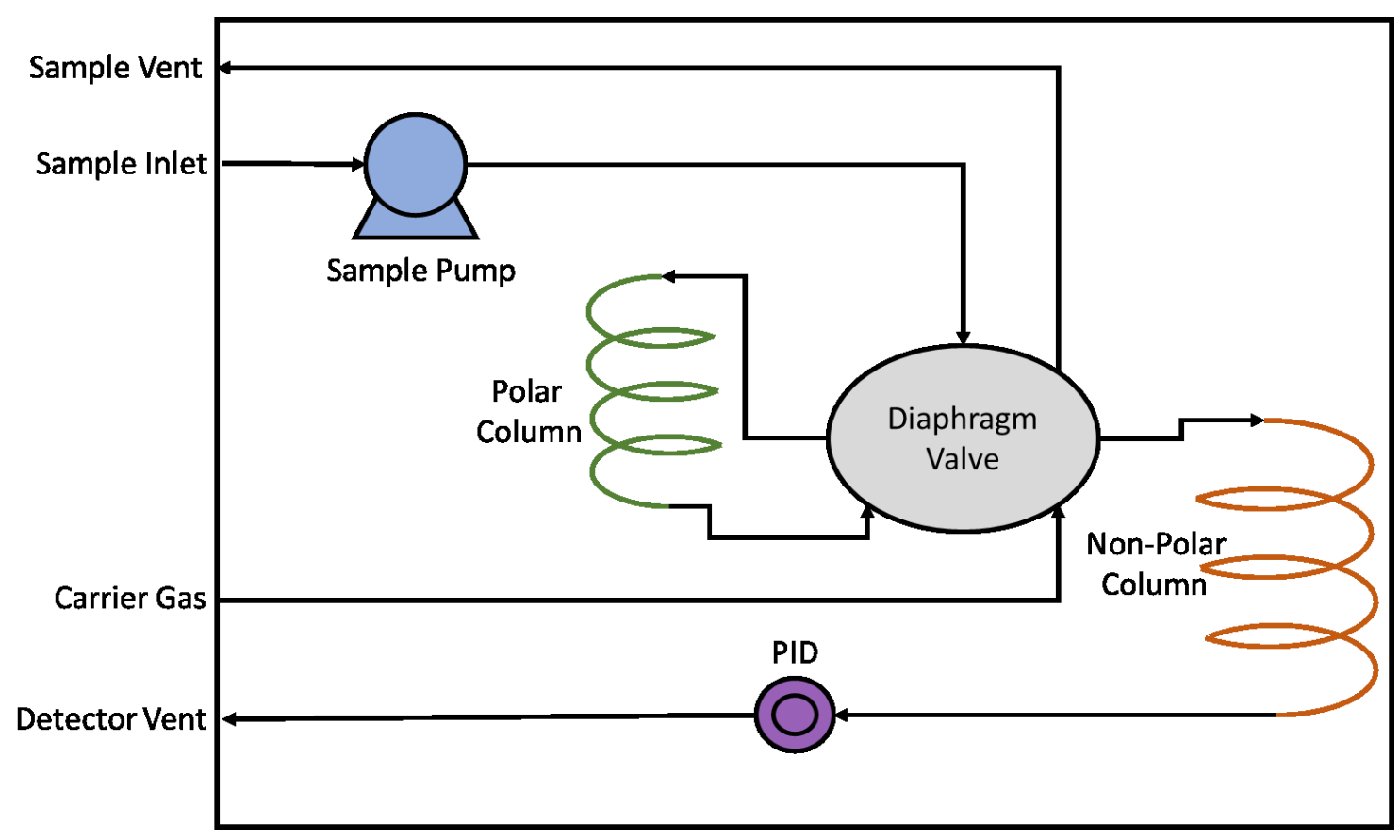

Figure 2.4: Baseline-Mocon Series 9100 GC column oven simplified schematic

Both columns are housed inside of the column oven, which maintains a set pressure and temperature to ensure a specific migration rate of gas through the columns. Migration rate is the main factor in determining the separation of the substance bands. The migration rate will be affected by the column oven pressure, column oven temperature, column length, and carrier gas flow rate. Migration rate is directly related to temperature and carrier gas flow rate, and inversely related to pressure and column length.

\subsubsection{Baseline-Mocon Series 9100 GC Detection}

The Baseline-Mocon Series 9100 GC utilizes a PID for the detection of substances. A PID is a non-destructive detection method that uses the energy of light to ionize gas molecules [31]. Gas molecules ionize when they receive an amount of energy greater than what is called their ionization potential, usually presented in electron volts $(\mathrm{eV})$. A plot of ionization potentials for the different gases expected to be present in the sample stream for the current experiments is shown in Figure 2.5. The Baseline-Mocon GC uses a $10.6 \mathrm{eV}$ krypton lamp for ionization, which is sufficient to ionize benzene whose potential is $9.3 \mathrm{eV}$. Though butane, pentane, hexane, and heptane may also be ionized by a $10.6 \mathrm{eV}$ PID lamp, the separation process described in Section 2.2.1 ensures that none of these gases will pass through the PID at the same time as benzene. 


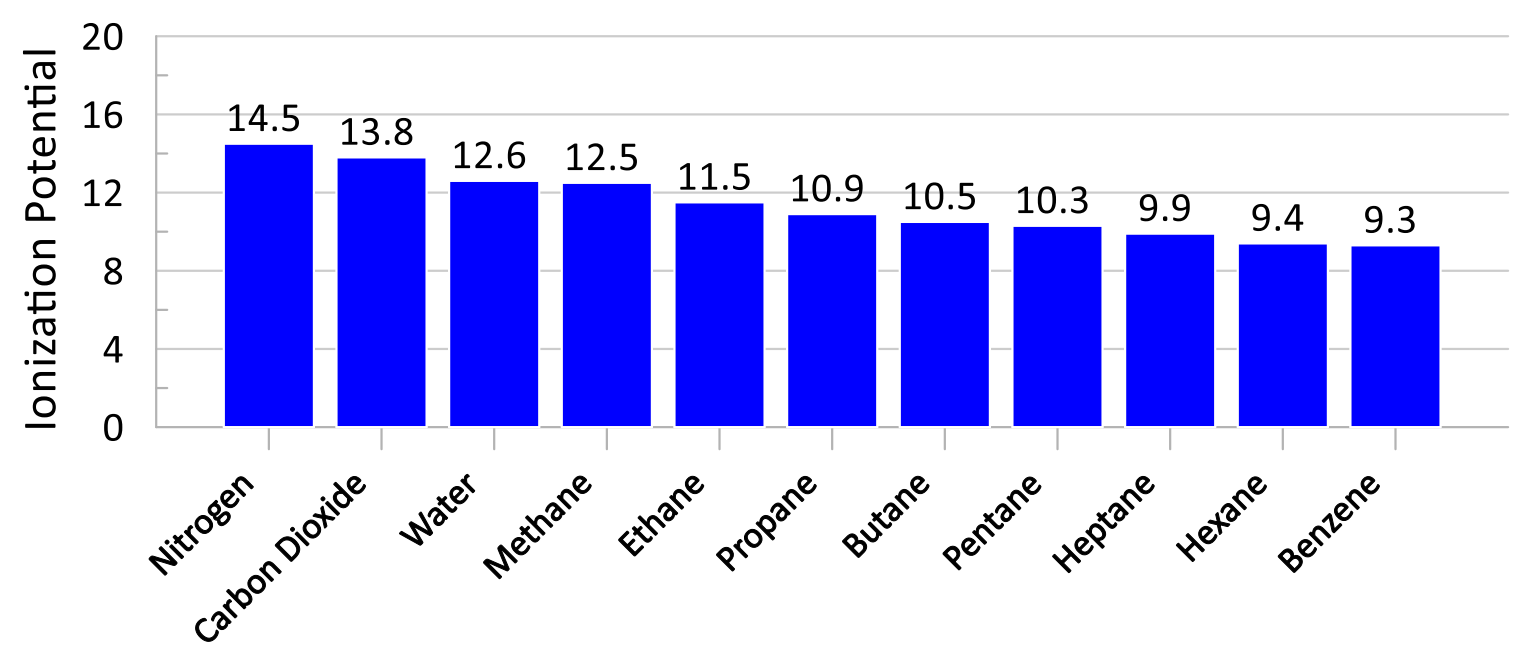

Figure 2.5: Ionization potentials of gases expected to be present in combustion products.

Following ionization, the flow is directed between a pair of charged plates. The positively charged benzene ion and negatively charged electron that result from the ionization process are then attracted to each of the plates, creating a potential and thus a current between them. The current is measured and then processed by a Windows Embedded Compact computer with an integrated Baseline-Mocon GC software, which interprets the current as what it terms "light counts". These light counts are then used to calculate benzene concentration by interpolation with the GC calibration. After the benzene ion has passed through the PID lamp, the ion and electron reform into a benzene particle and are vented from the GC. A simplified schematic of the ionization and detection process of a benzene molecule is shown in Figure 2.6. The manufacturer specifies that the Series $9100 \mathrm{GC}$ has the capability of measuring benzene to a lower detection limit of $0.5 \mathrm{ppb}$ with an accuracy of $5 \%$. During the entire measurement process the combustion products are continuously drawn into the $\mathrm{GC}$ and vented to ensure that when a sample is injected it accurately represents what is being flared. 


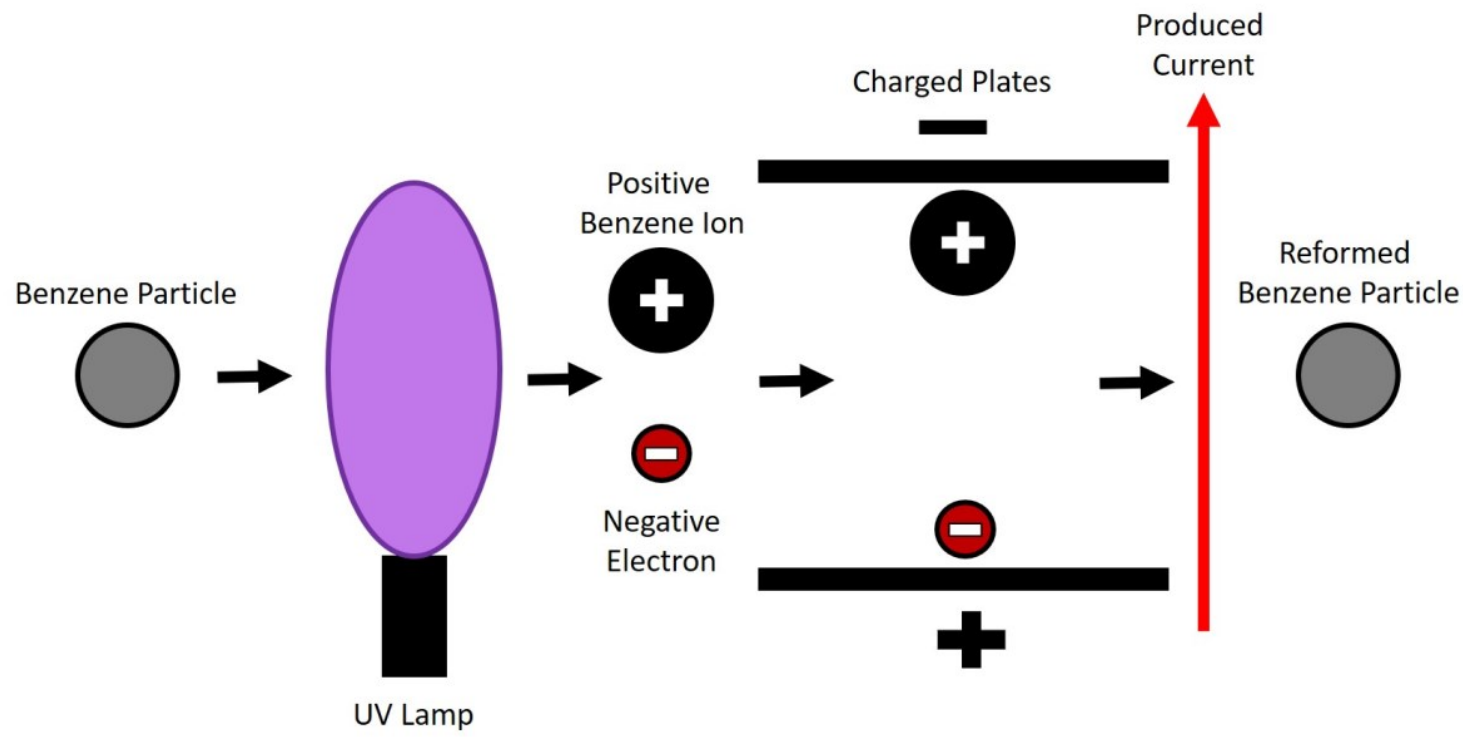

Figure 2.6: Simplified schematic of PID operation

\subsubsection{Chromatograph and Calibration}

Figure 2.7 shows a chromatogram produced by the Baseline-Mocon Series 9100 GC, which gives the benzene substance band produced from sampling calibration gas. The GC requires five minutes to analyze one sample, which yields one concentration reading. Benzene exits the second column and enters the PID lamp halfway through the sampling time at 150 seconds. Two calibration gases were used for the GC, containing either $64.5 \mathrm{ppb}$ or $199 \mathrm{ppb}$ of benzene in nitrogen. These benzene concentrations were measured by the gas supplier to a primary NIST-traceable standard accurate to $5 \%(2 \sigma)$.

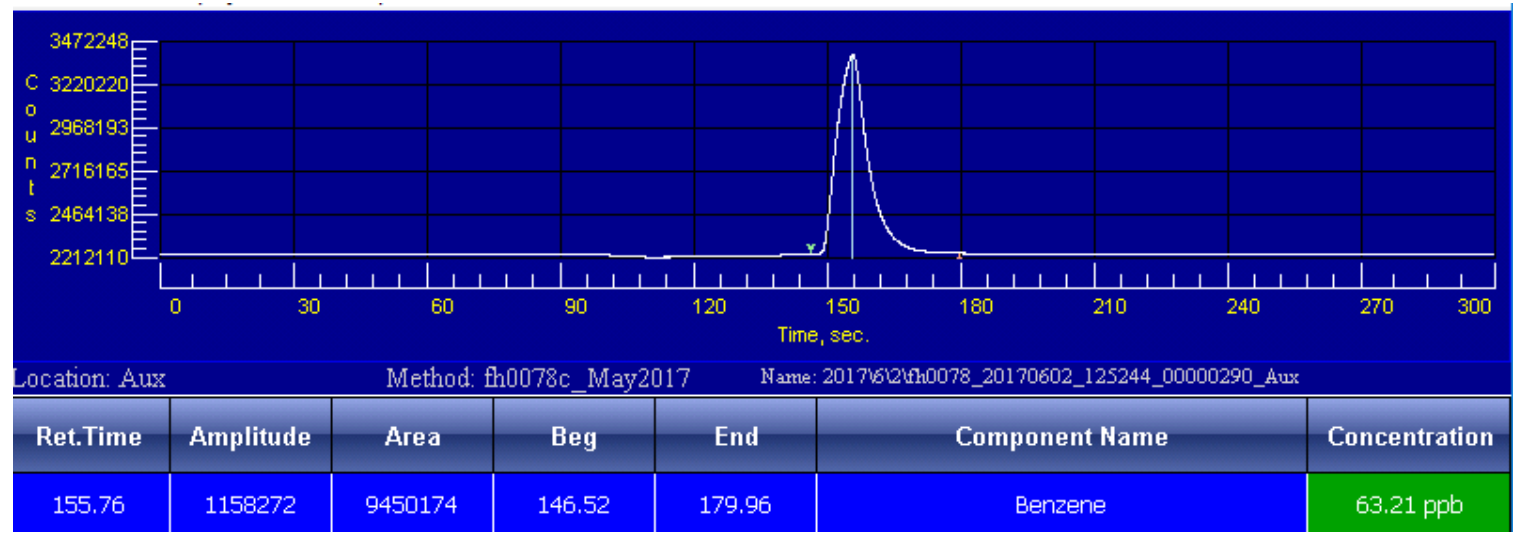

Figure 2.7: Baseline-Mocon series 9100 GC calibration peak 
This calibration gas is analyzed by the GC and the substance band is integrated to determine the area under the curve. This is done a minimum of five times to get an average calibration area. During experiments the calculated area under the substance band for a sample will be linearly interpolated between $0 \mathrm{ppb}$ and the calibration gas concentration (64.5 or $199 \mathrm{ppb}$ ) giving the benzene concentration of the sample. For this research the calibration curve was set linearly from 0 to $64.5 \mathrm{ppb}$ after preliminary experiments determined that all measured concentrations were expected to be less than $64.5 \mathrm{ppb}$. The calibration coefficients were monitored during the course of this research and remained stable to within $1 \%$.

\subsection{Organic Carbon and Elemental Carbon}

Particulate emissions from the flare were measured using a Sunset Labs model 4 thermaloptical organic carbon (OC) / elemental carbon (EC) analyzer. Elemental carbon in the case of this research is all in the form of $\mathrm{BC}$, which is typically created through incomplete combustion of carbon-based fuels combusted with insufficient oxygen [32]. The thermal evaluation protocol used by the Sunset Labs instrument to measure BC yield in the CUFF is based on the National Institute of Occupational Safety and Heath (NIOSH) 5040 standard [33]. The Sunset Labs instrument analyzes samples using thermal evolution analysis. After the sample has been collected onto a quartz-fibre filter, the oven is heated according to the NIOSH 5040 heating curve while helium is flowed through the filter. This first phase causes mostly OC to be released from the filter into the helium stream, which is carried to a manganese dioxide oven where the $\mathrm{OC}$ is converted to carbon dioxide. The carbon dioxide is then measured by a non-dispersive infrared (NDIR) detector, whose signal is then time-integrated to allow for the determination of the original total OC content on the filter. Next the sample is cooled slightly before being heated again, still following the NIOSH 5040 heating curve, while a gas stream of helium containing 2\% oxygen (by volume) is flowed through the filter. This second phase causes mostly EC to be released from the sample, which is again converted into carbon dioxide in the manganese dioxide oven and measured by the NDIR.

The analyzer has a laser and photodetector that it uses to makes an additional measurement to correct for any charring of the OC fraction on the filter. Such charring 
would result in charred OC remaining on the filter throughout the first phase and coming off of the filter during the second phase. The laser and photodetector are set up on opposite sides of the sample filter and used to measure the attenuation of the laser beam before and after sample collection as well as during the entirety of the heating cycle. During the first phase of the heating cycle any charred OC will cause an attenuation of the laser signal. At the start of the second phase the laser signal will increase as both charred OC and EC begin to be oxidized off of the filter. The moment in the second phase when the laser signal returns to the power measured at the start of the first phase is referred to as the split point; all carbon measured before the split point is assumed to be OC, while all carbon measured after the split point is assume to be EC [33].

\subsection{Glycol Dehydrator Still Gas Compositions}

Glycol dehydrator composition data are not typically publicly available, making the data very limited. Two sets of glycol dehydrator still gas data were provided for this research by a source in the industry in Alberta that wished to remain anonymous. One data set was composed of thirty glycol dehydrator still gas compositions, which were simulated using GRI-GLYCalc based on measured operating parameters of existing glycol dehydrators. GRI-GLYCalc is a Gas Technology Institute program that is used for estimating emissions from glycol dehydrators, which aids in determining if dehydrators need emission controls put in place. The simulated glycol dehydrator still gas composition data are presented in Table A.3. These data were then bootstrapped, following the method described in Section 2.4.1, to generate three simulated gas compositions referred to as Simulated Light-11, Simulated Medium-11 (or S-M11), and Simulated Heavy-11, where light, medium, and heavy refer to the volumetric higher heating value of the mixtures. Due to limitations of the fuel delivery system the light and heavy cases were not achievable, thus only the medium case and a modified version of the medium case were used. The modified mixture, called S-M11 $+\mathrm{C}_{6} \mathrm{H}_{6}$, is the S-M11 composition with increased benzene mole fraction and was used to determine the effect on DRE and soot yield.

Seven additional sets of direct measurements from glycol dehydrators operating in Alberta were also provided. These data sets included mass and volume flow rates for dry gases, condensable gases, and water, as well as mass fractions of gases which were 
condensed and various operating parameters such as pressure and temperature. Fuel compositions for each of the seven records are detailed in Table 2.1. The seven glycol dehydrator still compositions were bootstrapped using the method described in Section 2.4.1 to generate three compositions that represent the expected $5^{\text {th }}, 50^{\text {th }}$, and $95^{\text {th }}$ percentiles of likely glycol dehydrator still gas compositions in Alberta. These compositions were labeled Light-11 (L11), Medium-11 (M11), and Heavy-11 (H11). The "11" in the composition label refers to the eleven species that make up the fuel composition: methane, ethane, propane, butane, pentane, hexane, heptane, nitrogen, carbon dioxide, benzene, and water.

Table 2.1: Composition and flow rate data from glycol dehydrator still vents operating in Alberta

\begin{tabular}{|l|l|l|l|l|l|l|l|l|}
\hline Dehydrator \# & $\mathbf{1}$ & $\mathbf{2}$ & $\mathbf{3}$ & $\mathbf{4}$ & $\mathbf{5}$ & $\mathbf{6}$ & $\mathbf{7}$ \\
\hline Flow rate [SLPM] & 51 & 5.9 & 13 & 17 & 58 & 85 & 6.0 \\
\hline HHV [MJ/m ] & 65 & 58.7 & 69 & 59 & 47 & 41 & 78.0 \\
\hline Species & \multicolumn{7}{|c|}{ Still Gas Mole Fraction [\%] } \\
\hline Helium & $<0.01$ & 0 & 0 & 0 & 0.32 & 0.56 & 0 \\
\hline Hydrogen & 0 & 0 & 0 & 0 & 0 & 0 & 0 \\
\hline Oxygen & 0.17 & 1.49 & 1.11 & 3.01 & 0.40 & 0.14 & 3.63 \\
\hline Nitrogen & 0.78 & 5.53 & 4.14 & 11.2 & 4.80 & 5.27 & 13.6 \\
\hline Carbon Dioxide & 4.73 & 33.6 & 8.80 & 9.06 & 0.21 & 0.11 & 1.72 \\
\hline Hydrogen sulfide & 0 & 0 & 0 & 0 & 0 & 0 & 0 \\
\hline Water & 10.7 & 1.86 & 1.56 & 0.77 & 2.56 & 3.99 & 2.88 \\
\hline Methanol & 2.58 & 0.76 & 0.071 & 0.29 & $<0.01$ & 0.21 & $<0.01$ \\
\hline Methane & 50.3 & 13.6 & 35.9 & 32.9 & 78 & 82.30 & 22.2 \\
\hline Ethane & 7.88 & 9.15 & 12.9 & 13.0 & 3.37 & 2.88 & 9.75 \\
\hline Propane & 5.19 & 7.46 & 11.2 & 10.9 & 1.66 & 1.15 & 13.0 \\
\hline Butanes & 3.86 & 9.88 & 8.54 & 8.61 & 1.16 & 0.64 & 13.6 \\
\hline Pentanes & 2.29 & 6.54 & 5.15 & 3.87 & 0.76 & 0.29 & 10.2 \\
\hline Hexanes & 1.61 & 3.62 & 2.67 & 1.59 & 0.61 & 0.22 & 4.42 \\
\hline Heptanes & 4.71 & 4.00 & 4.34 & 2.61 & 3.13 & 0.87 & 3.25 \\
\hline Octanes & 1.68 & 0.56 & 0.59 & 0.44 & 0.64 & 0.38 & 0.58 \\
\hline Nonanes & 0.06 & 0.02 & 0.02 & 0.01 & 0.03 & 0.14 & 0.03 \\
\hline Decanes+ & 0 & 0 & 0 & 0 & $<0.01$ & $<0.01$ & 0 \\
\hline Benzene & 2.44 & 1.80 & 2.66 & 1.47 & 2.26 & 0.54 & 1.00 \\
\hline Toluene & 0.78 & 0.17 & 0.22 & 0.14 & 0.21 & 0.23 & 0.14 \\
\hline Ethylbenzene & 0.03 & $<0.01$ & 0.01 & $<0.01$ & 0.02 & 0.01 & $<0.01$ \\
\hline Xylenes & 0.16 & 0.03 & 0.07 & 0.05 & 0.09 & 0.05 & 0.05 \\
\hline & & & & & & & \\
\hline
\end{tabular}

\subsubsection{Test Matrix Development Based on Higher Heating Value}

To develop representative test compositions from the available simulated and measured composition samples, a statistical method called bootstrapping was used. Bootstrapping was first proposed by Efron in 1979, and is used in the case of this research to generate 
thousands of additional compositions that accurately represent the variance of the mean glycol dehydrator still gas composition [34]. This is done by resampling the glycol dehydrator still gas compositions with replacement [35]. For example, to generate a distribution on the average of methane mole fractions based on the $n=7$ measured compositions, one of the original seven records is drawn at random and the mole fraction of methane from that record is used in the generated composition. This process is then repeated for each species, drawing a new record number each time, until all species in the generated composition have a mole fraction assigned to them. The generated data set is then normalized such that the sum of the mole fractions equals 1 . $N=20,000$ new gas compositions were generated using this method to give a wide range of compositions that represent the existing data.

Once the bootstrapping procedure was completed the higher heating value (HHV) was calculated for all of the randomly generated data sets by summing the product of the mole fraction $\left(X_{i}\right)$ and HHV $\left(H H V_{i}\right)$ for each species $i$ in a composition with a number of species $n$.

$$
H H V_{\text {mixture }}=\sum_{i=1}^{n} X_{i} H H V_{i}
$$

The $N=20,000$ randomly generated data sets were then sorted by their HHV from smallest to largest. To generate test cases that represented the $5^{\text {th }}, 50^{\text {th }}$, and $95^{\text {th }}$ percentile glycol dehydrator still gas compositions, averages of the mole fractions of each species were taken in a $5 \%$ range around the $5^{\text {th }}, 50^{\text {th }}$, and $95^{\text {th }}$ percentile HHVs. This corresponded to averaging the mole fractions of each species from the $2.5^{\text {th }}$ to $7.5^{\text {th }}, 47.5^{\text {th }}$ to $52.5^{\text {th }}$, and $92.5^{\text {th }}$ to $97.5^{\text {th }}$ percentile HHVs.

Lastly the three representative compositions were adjusted to account for the limited number of species available in the CUFF, i.e. $\mathrm{CO}_{2}, \mathrm{~N}_{2}, \mathrm{C} 1-\mathrm{C} 7$ hydrocarbons, $\mathrm{C}_{6} \mathrm{H}_{6}$, and $\mathrm{H}_{2} \mathrm{O}$. Species not available for use in the CUFF (i.e. mostly C8+ species) were removed from the composition, which also had the effect of altering the HHV. The mole 
fraction of heptane (C7) was then adjusted up or down to retain the HHV associated with HHV percentiles of interest.

\subsection{Experimental Procedure}

The GC and the OCEC were calibrated daily for the current work. Before beginning tests, the benzene levels in the CUFF were monitored to ensure that they were stable and at expected levels $(<1.00 \mathrm{ppb}$ for at least 2 hours $)$.

At the start of a day of testing the CEM, heated line, and water baths were turned on and adjusted to their appropriate temperature set points. Next the OCEC was run while sampling ambient laboratory air to obtain soot levels inside of the CUFF. At the same time the flare was ignited with a low flow of pure methane to warm up the burner nozzle and the exhaust hood fan speed was set to the level to be used for the upcoming tests. Once the burner had warmed up and the OCEC background had finished, an experimental run for a single condition could begin.

An experimental run began with a measurement of laboratory air background levels for benzene, methane, carbon dioxide, carbon monoxide, nitrogen monoxide, and nitrogen dioxide. Next the liquid fuel MFCs were zeroed and the OCEC oven cleaning process was started. After the MFCs were zeroed, the fuels were set to provide the desired flow rate and fuel composition. Once the fuels were at the desired flow rates, the sample line for the gas phase analyzers was switched to draw from the duct instead of ambient lab air. Once the gas concentrations had all stabilized the official test readings began. The test then ran long enough for the GC to take 4 benzene readings, or about 20 minutes, while other gas concentrations were continuously recorded at a sample rate of $1 \mathrm{~Hz}$.

After the test recordings had completed, the flare was turned down to a low flow rate to keep the burner hot while conserving fuel, the liquid fuels were shut off, the flare was switched to pure methane, and the gas phase analyzers were set to draw from ambient. Once the gas concentrations had all stabilized a post-test background was taken. If there was time between tests, a background was taken with the OCEC. For each experimental condition all the previous steps were repeated. 


\section{Chapter 3 System Verification, Test Matrix, and Calculation Procedures}

\subsection{System Verification and Validation}

Tests were first performed to prove that the GC was capable of measuring the very low benzene concentrations expected to be found in the combustion products. Two initial verification tests performed: one burning solely methane $\left(\mathrm{CH}_{4}\right)$ and another burning methane mixed with $1.20 \%$ by volume benzene $\left(\mathrm{CH}_{4}+\mathrm{C}_{6} \mathrm{H}_{6}\right)$ as shown in Table 3.1. The total flow rate for both of these cases was 40 SLPM and both tests were performed on a $50.8 \mathrm{~mm}$ diameter burner stack.

Table 3.1: System verification and validation tests ( $1 \mathrm{~atm}$ and $\left.15^{\circ} \mathrm{C}\right)$

\begin{tabular}{|c|c|c|c|c|c|c|c|c|c|c|c|c|c|}
\hline & & & & & & Ga & pe & Mc & $\mathrm{rac}$ & n [\% & & & \\
\hline & t \# / Name & $\underline{\Sigma}$ & 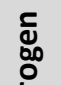 & 은 은 & 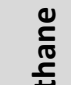 & 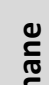 & 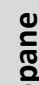 & 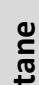 & $\frac{0}{\pi}$ & 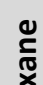 & 竞 & 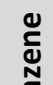 & $\underbrace{ \pm}_{\pi}$ \\
\hline 1 & $\mathrm{CH}_{4}$ & 38.49 & 0 & 0 & 100 & 0 & 0 & 0 & 0 & 0 & 0 & 0 & 0 \\
\hline 2 & $\mathrm{CH}_{4}+\mathrm{C}_{6} \mathrm{H}_{6}$ & 39.74 & 0 & 0 & 98.8 & 0 & 0 & 0 & 0 & 0 & 0 & 1.2 & 0 \\
\hline
\end{tabular}

During these tests the benzene levels in the plume and ambient lab air were measured. DRE and benzene yield were then calculated following the methods in Sections 3.3, 3.3.1, and 3.3.2. The results from these system verification and validation tests are summarized in Table 3.2 .

Table 3.2: System verification and validation test results

\begin{tabular}{|c|c|c|c|c|c|c|}
\hline \multicolumn{2}{|c|}{ Test Case } & $\begin{array}{c}\text { Average Benzene } \\
\text { Detected in } \\
\text { plume [ppb] }\end{array}$ & $\begin{array}{c}\text { Ambient } \\
\text { Benzene in Lab } \\
\text { Air [ppb] }\end{array}$ & $\begin{array}{c}\text { Average DRE } \\
{[\%]}\end{array}$ & $\begin{array}{c}\text { Benzene } \\
\text { Injected } \\
{\left[\mathrm{g} / \mathrm{m}^{3}\right]}\end{array}$ & $\begin{array}{c}\text { Benzene } \\
\text { Yield } \\
{\left[\mathrm{mg} / \mathrm{m}^{3}\right]}\end{array}$ \\
\hline 1 & $\mathrm{CH}_{4}$ & $0.40 \pm 0.03$ & $0.19 \pm 0.01$ & N/A & 0 & $0.65 \pm 0.16$ \\
\hline 2 & $\begin{array}{c}\mathrm{CH}_{4}+ \\
\mathrm{C}_{6} \mathrm{H}_{6}\end{array}$ & $1.58 \pm 0.11$ & $0.19 \pm 0.01$ & $99.981 \pm 0.027$ & 39.6 & $4.42 \pm 1.10$ \\
\hline
\end{tabular}

The ambient benzene levels in the lab were $0.19 \pm 0.01 \mathrm{ppb}$ for both tests, which is in the expected range of background atmospheric benzene concentrations. The uncertainty 
on the benzene concentration was determined by combining the elemental uncertainty from the manufacturers specified accuracy of the GC, bias error on the calibration gas, and measured repeatability. When burning the $\mathrm{CH}_{4}$ case in the flare at 40 SLPM, the benzene levels rose to an average of about $0.40 \pm 0.03 \mathrm{ppb}$. The benzene yield, calculated with total uncertainty estimated using instrument bias error and benzene yield precision error determined in Section 3.3.6, was $0.65 \pm 0.16 \mathrm{mg} / \mathrm{m}^{3}$. Thus, even when considering the total uncertainty, there is still a non-zero benzene yield from a pure methane flare. This means that even with no benzene input into the flare, there is some benzene being produced. This is later confirmed with two zero benzene input tests in Section 4.2. When pure methane was doped with $1.2 \%$ benzene (the $\mathrm{CH}_{4}+\mathrm{C}_{6} \mathrm{H}_{6}$ case) the benzene levels in the plume rose to an average of $1.58 \pm 0.11 \mathrm{ppb}$. This resulted in an increase in benzene yield by nearly seven-fold to $4.42 \pm 1.10 \mathrm{mg} / \mathrm{m}^{3}$. This successfully demonstrated that the experiment was sufficiently sensitive to measure benzene yields.

\subsection{Test Matrix}

Though it is known that gas mixtures containing benzene are being vented from glycol dehydrators, the exact composition and flow rate of the gas mixtures is not typically made public. Combined with minimum emission thresholds for mandatory reporting, it becomes difficult if not impossible to know how much benzene is being released and to propose and evaluate potential methods of emissions control. Seven measured glycol dehydrator still gas compositions were obtained from a source that wished to remain anonymous. These seven samples were from glycol dehydrators operating in Alberta, which were then used to generate the L11, M11, and H11 compositions using the method shown in Chapter 2.

The L11, M11, and H11 compositions represent the $5^{\text {th }}, 50^{\text {th }}$, and $95^{\text {th }}$ percentile glycol dehydrator still gas compositions, but to simulate additional scenarios in which the composition or flow may vary, the M11 composition was further manipulated to simulate the following scenarios:

- Glycol dehydrator still vent gas that is tied-in to a predominately methane flare, corresponding to a higher mole fraction of methane in the flare gas;

- Higher mole fraction of water vapour in the still vent gas; 
- Higher mole fraction of benzene in the still vent gas; and

- Flare liftoff causing fuel stripping, achieved by lowering the HHV of the flare gas by diluting with carbon dioxide until flame becomes unstable.

To simulate the glycol dehydrator still vent gas being tied-in to a methane flare, the M11 methane flow rate was increased by $50 \%$ and by $100 \%$. The result was then renormalized, giving the $\mathrm{M} 11+\mathrm{CH}_{4} \mathrm{a}$ and $\mathrm{M} 11+\mathrm{CH}_{4} \mathrm{~b}$ compositions respectively. A similar procedure was used to test a higher concentration of benzene in the still vent gas, generating the $\mathrm{M} 11+\mathrm{C}_{6} \mathrm{H}_{6} \mathrm{a}$ and $\mathrm{M} 11+\mathrm{C}_{6} \mathrm{H}_{6} \mathrm{~b}$ cases.

The same procedure was also used to create compositions with increased water vapour concentration, but the fuel vaporization and delivery system could not handle the increase in water vapour. Even after increasing the setpoint of the heated line used to deliver vaporized fuels to the gas mixing manifold and insulating the piping from the manifold to the burner, mole fractions of water in the fuel mixture above about $4 \%$ caused condensation in the fuel delivery system. Thus, instead of increasing the flow rate of water, it was decreased. The M11 water vapour concentration composition was reduced by $50 \%$ and $75 \%$, yielding the $\mathrm{M} 11-\mathrm{H}_{2} \mathrm{Oa}$ and $\mathrm{M} 11-\mathrm{H}_{2} \mathrm{Ob}$ compositions, respectively.

Two further test cases were selected from provided simulated glycol dehydrator still gas compositions from GRI-GLYCalc based on actual dehydrator operating parameters (S-M11 and S-M11+ $\mathrm{C}_{6} \mathrm{H}_{6}$ ). These two tests were selected to observe the effect of a higher quantity of benzene in the flare gas.

To simulate scenarios where flame liftoff may occur, the M11 fuel was increasingly diluted with $\mathrm{CO}_{2}$ until the $\mathrm{HHV}$ of the fuel became low enough to cause instability and thus liftoff. The $\mathrm{CO}_{2}$ mole fraction in the M11 case was increased to $20 \%, 50 \%$, and $70 \%$ to create the compositions labeled $\mathrm{M} 11+\mathrm{CO}_{2} \mathrm{a}, \mathrm{M} 11+\mathrm{CO}_{2} \mathrm{~b}$, and $\mathrm{M} 11+\mathrm{CO}_{2} \mathrm{c}$. To gather data regarding varying benzene concentrations at the diluted conditions, $\mathrm{CO}_{2}$ dilution was also performed with the $\mathrm{M}_{11}+\mathrm{C}_{6} \mathrm{H}_{6} \mathrm{~b}$ case yielding the compositions labeled $\mathrm{C}_{6} \mathrm{H}_{6}+\mathrm{CO}_{2} \mathrm{a}$, $\mathrm{C}_{6} \mathrm{H}_{6}+\mathrm{CO}_{2} \mathrm{~b}$, and $\mathrm{C}_{6} \mathrm{H}_{6}+\mathrm{CO}_{2} \mathrm{c}$. With a carbon dioxide mole fraction of $70 \%$, the flame became visibly lifted. 
Lastly, two typical multi-component flare compositions were selected to quantify benzene emissions for cases without benzene in the flare gas. These two compositions, AB M9 and EC O4, were generated from available flare composition measurements. The AB M9 composition is a nine-component $\mathrm{C} 1-\mathrm{C} 7$ alkane, $\mathrm{CO}_{2}$ and $\mathrm{N}_{2}$ mixture used in the CUFF and generated from gas sample data from Alberta, Canada. The EC O4 composition is also a nine-component alkane fuel mixture that was generated based on in-field flare composition measurements taken in Ecuador [36]. Table 3.3 shows all the composition of all mixtures used in the final test matrix.

Table 3.3: Experimental test cases gas compositions

\begin{tabular}{|c|c|c|c|c|c|c|c|c|c|c|c|c|}
\hline \multirow[b]{2}{*}{$\begin{array}{c}\text { Test } \\
@ \\
75 \text { SLPM }\end{array}$} & \multirow{2}{*}{ 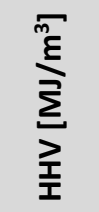 } & \multicolumn{11}{|c|}{ Flare Gas Species Mole Fraction [\%] } \\
\hline & & $\begin{array}{l}\text { c } \\
0 \\
0 \\
0 \\
\frac{1}{2} \\
z\end{array}$ & 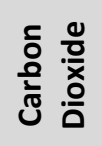 & 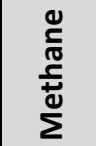 & $\begin{array}{l}\stackrel{0}{c} \\
\stackrel{0}{0} \\
\stackrel{⿱ ㇒}{ \pm}\end{array}$ & $\begin{array}{l}\frac{0}{\frac{1}{\pi}} \\
\frac{0}{0} \\
\frac{0}{2}\end{array}$ & 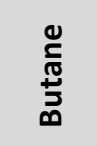 & 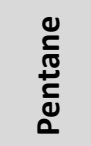 & $\begin{array}{l}\stackrel{0}{c} \\
\stackrel{\mathbb{T}}{x} \\
\stackrel{0}{1}\end{array}$ & $\begin{array}{l}\frac{0}{c} \\
\frac{1}{0} \\
\stackrel{0}{0} \\
\frac{0}{1}\end{array}$ & 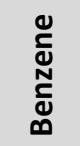 & $\begin{array}{l}\frac{1}{ \pm} \\
\frac{\pi}{\pi}\end{array}$ \\
\hline L11 & 43.40 & 6.66 & 23.15 & 41.13 & 6.48 & 7.45 & 2.84 & 3.42 & 1.38 & 2.11 & 1.38 & 4.00 \\
\hline M11 & 66.16 & 6.50 & 4.75 & 45.30 & 8.21 & 13.23 & 6.08 & 5.73 & 1.89 & 2.66 & 1.71 & 3.94 \\
\hline H11 & 85.89 & 6.31 & 4.62 & 24.72 & 10.54 & 19.88 & 10.03 & 10.40 & 3.15 & 4.32 & 2.29 & 3.74 \\
\hline $\mathrm{M} 11+\mathrm{CH}_{4 a}$ & 61.44 & 5.30 & 3.87 & 55.40 & 6.69 & 10.79 & 4.96 & 4.67 & 1.54 & 2.17 & 1.39 & 3.22 \\
\hline $\mathrm{M} 11+\mathrm{CH}_{4} \mathrm{~b}$ & 58.19 & 4.47 & 3.27 & 62.35 & 5.65 & 9.11 & 4.18 & 3.94 & 1.30 & 1.83 & 1.17 & 2.71 \\
\hline $\mathrm{M} 11+\mathrm{C}_{6} \mathrm{H}_{6} \mathrm{a}$ & 66.87 & 6.44 & 4.71 & 44.92 & 8.14 & 13.12 & 6.03 & 5.68 & 1.88 & 2.63 & 2.54 & 3.91 \\
\hline $\mathrm{M} 11+\mathrm{C}_{6} \mathrm{H}_{6} \mathrm{~b}$ & 67.58 & 6.39 & 4.67 & 44.54 & 8.07 & 13.01 & 5.98 & 5.64 & 1.86 & 2.61 & 3.36 & 3.88 \\
\hline $\mathrm{M} 11-\mathrm{H}_{2} \mathrm{Oa}$ & 67.45 & 6.63 & 4.84 & 46.21 & 8.37 & 13.50 & 6.20 & 5.85 & 1.93 & 2.71 & 1.74 & 2.01 \\
\hline $\mathrm{M} 11-\mathrm{H}_{2} \mathrm{Ob}$ & 68.12 & 6.70 & 4.89 & 46.68 & 8.46 & 13.64 & 6.26 & 5.91 & 1.95 & 2.74 & 1.76 & 1.02 \\
\hline AB M9 & 44.55 & 1.62 & 1.22 & 86.36 & 6.83 & 2.36 & 0.97 & 0.33 & 0.13 & 0.18 & 0.00 & 0.00 \\
\hline EC 04 & 61.15 & 4.12 & 6.31 & 55.22 & 7.63 & 11.65 & 8.79 & 3.95 & 1.37 & 0.94 & 0.00 & 0.00 \\
\hline $\mathrm{M} 11+\mathrm{CO}_{2} \mathrm{a}$ & 52.69 & 5.46 & 20.00 & 38.05 & 6.89 & 11.12 & 5.11 & 4.81 & 1.59 & 2.23 & 1.43 & 3.31 \\
\hline $\mathrm{M} 11+\mathrm{CO}_{2} \mathrm{~b}$ & 26.20 & 3.41 & 50.00 & 23.78 & 4.31 & 6.95 & 3.19 & 3.01 & 0.99 & 1.39 & 0.90 & 2.07 \\
\hline $\mathrm{M} 11+\mathrm{CO}_{2} \mathrm{C}$ & 8.54 & 2.05 & 70.00 & 14.27 & 2.58 & 4.17 & 1.91 & 1.81 & 0.60 & 0.84 & 0.54 & 1.24 \\
\hline $\mathrm{C}_{6} \mathrm{H}_{6} \mathrm{~b}+\mathrm{CO}_{2} \mathrm{a}$ & 53.82 & 5.36 & 20.00 & 37.38 & 6.77 & 10.92 & 5.02 & 4.73 & 1.56 & 2.19 & 2.82 & 3.25 \\
\hline $\mathrm{C}_{6} \mathrm{H}_{6} \mathrm{~b}+\mathrm{CO}_{2} \mathrm{~b}$ & 26.91 & 3.35 & 50.00 & 23.36 & 4.23 & 6.83 & 3.13 & 2.96 & 0.98 & 1.37 & 1.76 & 2.03 \\
\hline $\mathrm{C}_{6} \mathrm{H}_{6} \mathrm{~b}+\mathrm{CO}_{2} \mathrm{C}$ & 8.97 & 2.01 & 70.00 & 14.02 & 2.54 & 4.10 & 1.88 & 1.77 & 0.59 & 0.82 & 1.06 & 1.22 \\
\hline S-M11* & 43.80 & 0 & 26.34 & 54.28 & 6.00 & 3.86 & 1.74 & 0.54 & 0.25 & 4.02 & 2.98 & 0 \\
\hline $\mathrm{S}-\mathrm{M} 11+\mathrm{C}_{6} \mathrm{H}_{6} *$ & 43.80 & 0 & 25.95 & 53.47 & 5.91 & 3.80 & 1.71 & 0.54 & 0.26 & 1.83 & 6.52 & 0 \\
\hline
\end{tabular}

${ }^{*}$ Performed at a flow rate of 35 SLPM 


\subsection{Calculation of Destruction and Removal Efficiency}

The full theory and derivation for the DRE of any combustible species present in the flare gas stream can be found in Corbin \& Johnson [37] and is only briefly reviewed here. The DRE of a benzene in a flare can generally be defined as [37]:

$$
D R E_{C_{6} H_{6}}=\left[1-\frac{\dot{n}_{C_{6} H_{6}, p}}{X_{C_{6} H_{6}, F G} \dot{n}_{F G}}\right]
$$

where $\dot{n}_{C_{6} H_{6}, p}$ is the molar flow rate of benzene in the plume, $X_{C_{6} H_{6}, F G}$ is the mole fraction of benzene in the flare gas, and $\dot{n}_{F G}$ is the molar flow rate of the flare gas. To calculate the DRE for a single species in the fuel, it is assumed that all of the combustion products are gas-phase only. Although there is black carbon present in the combustion products, its mass is negligible in the context of the DRE calculation, as shown in Appendix B. Because the CUFF gathers and dilutes combustion products with ambient air in a collection hood, it is reasonable [37] to assume that the molar mass of the plume $M_{p}$ is equal to the molar mass of the ambient air $M_{\infty}$. This assumption is tested for a sample test case in Appendix B. With these assumptions, and by applying a carbon balance to the system, the DRE of benzene in the flare can be expressed in terms of the mole fractions of gases in the flare fuel gas $\left(X_{C_{2}, F G}, X_{C_{X} H_{y}, F G}, X_{C_{6} H_{6}, F G}\right)$, the mole fractions of gases in the plume $\left(X_{C O_{2} . p}\right.$, $\left.X_{C O, p}, X_{C H_{4}, p}, X_{C_{6} H_{6}, p}\right)$, the mole fractions of gases in ambient air $\left(X_{C O_{2} . \infty}, X_{C O, \infty}, X_{C H_{4}, \infty}\right.$, $X_{C_{6} H_{6}, \infty}$ ), the number of carbon atoms in certain gases ( $\# C_{F G}, \# C_{C_{6} H_{6}}$ ), the mass flow of the flare gas $\dot{m}_{F G}$, and the molar mass of ambient air $M_{\infty}$ in (3.2). All species other than benzene were measured by two separate cavity ringdown analyzers, one measured methane and the other measured carbon monoxide and carbon dioxide. 


$$
\begin{aligned}
& D R E_{C_{6} H_{6}}=\left[1-\frac{\left(\# C_{F G}\left(X_{C_{x} H_{y}, F G}\right)+X_{C O_{2} \cdot F G}\right)\left(X_{C_{6} H_{6}, p}-X_{C_{6} H_{6}, \infty}\right)}{\left(X_{C_{6} H_{6}, F G}\right)\left(X_{C O_{2} \cdot p}-X_{C O_{2} \cdot \infty}+A\right)}\right. \\
& \left.+\frac{\left(X_{C_{6} H_{6}, \infty}\left(X_{C O_{2} \cdot p}+D\right)-X_{C_{6} H_{6}, p}\left(X_{C O_{2} \cdot \infty}+E\right)\right) \frac{\dot{m}_{F G}}{M_{\infty}}}{\left(X_{C_{6} H_{6}, F G}\right)\left(X_{C O_{2} \cdot p}-X_{C O_{2} \cdot \infty}+A\right)}\right]
\end{aligned}
$$

where:

$$
\begin{gathered}
A=X_{C O, p}-X_{C O, \infty}+X_{C H_{4}, p}-X_{C H_{4}, \infty}+\# C_{C_{6} H_{6}}\left(X_{C_{6} H_{6}, p}-X_{C_{6} H_{6}, \infty}\right) \\
D=X_{C O, p}+X_{C H_{4}, p}+\# C_{C_{6} H_{6}} X_{C_{6} H_{6}, p} \\
E=X_{C O, \infty}+X_{C H_{4}, \infty}+\# C_{C_{6} H_{6}} X_{C_{6} H_{6}, \infty}
\end{gathered}
$$

\subsubsection{DRE Uncertainty Analysis}

The uncertainty analysis that is outlined below is based on the ANSI/ASME (1985) standard and follows the detailed approach of Corbin \& Johnson [37]. Uncertainty is the rooted sum of the squares of both the systematic error and precision error of a measurement. Precision error is determined by repeated measurements of the of the experimental parameter of interest (i.e. DRE or benzene yield) and calculated using the Student t-value for a two-sided $95 \%$ confidence interval and appropriate number of degrees of freedom. To determine the systematic error for the DRE calculation of benzene in a flare, we follow the method developed in [38], shown in (3.6). The term $\theta_{D R E_{i}}$ represents the sensitivity indices for DRE and $B_{x}$ is the systematic error for certain variables. To calculate the systematic error on the DRE, the sensitivity indices for variables $i=1$ through $i=9, i=$ 12 through $i=16$, and $i=21$ through $i=23$ were required as per the carbon balance approach in [38]. The complete list of variables is available in [38] (Table A1 in [38]). Only some of the terms, and thus some of the subscripts, described in [38] are of interest to the current calculation. Variables $i=10$ and $i=11$ refer to non-methane gases, which made a negligible contribution to the flow of gases in the flare plume. Also, the sensitivity indices $i=17$ through $i=20$ are not needed since the carbon balance method was used. 


$$
\begin{aligned}
B_{D R E_{C_{6} H_{6}}}=\left(\sum_{i=1}^{9}\left[\theta_{D R E_{C_{6} H_{6}}, i} B_{x_{i}}\right]^{2}+\sum_{i=12}^{16}\left[\theta_{D R E_{C_{6} H_{6}}, i} B_{x_{i}}\right]^{2}\right. \\
\left.+\sum_{i=21}^{23}\left[\theta_{D R E_{C_{6} H_{6}}, i} B_{x_{i}}\right]^{2}\right)^{\frac{1}{2}}
\end{aligned}
$$

All of the equations required to calculate the sensitivity indices are detailed in [38] (Table A10 in [38]). All of the sensitivity indices except for indices $i=15, i=21, i=$ 22 , and $i=23$ when added into (3.6) resulted in products that were at least six orders of magnitude smaller than the four mentioned indices, thus are small enough to be neglected from the calculations. The subscript numbered $i=15$ is the molar mass of the flare gas, $i=21$ is the mole fraction of benzene in the plume, $i=22$ is the mole fraction of benzene in ambient lab air, and $i=23$ is the mole fraction of benzene in the flare gas. To evaluate this equation the sensitivity indices for each of the previously listed variables are needed and are provided in [38] as:

$$
\begin{gathered}
\theta_{D R E_{C_{6} H_{6}, 15}}=-\frac{\left(X_{C_{6} H_{6}, p}-X_{C_{6} H_{6}, \infty}\right)\left(\dot{n}_{p}+M_{F G} \theta_{\dot{n}_{p, 15}}\right)+X_{i, \infty} \frac{\dot{m}_{F G}}{M_{\infty}}}{X_{C_{6} H_{6}, F G} \dot{m}_{F G}} \\
\theta_{D R E_{C_{6} H_{6}, 21}}=-\frac{\dot{n}_{p}+\left(X_{C_{6} H_{6}, p}-X_{C_{6} H_{6}, \infty}\right) \theta_{\dot{n}_{p, 21}}}{X_{C_{6} H_{6}, F G} \frac{\dot{m}_{F G}}{M_{F G}}} \\
\theta_{D R E_{C_{6} H_{6}, 22}}=\frac{\dot{n}_{p}-\frac{\dot{m}_{F G}}{M_{\infty}}-\left(X_{C_{6} H_{6}, p}-X_{C_{6} H_{6}, \infty}\right) \theta_{\dot{n}_{p, 22}}}{X_{C_{6} H_{6}, F G} \frac{\dot{m}_{F G}}{M_{F G}}} \\
\theta_{D R E_{C_{6} H_{6}, 23}}=\frac{\left(X_{C_{6} H_{6}, p}-X_{C_{6} H_{6}, \infty}\right) \dot{n}_{p}+X_{C_{6} H_{6}, \infty} \frac{\dot{m}_{F G}}{M_{\infty}}}{X_{C_{6} H_{6}, F G} \frac{\dot{m}_{F G}}{M_{F G}}}
\end{gathered}
$$

where $\dot{n}_{p}$ is the molar flow rate of the plume, $M_{F G}$ is the molar mass of the flare gas, and $M_{i}$ is the molar mass of benzene. The systematic errors for all of the variables with a non negligible contribution are given in [38] (Table A1 in [38]). For sensitivity indices $i=$ $15,21,22$, and 23 the systematic errors are given as follows: 


$$
\begin{gathered}
B_{X_{15}}=0.017 M_{F G} \\
B_{X_{21}}=0.0707 X_{C_{6} H_{6}, p} \\
B_{X_{22}}=0.0707 X_{C_{6} H_{6}, \infty} \\
B_{X_{23}}=0.0024 \dot{m}_{F G} X_{C_{6} H_{6}, F G}
\end{gathered}
$$

It should be noted that there is a potential correlation between the variables for sensitivity indices $i=2,3,23$, the mole fractions of hydrocarbon, carbon dioxide, and benzene in the flare gas, and $i=15,16$, the molar mass of flare gas and the mass flow rate of the flare gas. These parameters are all calculated from reported individual species fuel flowrates from the independent MFCs. However, the covariance between these variables has negligible impact on the DRE and yield calculations. The previously listed equations were thus used to calculate systematic error. To estimate the precision error, seven tests of the M11 composition were repeated as detailed in Section 3.3.5. The standard deviation, $\sigma$, and student t-value, $t$, were calculated, and the following equation was used to calculate the precision error, $P_{D R E}$.

$$
P_{D R E}=\frac{t \sigma}{\sqrt{N}}
$$

\subsubsection{Benzene Yield Calculation and Uncertainty Analysis}

The benzene yield, $Y_{C_{6} H_{6}}$, was calculated using the following equation which was manipulated to give yield in terms of $m g$ of benzene per $m^{3}$ of fuel:

$$
Y_{C_{6} H_{6}}=\frac{\dot{n}_{C_{6} H_{6}, p} M_{C_{6} H_{6}}}{Q_{F G}}\left[\mathrm{~g} / \mathrm{m}^{3}\right]=\frac{\left(X_{C_{6} H_{6}, p}-X_{C_{6} H_{6}, \infty}\right) \dot{n}_{p} M_{C_{6} H_{6}}}{Q_{F G}}
$$

where $Q_{F G}$ is the volumetric flow rate of the flare gas and $M_{C_{6} H_{6}}$ is the molar mass of benzene. The uncertainty on the emission factor of benzene was calculated by using the uncertainties of each variable in (3.12). However, this was complicated by the fact that the uncertainties in the $X_{C_{6} H_{6}, p}$ and $X_{C_{6} H_{6}, \infty}$ are partially correlated. Although the precision errors would be independent and estimable through in repeated measurements of DRE or benzene yield, the bias errors in $X_{C_{6} H_{6}, p}$ and $X_{C_{6} H_{6}, \infty}$ (e.g. due to the calibration uncertainty 
of the instrument) would be effectively the same. The single instrument bias uncertainty $B_{\Delta X_{C_{6} H_{6}}}$ of $7.07 \%$ on the difference in benzene mole fraction $\Delta X_{C_{6} H_{6}}$ was added in quadrature with the uncertainty on the plume molar flow rate $U N C_{\dot{n}_{p}}$ and the uncertainty on the volumetric flow rate $U N C_{Q_{F G}}$ to give the bias uncertainty on the benzene yield. This was then combined in quadrature with the calculated precision error (calculated based on seven repeated M11 benzene yield measurements as shown in Section 3.3.6) to give uncertainty on the benzene yield, $U N C_{\Delta X_{C_{6} H_{6}}}$ in (3.13).

$$
\begin{aligned}
& B_{Y_{C_{6} H_{6}}}=Y_{C_{6} H_{6}} \sqrt{B_{\Delta X_{C_{6} H_{6}}{ }^{2}+U N C_{\dot{n}_{p}}{ }^{2}+U N C_{Q_{F G}}{ }^{2}}} \\
& U N C_{Y_{C_{6} H_{6}}}=\sqrt{P_{Y_{C_{6} H_{6}}}{ }^{2}+B_{Y_{C_{6} H_{6}}}{ }^{2}}
\end{aligned}
$$

\subsubsection{Repeatability Experiments and Sample Calculations}

Seven repeated experiments were performed using the M11 composition at the same flow rate, nozzle diameter, and exit velocity. The same fan speed was set for the collection hood for each of the seven tests, though may have slight variations due to changes in ambient conditions. The seven M11 cases were performed over five separate days, each day using a fresh calibration. The variables needed to calculate DRE and uncertainty for one of the seven repeated M11 tests are shown in Table 3.4.

\begin{tabular}{|c|c|c|}
\hline Variable & Value & Unit \\
\hline$x$ & 1.946 & - \\
\hline$X_{C_{2} \mathrm{H}_{2}}$ & 2 & - \\
\hline$X_{C_{x} H_{y}, F G}$ & 84.81 & $\%$ \\
\hline$X_{\mathrm{CO}_{2}, \mathrm{FG}}$ & 4.75 & $\%$ \\
\hline$X_{i, F G}$ & 1.71 & $\%$ \\
\hline$X_{\mathrm{CO}_{2, p}}$ & 3507.98 & ppm \\
\hline$X_{C O, p}$ & 4.15 & ppm \\
\hline$B_{X_{20}}$ & 0.0119 & - \\
\hline$B_{X_{23}}$ & 0.00237 & - \\
\hline$X_{C H_{4}, p}$ & 5.80 & ppm \\
\hline$X_{\mathrm{CO}_{2, \infty}}$ & 514.30 & ppm \\
\hline $\boldsymbol{X}_{\boldsymbol{C O}, \infty}$ & 0.00 & ppm \\
\hline
\end{tabular}

Table 3.4: Variables needed for DRE calculation

\begin{tabular}{|c|c|c|}
\hline Variable & Value & Unit \\
\hline $\boldsymbol{X}_{C_{4}, \infty}$ & 6.85 & $p p m$ \\
\hline $\boldsymbol{X}_{i, p}$ & 3.60 & $p p b$ \\
\hline$B_{\boldsymbol{X}_{21}}$ & 0.17 & - \\
\hline$\dot{\boldsymbol{n}}_{p}$ & 0.0375 & $\mathrm{kmol} / \mathrm{s}$ \\
\hline $\boldsymbol{X}_{i, \infty}$ & 0.75 & $\mathrm{ppb}$ \\
\hline$\dot{\boldsymbol{m}}_{F G}$ & 0.001867 & $\mathrm{~kg} / \mathrm{s}$ \\
\hline $\boldsymbol{M}_{\infty}$ & 28.84 & $\mathrm{~kg} / \mathrm{kmol}$ \\
\hline $\boldsymbol{M}_{i}$ & 78.11 & $\mathrm{~kg} / \mathrm{kmol}$ \\
\hline $\boldsymbol{M}_{F G}$ & 33.49 & $\mathrm{~kg} / \mathrm{kmol}$ \\
\hline$\# \boldsymbol{C}_{C_{6} H_{6}}$ & 62 & -- \\
\hline$B_{\boldsymbol{X}_{22}}$ & 0.176 & -- \\
\hline
\end{tabular}




\subsubsection{DRE Sample Calculation}

To calculate the DRE of benzene in a flare, variables $A, D$, and $E$ from (3.3), (3.4), and (3.5) are calculated. Beginning with (3.3) to calculate $A$ :

$$
\begin{gathered}
A=X_{C O, p}-X_{C O, \infty}+X_{C_{4}, p}-X_{C_{4}, \infty}+\# C_{C_{6} H_{6}}\left(X_{C_{6} H_{6}, p}-X_{C_{6} H_{6}, \infty}\right) \\
A=4.15 \times 10^{-6}-0+5.80 \times 10^{-6}-6.85 \times 10^{-6}+6\left(3.60 \times 10^{-9}\right. \\
\left.-0.75 \times 10^{-9}\right) \\
A=3.20 \times 10^{-6}
\end{gathered}
$$

Using (3.4) and calculating $D$ :

$$
\begin{gathered}
D=X_{C O, p}+X_{C H_{4}, p}+\# C_{C_{6} H_{6}} X_{C_{6} H_{6}, p} \\
D=4.15 \times 10^{-6}+5.80 \times 10^{-6}+6\left(3.60 \times 10^{-9}\right) \\
D=1.01 \times 10^{-5}
\end{gathered}
$$

Using (3.5) to calculate $E$.

$$
\begin{gathered}
E=X_{C O, \infty}+X_{C_{4}, \infty}+\# C_{C_{6} H_{6}} X_{C_{6} H_{6}, \infty} \\
E=0+6.85 \times 10^{-6}+6\left(0.75 \times 10^{-9}\right) \\
E=6.88 \times 10^{-6}
\end{gathered}
$$

Lastly, we can substitute $A, D, E$, and all known variables into (3.2) to calculate DRE:

$$
\begin{aligned}
D R E_{C_{6} H_{6}}= & {\left[\begin{array}{c}
1-\frac{\left(x\left(X_{C_{x} H_{y}, F G}\right)+X_{C O_{2} \cdot F G}\right)\left(X_{C_{6} H_{6}, p}-X_{C_{6} H_{6}, \infty}\right)}{\left(X_{i, F G}\right)\left(X_{C_{2} \cdot p}-X_{C_{2} \cdot \infty}+A\right)} \\
+
\end{array}\right.}
\end{aligned}
$$




$$
\begin{aligned}
& D R E_{C_{6} H_{6}} \\
& =\left[1-\frac{(1.946(0.8481)+0.0475)\left(3.60 \times 10^{-9}-0.75 \times 10^{-9}\right)}{(0.0171)\left(4.15 \times 10^{-6}-0+3.20 \times 10^{-6}\right)}\right. \\
& \left.+\frac{\left(0.75 \times 10^{-9}\left(4.15 \times 10^{-6}+1.01 \times 10^{-5}\right)-3.60 \times 10^{-9}\left(0+6.88 \times 10^{-6}\right)\right) \frac{0.001867}{28.84}}{(0.0171)\left(4.15 \times 10^{-6}-0+3.20 \times 10^{-6}\right)}\right] \\
& \operatorname{DRE}_{\boldsymbol{C}_{6} \boldsymbol{H}_{6}}=\mathbf{9 9 . 9 9 1 \%}
\end{aligned}
$$

\subsubsection{DRE Uncertainty Sample Calculation}

All the terms defined in (3.7) through (3.8) must first be calculated before the uncertainty on the DRE of benzene in a flare can be determined using (3.6). First, we will begin by substituting all known variables into (3.7) and calculating $\Theta_{D R E, 15}$.

$$
\begin{gathered}
\theta_{D R E_{C_{6} H_{6}, 15}}=-\frac{\left(X_{C_{6} H_{6}, p}-X_{C_{6} H_{6}, \infty}\right)\left(\dot{n}_{p}+M_{F G} \Theta_{\dot{n}_{p, 15}}\right)+X_{i, \infty} \frac{\dot{m}_{F G}}{M_{\infty}}}{X_{C_{6} H_{6}, F G} \dot{m}_{F G}} \\
\theta_{D R E_{C_{6} H_{6}, 15}} \\
=-\frac{\left(3.60 \times 10^{-9}-0.75 \times 10^{-9}\right)\left(0.0375-33.49\left(2.04 \times 10^{-7}\right)\right)+0.75 \times 10^{-9} \frac{0.001867}{28.84}}{0.0171 \times 0.001867} \\
\theta_{D R E_{i}, 15}=-0.01124
\end{gathered}
$$

Using (3.8) to calculate $\theta_{D R E_{C_{6} H_{6}}, 21}$ :

$$
\begin{gathered}
\theta_{D R E_{C_{6} H_{6}, 21}}=-\frac{\dot{n}_{p}+\left(X_{C_{6} H_{6}, p}-X_{C_{6} H_{6}, \infty}\right) \theta_{\dot{n}_{p, 21}}}{X_{C_{6} H_{6}, F G} \frac{\dot{m}_{F G}}{M_{F G}}} \\
\theta_{D R E_{C_{6} H_{6}, 21}}=-\frac{0.0375+\left(3.60 \times 10^{-9}-0.75 \times 10^{-9}\right)\left(-2.961 \times 10^{-6}\right)}{0.0171 \frac{0.001867}{33.49}} \\
\theta_{D R E_{C_{6} H_{6}, 21}}=-3938825.928
\end{gathered}
$$

Using (3.9) to calculate $\theta_{D R E_{C_{6} H_{6}}, 22}$ : 


$$
\begin{gathered}
\theta_{D R E_{C_{6} H_{6}, 22}}=\frac{\dot{n}_{p}-\frac{\dot{m}_{F G}}{M_{\infty}}-\left(X_{C_{6} H_{6}, p}-X_{C_{6} H_{6}, \infty}\right) \theta_{\dot{n}_{p, 22}}}{X_{C_{6} H_{6}, F G} \frac{\dot{m}_{F G}}{M_{F G}}} \\
=\frac{0.0375\left(\frac{0.001867}{28.84}-0.0375\right)-\frac{0.001867}{28.84}-\left(3.60 \times 10^{-9}-0.75 \times 10^{-9}\right)\left(-2.509 \times 10^{-5}\right)}{0.0171 \frac{0.001867}{33.49}} \\
\theta_{D R E_{C_{6} H_{6}, 22}} \\
\theta_{D E_{C_{6} H_{6}, 22}}=19126365.73
\end{gathered}
$$

Using (3.10) to calculate $\theta_{D R E_{C_{6} H_{6}}, 23}$ :

$$
\begin{gathered}
\theta_{D R E_{C_{6} H_{6}, 23}}=\frac{\left(X_{C_{6} H_{6}, p}-X_{C_{6} H_{6}, \infty}\right) \dot{n}_{p}+X_{C_{6} H_{6}, \infty} \frac{\dot{m}_{F G}}{M_{\infty}}}{X_{C_{6} H_{6}, F G}{ }^{2} \frac{\dot{m}_{F G}}{M_{F G}}} \\
\theta_{D R E_{C_{6} H_{6}, 23}}=\frac{\left(3.60 \times 10^{-9}-0.75 \times 10^{-9}\right) 0.0375+0.75 \times 10^{-9} \frac{0.001867}{28.84}}{0.0171^{2} \frac{0.001867}{33.49}} \\
\theta_{D R E_{C_{6} H_{6}, 23}}=0.65874
\end{gathered}
$$

Lastly, (3.11) is used to calculate the DRE uncertainty:

$$
\begin{gathered}
B_{D R E_{C_{6} H_{6}}}=\left(\sum_{i=15}^{15}\left[\theta_{D R E_{C_{6} H_{6}, i}} B_{x_{i}}\right]^{2}+\sum_{i=21}^{23}\left[\theta_{D R E_{C_{6} H_{6},}} B_{x_{i}}\right]^{2}\right)^{\frac{1}{2}} \\
B_{D R E_{C_{6} H_{6}}=[(-0.000336)(0.017 \times 33.49)]^{2}} \\
+\left[(-3938825.928)\left(0.0707 \times 3.60 \times 10^{-9}\right)\right]^{2} \\
+\left[19126365.73\left(0.0707 \times 0.75 \times 10^{-9}\right)\right]^{2} \\
+[0.65874(0.0024 \times 0.001867 \times 0.0171)]^{2} \\
B_{D R E_{i}}=0.002728 \%
\end{gathered}
$$

This result gives the systematic error on the DRE calculation. To get the total uncertainty, precision error is also needed. A plot of seven of the repeated measurements of DRE is shown in Figure 3.1. The average DRE value was 99.990\%. Using the t-score and standard deviation of the seven DREs, the repeatability error at a 95\% confidence interval was calculated to be $0.0025 \%$. This precision error could then be combined with the calculated systematic error to give the total uncertainty. It was assumed that the 
precision error obtained from these seven M11 measurements is applicable to all other DRE measurements and was used in all the uncertainty calculations.

$$
\begin{gathered}
U N C_{D R E}=\sqrt{B_{D R E}^{2}+P_{D R E}^{2}} \\
P_{D R E}=\frac{t \sigma}{\sqrt{N}}=\frac{2.447 \times 0.0000269}{\sqrt{7}} \approx 0.0025 \% \\
\boldsymbol{U N C}_{\text {DRE }}=\sqrt{\mathbf{0 . 0 0 2 7 2 8}^{2}+\mathbf{0 . 0 0 0 0 2 5}^{2}} \approx \mathbf{0 . 0 0 4} \%
\end{gathered}
$$

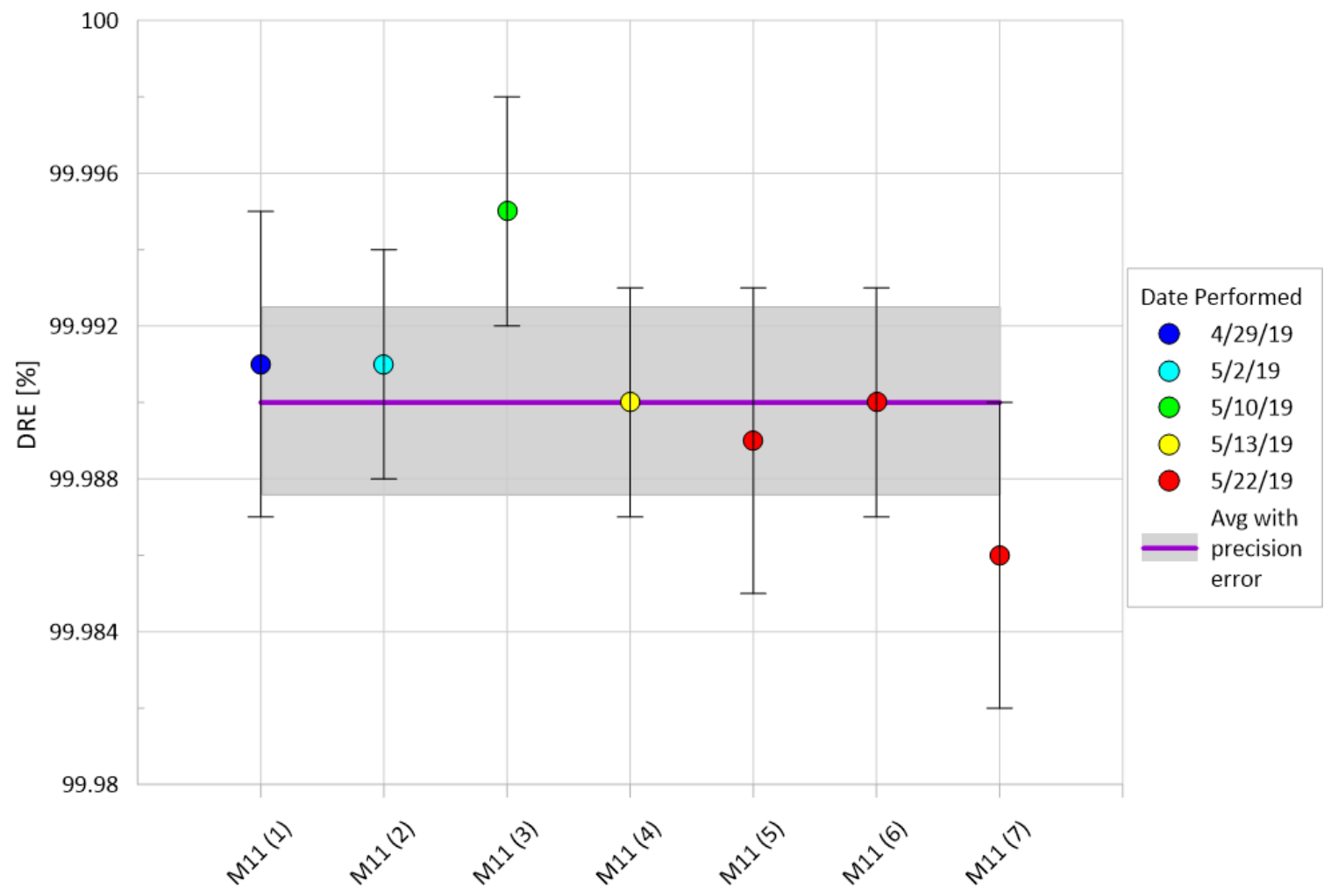

Figure 3.1: M11 DRE repeatability measurements

\subsubsection{Benzene Yield and Uncertainty Sample Calculation}

To calculate the benzene yield and its corresponding uncertainty, all known variables can be substituted into (3.12) and (3.13). 


$$
\begin{gathered}
Y_{C_{6} H_{6}}=\frac{1000\left(X_{C_{6} H_{6}, p}-X_{C_{6} H_{6}, \infty}\right) \dot{n}_{p} M_{C_{6} H_{6}}}{60 Q_{F G}} \\
Y_{C_{6} H_{6}}=\frac{1000\left(3.60 \times 10^{-9}-0.75 \times 10^{-9}\right) 0.0375 \times 78.11}{60 \times 75} \\
\boldsymbol{Y}_{\boldsymbol{C}_{6} \boldsymbol{H}_{6}}=\mathbf{6 . 6 8}\left[\mathbf{m g} / \mathbf{m}^{3}\right]
\end{gathered}
$$

To calculate uncertainty the bias error is first calculated:

$$
\begin{aligned}
B_{Y_{C_{6} H_{6}}=}= & Y_{C_{6} H_{6}} \sqrt{B_{\Delta X_{C_{6} H_{6}}}{ }^{2}+U N C_{\dot{n}_{p}}{ }^{2}+U N C_{Q_{F G}}{ }^{2}} \\
B_{Y_{C_{6} H_{6}}=}= & 6.68 \sqrt{0.0707^{2}+0.0119^{2}+0.0022^{2}} \\
& \boldsymbol{B}_{Y_{C_{6} H_{6}}}=\mathbf{0 . 4 8}\left[\mathbf{m g} / \mathbf{m}^{\mathbf{3}}\right]
\end{aligned}
$$

Next, the precision error is calculated based on seven repeated M11 benzene yield measurements and combined with the bias error to get total estimated uncertainty:

$$
\begin{aligned}
& P_{Y_{C_{6} H_{6}}}=\frac{t \sigma}{\sqrt{N}}=\frac{2.447 \times 1.777}{\sqrt{7}} \approx 1.64\left[\mathrm{mg} / \mathrm{m}^{3}\right] \\
& U N C_{Y_{C_{6} H_{6}}}=\sqrt{P_{Y_{C_{6} H_{6}}}{ }^{2}+B_{Y_{C_{6} H_{6}}}{ }^{2}} \\
& U N C_{Y_{C_{6} H_{6}}}=\sqrt{1.64^{2}+0.48^{2}} \\
& U N C_{Y_{C_{6} H_{6}}}=1.66\left[\mathrm{mg} / \mathrm{m}^{3}\right]
\end{aligned}
$$

\subsubsection{BC Yield and Uncertainty}

To calculate BC yield and its corresponding uncertainty, the software tool OCECgo [33] was used. OCECgo is a MATLAB-based software that analyzes results from a Sunset Labs thermal optical OCEC (organic carbon, elemental carbon) instrument and uses a Monte Carlo approach to calculate EC, OC, and TC along with their uncertainties. OCECgo was developed by Energy \& Emissions Research Laboratory (EERL) at Carleton University, and an in-depth look at all of the calculation theory and protocols can be found in [33]. 
To calculate $\mathrm{BC}$ yield, the $\mathrm{BC}$ production rate first needs to be calculated which is detailed in [38]. Only the subscripts have been modified in (3.14) from [38] for use with this research. The $\mathrm{BC}$ mass production rate is defined as:

$$
\dot{m}_{B C}=\rho_{B C} f_{v, \text { measured }} \frac{R_{u} T_{\text {sample }}}{P_{p}} \dot{n}_{p}
$$

where $\rho_{B C}$ is the density of $\mathrm{BC}, f_{v \text {,measured }}$ is the measured soot volume fraction, $R_{u}$ is the universal gas constant, $T_{\text {sample }}$ is the sample temperature, and $P_{p}$ is the static pressure of the plume. The $\mathrm{BC}$ yield is then simply the $\mathrm{BC}$ emission rate divided by the volumetric flow rate of the flare gas. The uncertainty on the $\mathrm{BC}$ emission rate is determined via the same method as DRE, i.e. calculate the systematic error using the $\mathrm{BC}$ emission rate sensitivity indices and then combine (as the root of the sum of the squares) with the precision error. The $\mathrm{BC}$ emission rate uncertainty is calculated using the following equation found in [38] along with its respective sensitivity indices (found in the Table A9 of the appendix of [38]).

$$
B_{\dot{m}_{B C}}=\left(\sum_{i=1}^{16}\left[\Theta_{\dot{m}_{B C}, i} B_{x_{i}}\right]^{2}\right)^{\frac{1}{2}}
$$




\section{Chapter 4 Results and Discussion}

Experiments were performed following the text matrix described in in Chapter 3. The L11, M11, and H11 compositions were expected to be the cases most representative of "typical" glycol dehydrators operating in Alberta. Other compositions in this test matrix were used to investigate conditions where the $50^{\text {th }}$ percentile glycol dehydrator composition was diluted with methane or was modified to have a higher benzene content or lower water content (note that higher water content was not possible without incurring condensation in the lines feeding the flare). A final series of experiments added carbon dioxide to lower the HHV and provoke conditions where the flame becomes unstable. All tests were performed using a $50.8 \mathrm{~mm}$ diameter burner, and all but two were performed at a total fuel flow rate of 75 SLPM. Mixture S-M11 (the $50^{\text {th }}$ percentile mixture from acquired GRIGLYCalc simulations of still gas data using operating parameters of actual dehydrators) and $\mathrm{S}-\mathrm{M} 11+\mathrm{C}_{6} \mathrm{H}_{6}$ (a modified version with the same HHV and higher benzene content) were run at the mean flow rate of the simulated data points, 35 SLPM. Details of all results are provided in Table A.2.

\subsection{Benzene DRE}

Figure 4.1a shows the DRE results for all tests performed. All test cases had a DRE of nearly $100 \%$ — the lowest measured DRE value was $99.933 \pm 0.220 \%$. Even considering the bounds of $95 \%$ confidence intervals, the lowest likely value of DRE was $99.713 \%$. The two cases that were run at a lower flow rate of $35 \mathrm{SLPM}-\mathrm{S}-\mathrm{M} 11$ and S-M11 $+\mathrm{C}_{6} \mathrm{H}_{6}-$ had uncertainties more than an order of magnitude larger than the other test cases. Excluding these lower flow rate cases as shown in Figure 4.1b leads to a lowest measured DRE value of $99.986 \pm 0.004 \%$. Even considering the bounds of the $95 \%$ confidence intervals of the reduced data set, the lowest likely value of DRE in Figure 4.1b was still greater than $99.98 \%$. These results show that: (i) DRE was universally high for the present experiments on a 50.8-mm diameter flare, and (ii) that changes in the fuel composition had no discernable effect on DRE. 

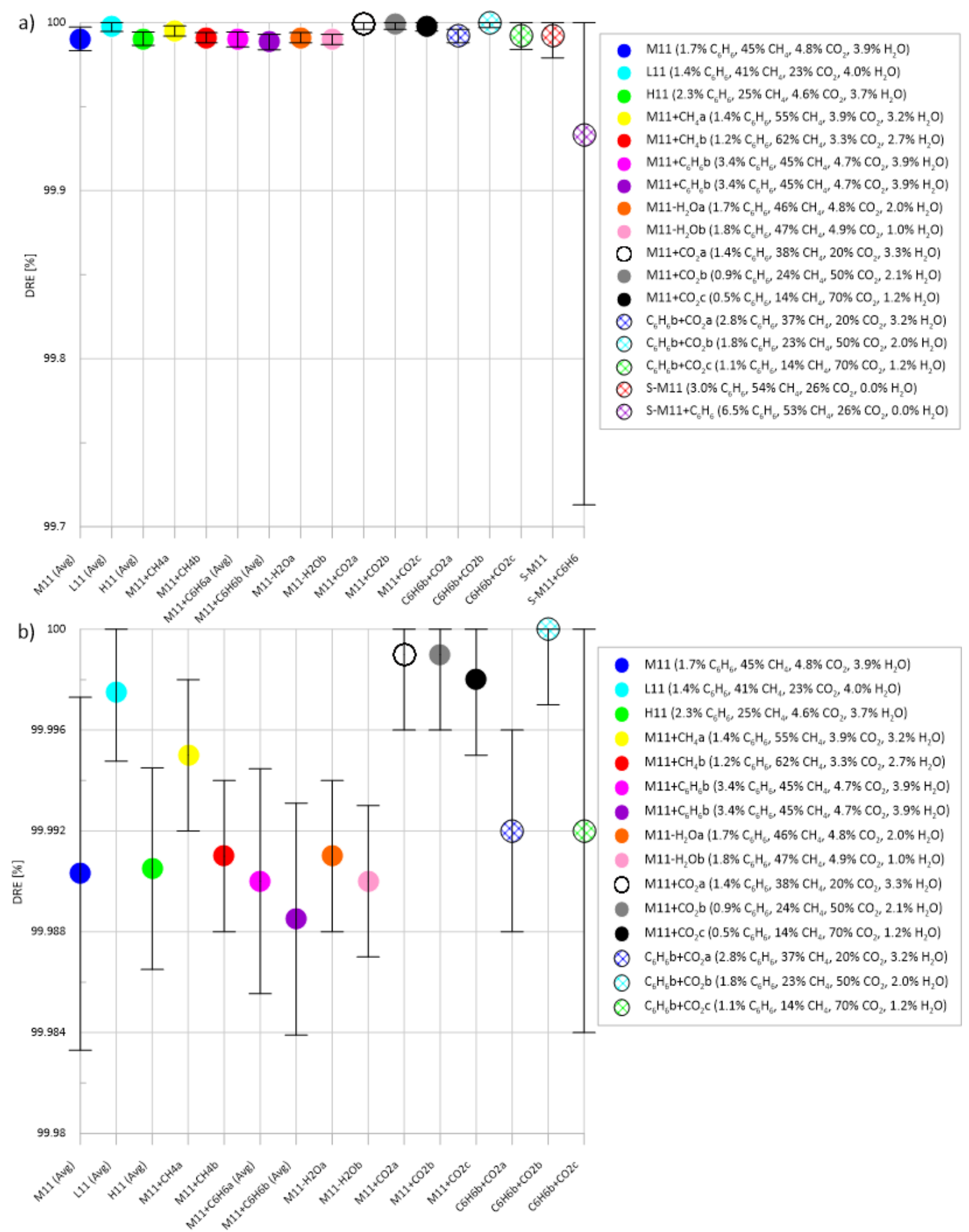

Figure 4.1: Benzene DRE in 50.8-mm diameter vertical flares burning a broad range of multicomponent fuel mixtures. (a) Plot including data for all performed experiments; (b) Same data as (a) but excluding the two low flowrate cases with the highest uncertainties. 


\subsection{Benzene Yield}

Benzene yields, expressed as $\mathrm{mg}$ of benzene per $\mathrm{m}^{3}$ of fuel (at $15^{\circ} \mathrm{C}$ and $1 \mathrm{~atm}$ ), were also derived for all test cases. Figure 4.2a plots results for all 19 fuel mixtures included in the present experiments as a function of benzene mole fraction in the flare gas. The benzene yields appear well-correlated $\left(\mathrm{r}^{2}=0.895\right)$ as an exponential function of the benzene mole fraction as detailed in the plot legend and shown as (4.1).

$$
Y_{C_{6} H_{6}}=X_{C_{6} H_{6}, F G}{ }^{2.552}
$$

This fit was obtained by performing a linear regression fit on the natural logarithm of the mole fraction of benzene in the flare gas and benzene yield data, then reverting the model by taking the exponential. This empirical model assumes that with zero benzene in the fuel stream, no benzene will be produced by flaring. The model is also derived using data up to a maximum benzene mole fraction of $6.5 \%$ in the flare gas. However, the measured yield of $150 \pm 36 \mathrm{mg} / \mathrm{m}^{3}$ for this highest mole fraction case $\left(\mathrm{S}-\mathrm{M} 11+\mathrm{C}_{6} \mathrm{H}_{6}\right)$ had a much larger uncertainty than the other tests and did not necessarily follow the same trend as the rest of the data. It is possible that as the only data point with a benzene mole fraction above $3.4 \%$, this point may be skewing the fit. Further experiments at benzene mole fractions between $3.4 \%$ and $6.5 \%$ or higher would be required to assess the validity of the fit in this range. It should be noted that this exponential model is purely an empirical fit of the obtained results, and that this result was not expected although it could suggest competing effects for benzene formation and destruction in the flame. Instead it was expected that benzene yield would follow a linear model, meaning that DRE should remain constant regardless of the amount of benzene in the flare.

To more accurately predict benzene yields for benzene flare gas mole fractions up to $3.4 \%$, the $\mathrm{S}-\mathrm{M} 11+\mathrm{C}_{6} \mathrm{H}_{6}$ case was removed as shown in Figure $4.2 \mathrm{~b}$. With the S-M11 $+\mathrm{C}_{6} \mathrm{H}_{6}$ case excluded, the highest benzene yield observed during this research was for the $\mathrm{M} 11+\mathrm{C}_{6} \mathrm{H}_{6} \mathrm{~b}$ case with a benzene yield of $19.5 \pm 4.8 \mathrm{mg} / \mathrm{m}^{3}$. Both linear $\left(\mathrm{r}^{2}=0.882\right)$ and exponential fits $\left(r^{2}=0.866\right)$ are shown in Figure 4.2b. The linear regression fit on the benzene yield data has a slightly higher $\mathrm{r}^{2}$ value and implies that DRE is constant for this range of conditions as elaborated upon further below. 

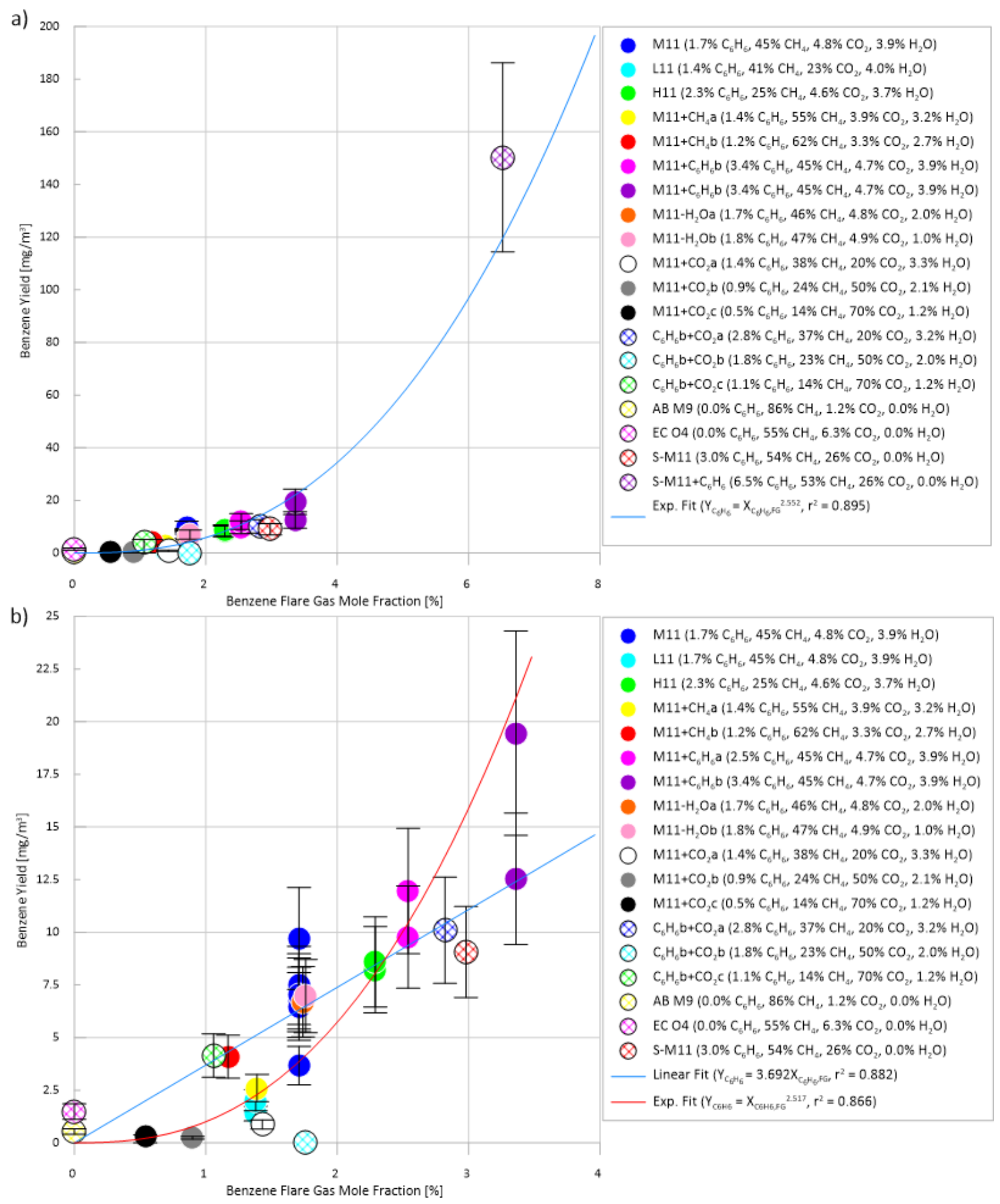

Figure 4.2: Benzene yield as a function of benzene flare gas mole fraction (a) including all tests performed with an exponential fit (b) excluding the $\mathrm{S}-\mathrm{M11}+\mathrm{C}_{6} \mathrm{H}_{6}$ case such that remaining data are for flare gas benzene mole fraction $\leq 3.4 \%$

A linear trend of benzene yield as a function of flare gas benzene mole fraction in Figure $4.2 \mathrm{~b}$ is expected in the case of a single, constant value for DRE. In this case, a 
relationship between benzene flare gas mole fraction, DRE, and benzene yield can be derived from the definitions of DRE, and yield. First, DRE of a species can be defined in terms of molar flow rates as:

$$
D R E=\frac{\dot{n}_{\text {in }}-\dot{n}_{\text {out }}}{\dot{n}_{\text {in }}}
$$

which simplifies to:

$$
1-D R E=\frac{\dot{n}_{\text {out }}}{\dot{n}_{\text {in }}}=\frac{\dot{n}_{C_{6} H_{6}, p}}{\dot{n}_{C_{6} H_{6}, F G}}
$$

where $\dot{n}_{C_{6} H_{6}, F G}$ is the molar flow rate of benzene in the flare gas. The benzene yield converted to moles per unit volume is:

$$
\frac{Y_{C_{6} H_{6}}\left[\mathrm{~g} / \mathrm{m}_{f g}^{3}\right]}{M_{C_{6} H_{6}}[\mathrm{~g} / \mathrm{mol}]}=\frac{\dot{n}_{C_{6} H_{6}, p}}{Q_{F G}}\left[\mathrm{~mol} / \mathrm{m}_{F G}^{3}\right]
$$

Using the ideal gas law, the volume fraction of benzene in the fuel gas is:

$$
\frac{X_{C_{6} H_{6}, F G}}{R T_{r e f} / P_{r e f}}=\frac{\dot{n}_{C_{6} H_{6}, F G}}{Q_{F G}}\left[\mathrm{~mol} / \mathrm{m}_{F G}^{3}\right]
$$

Taking the quotient of (4.4) and (4.3), substituting into (4.2), and rearranging terms produces:

$$
Y_{C_{6} H_{6}}\left[\frac{m g}{m_{F G}^{3}}\right]=c_{1} \cdot X_{C_{6} H_{6}, F G}
$$

where

$$
c_{1}=1000(1-D R E) \cdot \frac{M_{C_{6} H_{6}}\left[\frac{g}{m o l}\right]}{R T_{r e f} / P_{r e f}}
$$

The slope of the data in Figure 4.2b should thus be equal to the $c_{l}$ term in (4.6), where the only variable is $D R E$. Fitting a line to the data obtained while excluding the $\mathrm{S}-\mathrm{M} 11+\mathrm{C}_{6} \mathrm{H}_{6}$ case gives: 


$$
Y_{C_{6} H_{6}}\left[\frac{m g}{m_{f g}^{3}}\right]=3.692 X_{C_{6} H_{6}, F G}
$$

where $X_{C_{6} H_{6}, F G}$ is the mole fraction of benzene in the flare gas. Using the expression for $c_{1}$ in (4.6) yields a DRE estimate of $99.9999 \%$. This model was obtained by performing a linear regression with the $y$-intercept forced to zero, which assumes that with no benzene present in the fuel stream there will not be any benzene generated through combustion. However, although the AB M9 and EC O4 fuel mixtures do not contain benzene, their benzene emissions were found to be non-zero as shown in Figure 4.3. This agrees with the results of Section 3.1 in which pure methane was burned and low-levels of benzene emissions were observed. Alternatively, if a general linear regression fit is used (i.e. allowing for a non-zero intercept to account for benzene production even with zero benzene input), an adjusted $r^{2}=0.70$ is obtained. This is lower than the fit assuming that zero benzene input gives zero benzene produced (adjusted $r^{2}=0.85$ ). This justifies the use of the assumption on the linear model that zero-benzene input will give zero-benzene production, such that the production of benzene for the zero-benzene cases is negligible for this model. As noted, this model is only considered applicable for cases where the benzene mole fraction in the flare stream remains at or below $3.4 \%$.

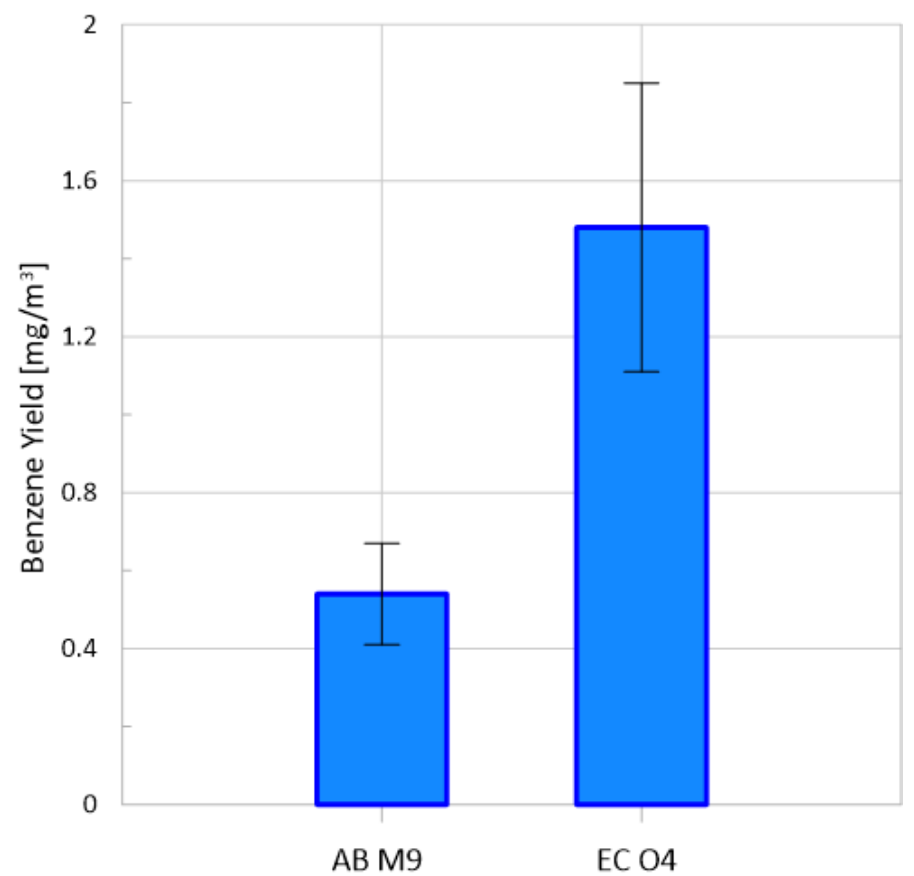

Figure 4.3: Benzene yield for compositions with zero benzene in fuel stream 


\subsection{Capture Container Measurements}

To compare and validate the results obtained using the GC, a second measurement method was employed where the diluted combustion products in the plume were captured using a VOC capture container for offsite GC-MSD (mass selective detector) analysis by a commercial laboratory, ALS Environmental. A VOC capture container is a stainless-steel pressure vessel that has been evacuated, creating a vacuum. Once the container is connected to the desired sample line, gases are drawn into the canister by opening a process valve on the canister. The containers are configured by ALS Environmental with flow restrictors so that they fill slowly over a desired time period.

Due to the high cost of analysis, capture container measurements were only made on a subset of ten tests: three repeats of the M11 composition, L11, H11, M11+ $\mathrm{C}_{6} \mathrm{H}_{6} \mathrm{a}$, $\mathrm{M} 11+\mathrm{C}_{6} \mathrm{H}_{6} \mathrm{~b}, \mathrm{C}_{6} \mathrm{H}_{6} \mathrm{~b}+\mathrm{CO}_{2} \mathrm{a}, \mathrm{C}_{6} \mathrm{H}_{6} \mathrm{~b}+\mathrm{CO}_{2} \mathrm{~b}$, and $\mathrm{C}_{6} \mathrm{H}_{6} \mathrm{~b}+\mathrm{CO}_{2} \mathrm{c}$. Two capture containers were used for each test, one for the plume sampling and one for sampling ambient lab air. Each container would draw in a sample for roughly fifteen minutes and would start at the same time that the GC and OCEC would begin taking samples from the plume. After all of the tests were conducted the now full canisters were sent off to ALS Environmental to be analyzed to obtain the concentration of benzene in the plume and in ambient lab air for each test. The results received by ALS Environmental along with the DRE and benzene yield calculated from these results are summarized in Table 4.1.

Table 4.1: ALS Environmental capture container results

\begin{tabular}{|l|l|l|l|l|l|l|}
\hline Test & $\begin{array}{l}\text { Average } \\
\text { Benzene } \\
\text { Detected } \\
\text { in plume } \\
\text { [ppb] }\end{array}$ & $\begin{array}{l}\text { Ambient } \\
\text { Benzene in } \\
\text { Lab Air } \\
\text { [ppb] }\end{array}$ & DRE [\%] & $\begin{array}{l}\text { Percent } \\
\text { Difference } \\
\text { from GC } \\
\text { DRE }\end{array}$ & $\begin{array}{l}\text { Benzene } \\
\text { Yield } \\
\text { [mg/m } \text { ] }\end{array}$ & $\begin{array}{l}\text { Percent } \\
\text { Difference } \\
\text { from GC } \\
\text { Benzene } \\
\text { Yield }\end{array}$ \\
\hline $\mathrm{M} 11(5)$ & $5.60 \pm 0.90$ & $1.89 \pm 0.31$ & $\begin{array}{l}99.988 \pm \\
0.007\end{array}$ & $1 \times 10^{-3}$ & $8.54 \pm 2.19$ & 13.18 \\
\hline $\mathrm{M} 11(6)$ & $4.33 \pm 0.71$ & $1.26 \pm 0.21$ & $\begin{array}{l}99.988 \pm \\
0.007\end{array}$ & $2 \times 10^{-3}$ & $8.21 \pm 1.98$ & 15.54 \\
\hline $\mathrm{M} 11(7)$ & $5.10 \pm 0.80$ & $1.60 \pm 0.27$ & $\begin{array}{l}99.986 \pm \\
0.008\end{array}$ & 0 & $9.37 \pm 2.46$ & 3.51 \\
\hline $\mathrm{M} 11+\mathrm{C}_{6} \mathrm{H}_{6 \mathrm{a}}(2)$ & $1.36 \pm 0.23$ & $0.92 \pm 0.16$ & $\begin{array}{l}99.999 \pm \\
0.004\end{array}$ & $9 \times 10^{-3}$ & $1.19 \pm 0.76$ & 163.86 \\
\hline $\mathrm{M} 11+\mathrm{C}_{6} \mathrm{H}_{6} \mathrm{~b}(2)$ & $9.90 \pm 1.60$ & $1.35 \pm 0.23$ & $\begin{array}{l}99.983 \pm \\
0.008\end{array}$ & $3 \times 10^{-3}$ & $23.08 \pm 4.37$ & 17.05 \\
\hline $\mathrm{L} 11(2)$ & $1.82 \pm 0.30$ & $1.28 \pm 0.21$ & $\begin{array}{l}99.998 \pm \\
0.006\end{array}$ & $2 \times 10^{-3}$ & $1.34 \pm 0.91$ & 40.15 \\
\hline
\end{tabular}




\begin{tabular}{|l|l|l|l|l|l|l|}
\hline $\mathrm{H} 11(2)$ & $4.90 \pm 0.80$ & $1.17 \pm 0.20$ & $\begin{array}{l}99.989 \pm \\
0.005\end{array}$ & $7 \times 10^{-3}$ & $9.90 \pm 2.19$ & 7.66 \\
\hline $\mathrm{C}_{6} \mathrm{H}_{6} \mathrm{~b}+\mathrm{CO}_{2} \mathrm{a}$ & $5.70 \pm 0.90$ & $1.56 \pm 0.26$ & $\begin{array}{l}99.992 \pm \\
0.007\end{array}$ & 0 & $10.35 \pm 2.35$ & 2.44 \\
\hline $\mathrm{C}_{6} \mathrm{H}_{6} \mathrm{~b}+\mathrm{CO}_{2} \mathrm{~b}$ & $0.82 \pm 0.14$ & $0.78 \pm 0.13$ & $\begin{array}{l}100.000 \pm \\
0.000\end{array}$ & 0 & $0.07 \pm 0.33$ & 200.00 \\
\hline $\mathrm{C}_{6} \mathrm{H}_{6} \mathrm{~b}+\mathrm{CO}_{2} \mathrm{C}$ & $0.94 \pm 0.16$ & $0.76 \pm 0.13$ & $\begin{array}{l}99.999 \pm \\
0.001\end{array}$ & $7 \times 10^{-3}$ & $0.42 \pm 0.49$ & 162.94 \\
\hline
\end{tabular}

Figure 4.4a compares the calculated DRE values using either the CUFF GC data or the capture container data. The results show that the DRE values calculated using the two different measurement methods are nearly identical, with all values being nearly $100 \%$. Figure $4.4 \mathrm{~b}$ shows a plot of the benzene yields calculated from both methods. When comparing the benzene yields calculated from the two different measurement methods, it is observed that the values are mostly similar. All but two of the values obtained from ALS Environmental fall within the bounds of uncertainty of the values measured using the GC in the CUFF. One exception is the $\mathrm{M} 11+\mathrm{C}_{6} \mathrm{H}_{6}$ a case, where the value obtained via the canister does not follow the trend that would be expected when comparing M11 with $\mathrm{M} 11+\mathrm{C}_{6} \mathrm{H}_{6} \mathrm{a}$ and $\mathrm{M} 11+\mathrm{C}_{6} \mathrm{H}_{6} \mathrm{~b}$. For this reason, it is expected that there was an issue with the canister sampling and/or the external lab analysis, though the exact reason for this difference is unknown. The other exception is the $\mathrm{C}_{6} \mathrm{H}_{6} \mathrm{~b}+\mathrm{CO}_{2} \mathrm{c}$ case which is also out of the bounds of uncertainty of the GC measurement. This is because the capture container takes an average reading over the entire test, and if the flare only has fuel stripping occasionally (as discussed in Section 4.4) it would be averaged out of this result. Most importantly, this second set of independent measurements using a complimentary analysis technique gives confidence in the reported benzene yield and DRE data from the CUFF. 

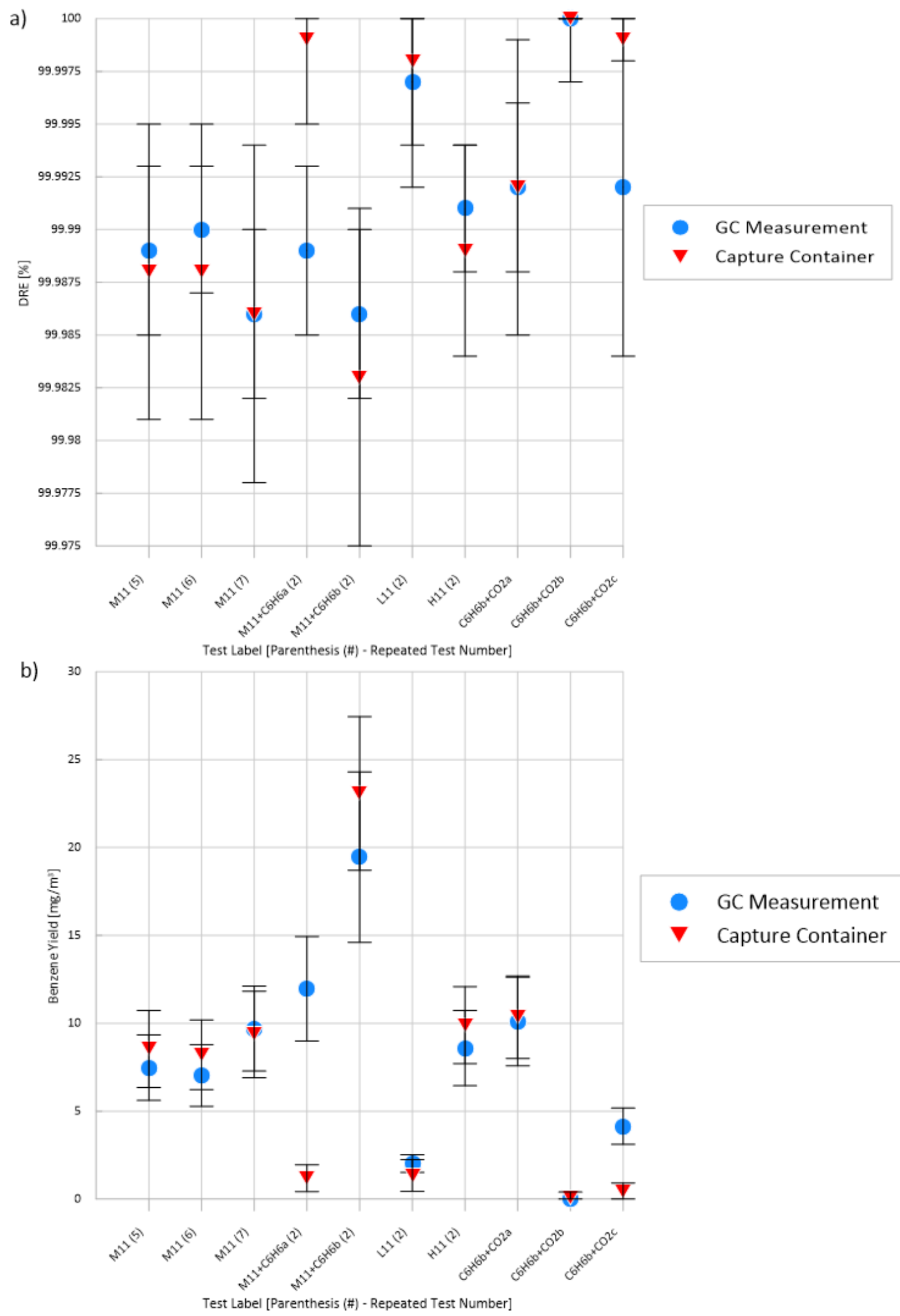

Figure 4.4: (a) DRE measured from GC and capture container (b) benzene yield measured from GC and capture container 


\subsection{Flame Instability}

To simulate a scenario where flare liftoff may occur, the $\mathrm{M} 11+\mathrm{C}_{6} \mathrm{H}_{6} \mathrm{~b}$ composition was diluted with carbon dioxide to lower the HHV of the flare up to the point of instability. Diluting the $\mathrm{M}_{11}+\mathrm{C}_{6} \mathrm{H}_{6} \mathrm{~b}$ composition with carbon dioxide mole fractions of $20 \%$ $\left(\mathrm{C}_{6} \mathrm{H}_{6} \mathrm{~b}+\mathrm{CO}_{2} \mathrm{a}\right)$ and $50 \%\left(\mathrm{C}_{6} \mathrm{H}_{6}+\mathrm{CO}_{2} \mathrm{~b}\right)$ produced a stable flame. When the mole fraction of carbon dioxide was raised to $70 \%\left(\mathrm{C}_{6} \mathrm{H}_{6} \mathrm{~b}+\mathrm{CO}_{2} \mathrm{c}\right)$, the flare became lifted, raising the possibility of emissions or stripping of unburned fuel. If fuel stripping occurs, it would be expected that benzene would escape being combusted in the flare and decrease the effective DRE of the flare. Although liftoff was achieved through dilution using carbon dioxide, in real-world industrial flares liftoff could also occur without dilution depending on the combination of fuel flow rate and fuel properties, as described by Kalghatgi [29]. Outdoor flares could also exhibit fuel stripping due to the effects of crosswinds [28].

At a carbon dioxide mole fraction of $70 \%$ (case $\mathrm{C}_{6} \mathrm{H}_{6}+\mathrm{CO}_{2} \mathrm{c}$ ), the $\mathrm{HHV}$ of the flare gas was only $8.97 \mathrm{MJ} / \mathrm{m}^{3}$. The flame was visibly lifted while burning this composition, but the flame was very unstable and hard to maintain at a steady state, fluctuating between being attached and lifted and occasionally blowing out. Figure 4.5 shows some examples of the amount of flame lift that occurred during testing with a red line overlaid in each of the images to indicate the top of the burner. Manual examination of 300 images taken over a five minute period indicates that the flame was partially (Figure 4.5a) or fully lifted (Figure $4.5 \mathrm{~b}$ and Figure $4.5 \mathrm{c}$ ) around $70 \%$ of the time. This means that for about $30 \%$ of

the test, the flame was seated on the burner (Figure 4.5d) and fuel stripping would presumably not be occurring. 
a)

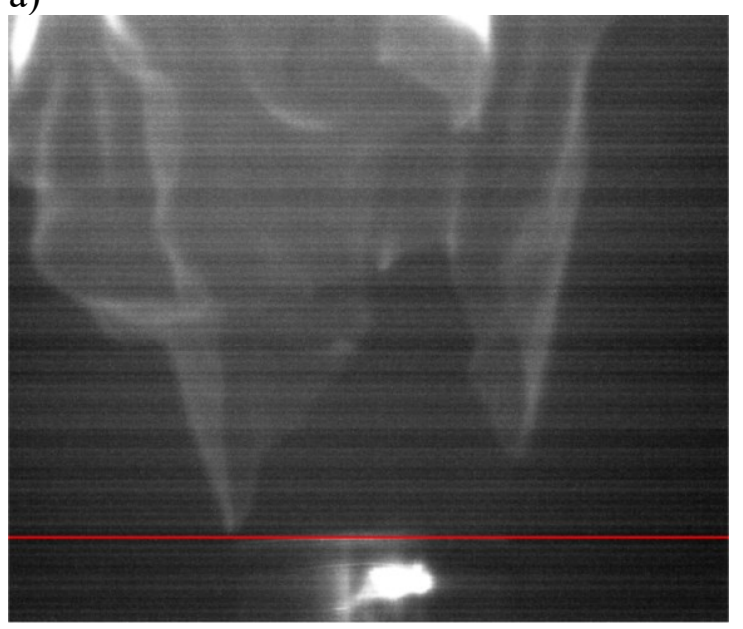

c)

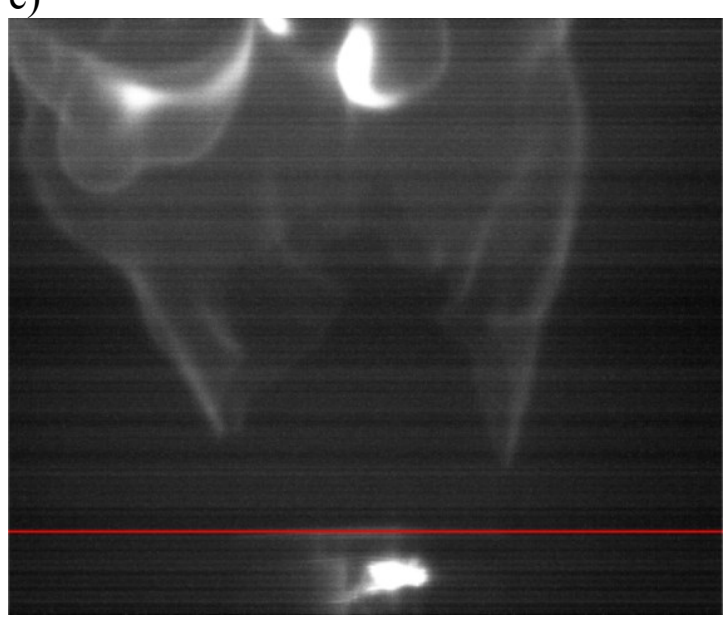

b)

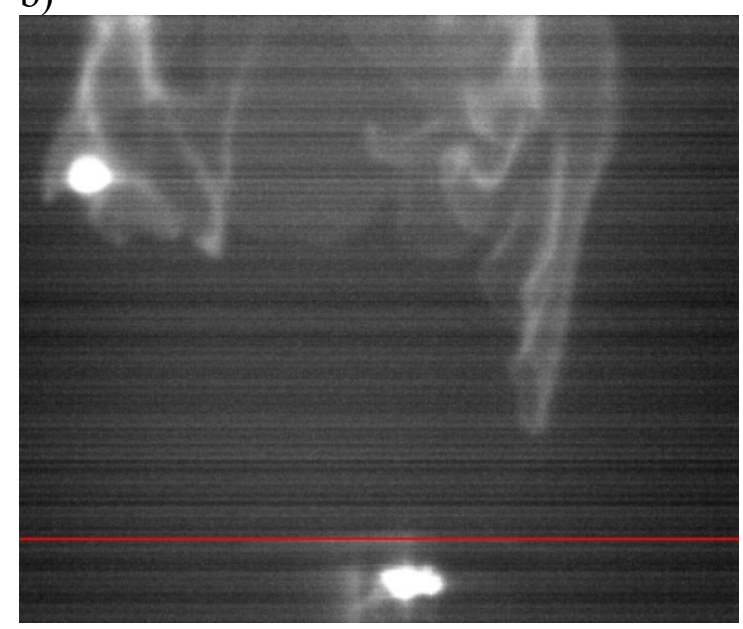

d)

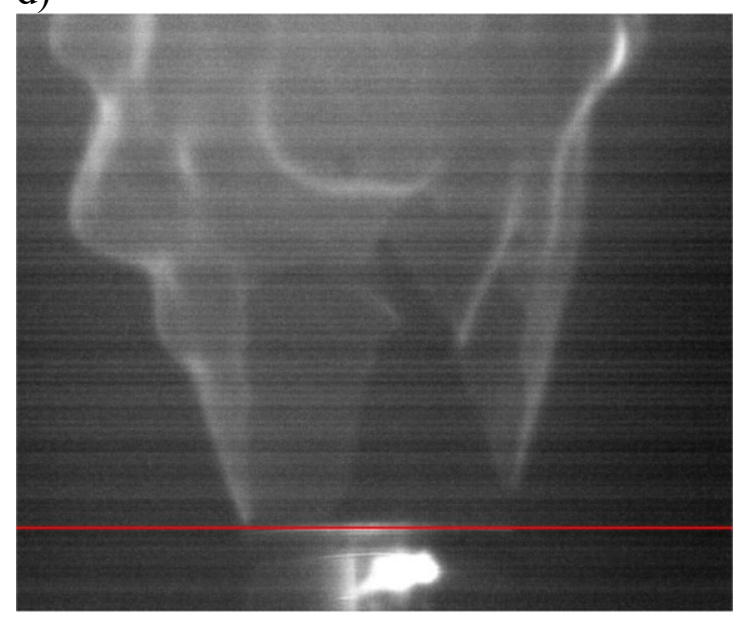

Figure 4.5: Flame lift from $\mathrm{CO}_{2}$ instability (a) flame is partially lifted (b) and (c) flame is fully lifted (d) flame is attached.

Looking at the results in Figure $4.2 \mathrm{~b}$, the benzene yields with $4.7 \% \mathrm{CO}_{2}$ $\left(\mathrm{M} 11+\mathrm{C}_{6} \mathrm{H}_{6} \mathrm{~b}\right)$ and $20 \% \mathrm{CO}_{2}\left(\mathrm{C}_{6} \mathrm{H}_{6} \mathrm{~b}+\mathrm{CO}_{2} \mathrm{a}\right)$ align closely with the constant DRE linear fit, implying that increasing the mole fraction of $\mathrm{CO}_{2}$ to as much as $20 \%$ has negligible effect on the combustion chemistry related to benzene DRE. When the mole fraction of $\mathrm{CO}_{2}$ was increased to $50 \%$ (i.e. case $\mathrm{C}_{6} \mathrm{H}_{6} \mathrm{~b}+\mathrm{CO}_{2} \mathrm{~b}$ ), benzene yields were effectively eliminated - the reading on the GC was below its detection threshold (and thus identical to the ambient benzene background level in the lab). The measurements from the canisters used for background and sample measurement during this test were 0.78 and $0.82 \mathrm{ppb}$, respectively. Though this results in a calculated benzene yield of $0.07 \mathrm{mg} / \mathrm{m}^{3}$, the signal to background ratio is so low that it is considered a zero-yield result, in agreement with the null result 
from the GC. With the $\mathrm{CO}_{2}$ mole fraction increased to $70 \%\left(\mathrm{C}_{6} \mathrm{H}_{6} \mathrm{~b}+\mathrm{CO}_{2} \mathrm{c}\right)$, the canister concentrations were $0.76 \mathrm{ppb}$ and $0.94 \mathrm{ppb}$ for the background and sample measurements, respectively. This resulted in a benzene yield of $0.42 \mathrm{mg} / \mathrm{m}^{3}$, still well below the prediction based on the constant DRE curve shown in Figure 4.2b, but significantly larger than that of the $\mathrm{C}_{6} \mathrm{H}_{6} \mathrm{~b}+\mathrm{CO}_{2} \mathrm{~b}$ case. It is important to note that the canister samples were taken over a 15 -minute period and thus represent a time-averaged benzene concentration. If fuel stripping was only occurring while the flame was detached, the canister measurements would only give an average benzene emission. The GC measurements during this test case produced a much higher benzene yield of $4.2 \pm 0.48 \mathrm{mg} / \mathrm{m}^{3}$. However, this was based on the four discrete measurements taken with very short sample durations $(<1 \mathrm{~s})$ at 5 -minute intervals during the test. The benzene yields for these four measurements - 9.4, 5.8, 0.96, and $0.49 \mathrm{mg} / \mathrm{m}^{3}$ - had a very large relative standard deviation of $102 \%$, larger than that of any other condition by a factor of two and approximately an order of magnitude greater than the average relative standard deviation of all other conditions. This would be consistent with the unstable flame images of Figure 4.5, suggesting that benzene emissions likely do rise as the flame becomes lifted.

\subsection{Black Carbon Yield}

Though lowering benzene emissions is a positive outcome of flaring glycol dehydrator still vent gas, flaring hydrocarbon gas will also generate black carbon emissions. The presence of benzene in the vent gas stream is expected to greatly increase the $\mathrm{BC}$ yield, since benzene is a known precursor to $\mathrm{BC}[26]$. Though a thorough comparison of the significance of benzene emissions relative to $\mathrm{BC}$ emissions is beyond the scope of this work, atmospheric BC is a known climate forcer [18]-[21], and may be the second-most important positive anthropogenic climate forcer after $\mathrm{CO}_{2}[19]$. To quantify the potential increase in $\mathrm{BC}$ emissions that would result from the flaring of still vent gas from glycol dehydrators, measurements of $\mathrm{BC}$ yield were performed simultaneous with the benzene measurements for all cases except the S-M11 and S-M11+ $\mathrm{C}_{6} \mathrm{H}_{6}$ test cases. BC was measured using the Sunset Labs model 4 OCEC analyzer using the analysis methods described in Chapter 3 [33]. 
Figure 4.6a shows the $\mathrm{BC}$ yield results in units of $\mathrm{g}$ of $\mathrm{BC}$ per $\mathrm{m}^{3}$ of fuel (at $15^{\circ} \mathrm{C}$ and $1 \mathrm{~atm}$ ), as a function of HHV. BC yield from flares has been shown to be wellcorrelated with HHV for alkane-only fuel mixtures as described in Conrad at al [39], whose proposed curve fit is overlaid in Figure 4.6a. It is expected that the presence of benzene in the fuel mixtures used in the current work will cause an increase in $\mathrm{BC}$ yield compared to the alkane-only trend. The highest measured BC yield during these experiments was 13.5 $\pm 1.1 \mathrm{~g} / \mathrm{m}^{3}$, which corresponds to one of the two repeated $\mathrm{H} 11$ test cases, which also had the highest HHV.

The water content in the fuel stream was lowered to determine the effect of water content on BC yield. No statistically significant effect was observed. In the present experiments it was not possible to raise the water content above the $3.94 \%$ value without risking condensation in the fuel line.

Figure 4.6b shows a plot of BC yield as a function of benzene mole fraction in the flare gas. Reinforcing the idea that benzene is known precursor to $\mathrm{BC}$, increasing the amount of benzene in the fuel stream increased the BC produced from the flare. The M11 composition produced an average BC yield of $7.60 \pm 1.72 \mathrm{~g} / \mathrm{m}^{3}$; when the benzene mole fraction was increased from $1.71 \%$ to $2.54 \%\left(\mathrm{M} 11+\mathrm{C}_{6} \mathrm{H}_{6} \mathrm{a}\right)$ the $\mathrm{BC}$ yield rose to $9.00 \pm$ $1.62 \mathrm{~g} / \mathrm{m}^{3}$. Further increasing the benzene concentration to $3.36 \%\left(\mathrm{M} 11+\mathrm{C}_{6} \mathrm{H}_{6} \mathrm{~b}\right)$ produced an average $\mathrm{BC}$ yield of $12.46 \pm 1.08 \mathrm{~g} / \mathrm{m}^{3}$ (about a $63.9 \%$ increase over the M11 case). 

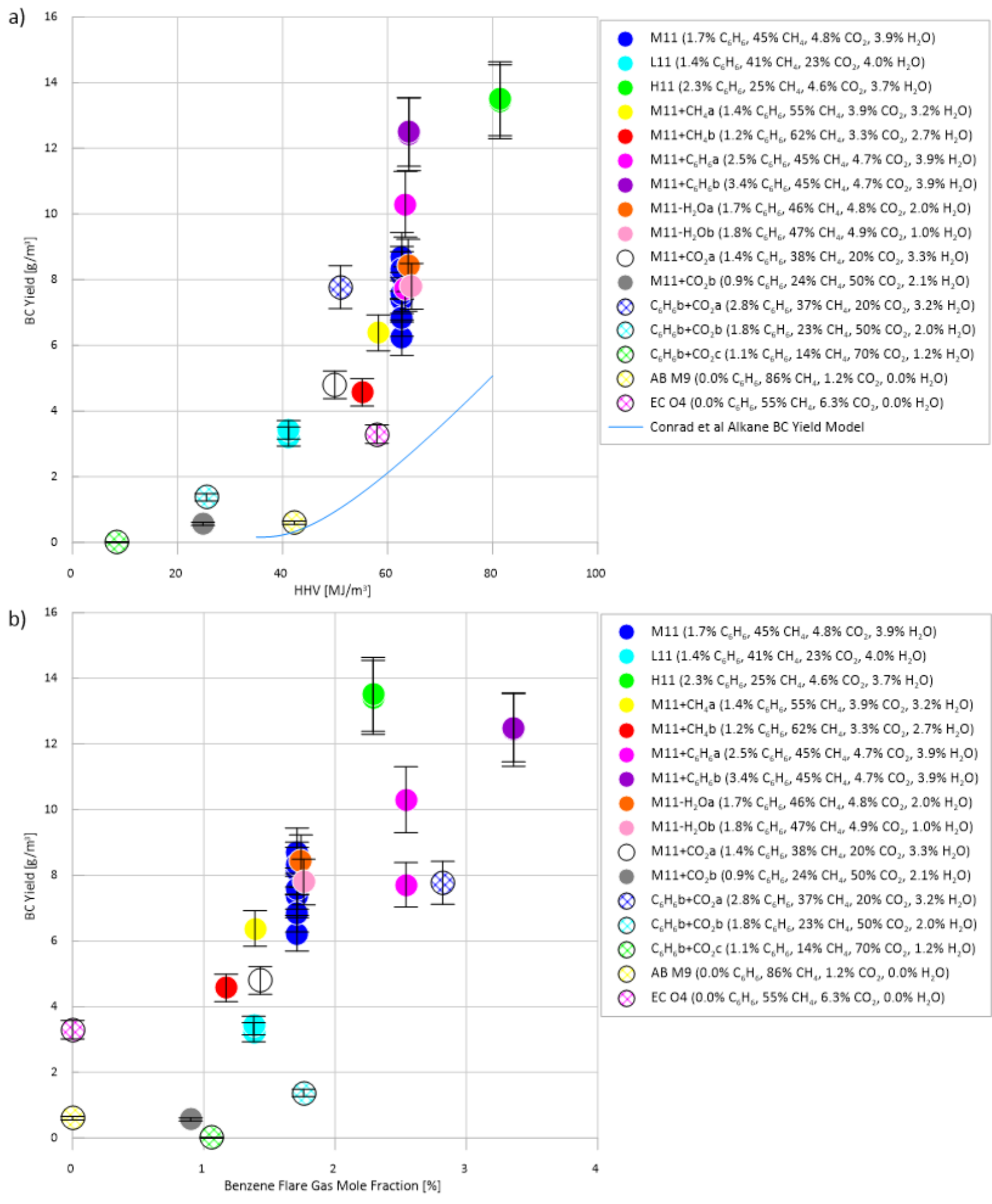

Figure 4.6: BC yield for all compositions measured with Sunset Labs Model 4 OCEC analyzer (a) as a function of $\mathrm{HHV}$ with alkane fuel $\mathrm{BC}$ yield model and (b) as a function of benzene flare gas mole fraction. 
As BC may be the second most important climate forcer [18]-[21], any proposal to reduce benzene emissions via flaring must also consider the inevitable increase in $\mathrm{BC}$ emissions that will result and take steps to reduce those emissions if possible. The M11 case was diluted with either $\mathrm{CH}_{4}$ or $\mathrm{CO}_{2}$ in an attempt to reduce $\mathrm{BC}$ emissions. Increasing the mole fraction of methane in the M11 case from $45.30 \%$ to $62.35 \%\left(\mathrm{M}_{11}+\mathrm{CH}_{4} \mathrm{~b}\right)$ decreased the BC yield to $4.57 \pm 0.42 \mathrm{~g} / \mathrm{m}^{3}$ or a reduction of about $40 \%$. This result was obtained with the overall flow rate being maintained at the same amount as the M11 case (75 SLPM). To consider a practical case in which methane (or available methane-rich sales-grade natural gas) is added to the mixture in an effort to reduce $\mathrm{BC}$ emissions, the resulting $\mathrm{BC}$ yield needs to be adjusted such that it represents the same amount of the M11 composition being burned. Thus, for a fixed amount of the M11 base mixture, the $\mathrm{M} 11+\mathrm{CH}_{4} \mathrm{~b}$ composition at a corresponding higher total flowrate of 108.9 SLPM (33.9 SLPM increase over the base flow of 75 SLPM) would be expected to produce a BC yield of $6.64 \pm 0.60 \mathrm{~g} / \mathrm{m}^{3}$. This represents a $12.6 \%$ decrease in $\mathrm{BC}$ emissions relative to the M11 case without added methane. Thus, it would be possible to reduce total BC emissions from benzene-heavy flares by adding methane. Since sales quality natural gas in Canada is very methane-rich, similar effects are expected when diluting with sales gas.

The compositions that showed the most dramatic reduction in $\mathrm{BC}$ emissions relative to the M11 case were the cases where a composition was diluted with carbon dioxide. This is expected as it has been shown carbon dioxide is effective at reducing BC yields in laminar diffusion flames [40]. The M11 composition was diluted with carbon dioxide to give mole fractions of $20 \%, 50 \%$, and $70 \%$. When increasing the mole fraction of carbon dioxide in the M11 composition from $4.75 \%$ (M11) to $20 \%\left(\mathrm{M} 11+\mathrm{CO}_{2} \mathrm{a}\right)$, the resulting $\mathrm{BC}$ yield dropped to $4.80 \pm 0.42 \mathrm{~g} / \mathrm{m}^{3}$ (a $36.8 \%$ reduction). Under a scenario where this same $\mathrm{CO}_{2}$ mole fraction is reached by adding 14.3 SLPM of $\mathrm{CO}_{2}$ to the fixed 75 SLPM base flow of M11 mixture, a BC yield of $5.44 \pm 0.48 \mathrm{~g} / \mathrm{m}^{3}$ would be expected (a $28.4 \%$ reduction in $\mathrm{BC}$ ). When the $\mathrm{M}_{11} 1+\mathrm{C}_{6} \mathrm{H}_{6} \mathrm{~b}$ case was diluted with carbon dioxide to give a mole fraction of $70 \%\left(\mathrm{C}_{6} \mathrm{H}_{6} \mathrm{~b}+\mathrm{CO}_{2} \mathrm{~b}\right)$ the resulting $\mathrm{BC}$ yield was $1.38 \pm 0.11 \mathrm{~g} / \mathrm{m}^{3}$. In a scenario where the same $\mathrm{CO}_{2}$ mole fraction was achieved by adding $167 \mathrm{SLPM}$ of $\mathrm{CO}_{2}$ $\left(\mathrm{C}_{6} \mathrm{H}_{6} \mathrm{~b}+\mathrm{CO}_{2} \mathrm{~b}\right)$ to the base flow rate of 75 SLPM, a BC yield of $4.45 \pm 0.36 \mathrm{~g} / \mathrm{m}^{3}$ would be expected (a $64.3 \%$ reduction in $\mathrm{BC}$ over the $\mathrm{M} 11+\mathrm{C}_{6} \mathrm{H}_{6} \mathrm{~b}$ case of $12.46 \pm 1.08 \mathrm{~g} / \mathrm{m}^{3}$ ). 
Although diluting with carbon dioxide seems to be an effective method at reducing $\mathrm{BC}$ emissions, this risks affecting flame stability and is also not likely to be a practical option at most facilities. By contrast, sales quality natural gas, which is mainly composed of methane, is the output product of glycol dehydrators and should be readily available.

\subsection{Implications}

In the Alberta Energy Regulator's 2018 ST60B report on flared and vented volumes for various oil and gas industry sectors, it is stated that in 2017 there were 1528 glycol dehydrators operating in Alberta [3] with total reported benzene emissions of 399 tonnes after emissions controls. It is also estimated that glycol dehydrators in Alberta emit on average about $1300 \mathrm{~m}^{3}$ of gas per month [41]. As the M11 test case was designed to be representative of the vent gas composition of the $50^{\text {th }}$ percentile (by HHV) glycol dehydrator operating in Alberta, it becomes possible to estimate the order of magnitude of the decrease in benzene emissions that would result if all glycol dehydrators in Alberta were to flare their still vent gas. Using an average emission rate of $6.89 \pm 2.12 \mathrm{mg} / \mathrm{m}^{3}$ from Table A.1, flaring all glycol dehydrator still gas in Alberta could potentially reduce benzene emissions from the 1528 glycol dehydrators in Alberta from 399 tonnes to $0.164 \pm 0.050$ tonnes $(164 \pm 50 \mathrm{~kg})$, assuming that all flares are operating with a stable flame throughout the entire year.. This would represent a three order of magnitude reduction in benzene emissions from glycol dehydrators.

In the same way it is possible to estimate the total $\mathrm{BC}$ emissions if all of the $23.8 \times 10^{6} \mathrm{~m}^{3}$ of glycol dehydrator still vent gas in Alberta in 2017 were flared. Once again assuming representative $\mathrm{BC}$ yields from the $\mathrm{M} 11$ case, flaring this gas would create an estimated $181 \pm 41$ tonnes of $\mathrm{BC}$ emissions. This would add $66 \%$ to the total estimated $\mathrm{BC}$ emissions of $275 \pm 65$ tonnes for all reported flaring in Alberta in 2017 [41]. As BC may be the second most important climate forcer [18]-[21], it would be important to minimize these emissions. In the scenario where $10.8 \times 10^{6} \mathrm{~m}^{3}$ of methane was added to the still gas prior to flaring, as in case $\mathrm{M} 11+\mathrm{CH}_{4} \mathrm{~b}$, this gas would create an estimated 158 \pm 14 tonnes of $\mathrm{BC}$ emissions. This would still add $58 \%$ to the total estimated $\mathrm{BC}$ emissions of $275 \pm 65$ tonnes for all reported flaring in Alberta in 2017 [41]. The amount of methane added to the still gas could be increased to further decrease the expected $\mathrm{BC}$ emissions. It 
would be up to the discretion of a policy maker to decide between the potential trade-offs of flaring glycol dehydrator still gas. Flaring is a way to potentially reduce benzene emissions by a factor of 1000 with the trade off of increasing overall flaring $\mathrm{BC}$ emissions by up to $66 \%$ (depending on sales-grade natural gas dilution amounts). Canada-wide BC emissions across all sectors were estimated to be 36,309 tonnes in 2017 [42]. This suggests that the total estimated BC emissions from flaring in 2017 in Alberta only accounted for only about $0.76 \%$ of overall $\mathrm{BC}$ emissions. By adding hypothetical dehydrator still gas flaring to the total flaring $\mathrm{BC}$ emissions, this would increase the contribution of flaring to $\mathrm{BC}$ emissions to about $1.26 \%$. By first diluting these still gases with sales grade natural gas, this value would decrease to $1.19 \%$. This would only be a $0.43 \%$ increase in flaring $\mathrm{BC}$ emissions in Alberta when compared to Canada-wide BC emissions, which is potentially negligible.

It should be noted that all of the tests performed in this research were with ideal ambient lab conditions. The effects of crosswinds, which would almost certainly serve to decrease the effective benzene DRE, were not considered. Also not considered were the effects that flowback salts in the fuel stream, steam-assisted flares, or air-assisted flares may have on the DRE of benzene in a flare or the effect on $\mathrm{BC}$ emissions.

Overall it was found in this research that flaring glycol dehydrator still gas is an effective mechanism for reducing benzene emissions in ideal lab conditions. DRE values obtained for benzene were consistently near $100 \%$. For benzene mole fractions in the flare gas below $3.4 \%$, benzene yields were linearly correlated with benzene mole fraction, which is consistent with a constant value of DRE of $99.9999 \%$. While experiments showed that benzene in flare gas significantly increases the $\mathrm{BC}$ produced from flaring, these may be partly compensated for by adding methane to the flare stream, which would be available as part of the sales-grade natural gas output from typical glycol dehydrators. 


\section{Chapter 5 Final Comments and Future Work}

The destruction and removal efficiency (DRE) of benzene in a large, laboratory flare was measured. From experiments running a broad range of industry-relevant multi-component fuel mixtures representative of a range of actual glycol dehydrator still gas compositions, benzene DRE was found to be universally near $100 \%$ under ideal conditions of no crosswind or flame liftoff. DRE values for all but one case were approximately $99.99 \%$ with uncertainties ranging from $\pm 0.003 \%$ to $\pm 0.013 \%$. The remaining case found a DRE of $99.93 \pm 0.22 \%$, which is consistent with the other cases within uncertainties. Changes in chemical composition such as diluting with methane, reducing water vapour, or increasing benzene content appeared to have no discernable effect on the DRE of benzene. Further experiments to intentionally provoke flame instability and liftoff via increased $\mathrm{CO}_{2}$ fraction in the flare gas showed that benzene emissions could be increased slightly, but only as the flame began to liftoff. This suggests that so long as flare flames remain stably attached to the flare tip, near $100 \%$ benzene DRE could be expected.

Benzene yields were measured to determine the effect that flaring would have on overall benzene emissions. As the DRE for all cases was nearly 100\%, benzene emissions are reduced significantly. A simple linear model for predicting benzene yields based on benzene flare gas mole fraction was found by performing a linear regression fit on the benzene yield data. This model has been experimentally shown to be accurate for benzene flare gas mole fractions of up to about $3.4 \%$. If the benzene mole fraction is increased further, the data seemed to follow an exponential model up to a benzene mole fraction of about $6.5 \%$. Though with only one data point (which had comparatively high uncertainty) above a benzene mole fraction of $3.4 \%$, more tests would need to be performed to verify this model. Hypothetically, if the still gases of all glycol dehydrators were to be flared, benzene emissions from glycol dehydrators could be expected to be reduced by about three orders of magnitude.

Black carbon yields were also measured. As expected, higher benzene fractions in the

flare stream induced higher BC yields, but this could be counteracted somewhat by increasing the carbon dioxide or methane fraction in the flare gas. The latter offers a 
practical solution to partially mitigating increased $\mathrm{BC}$ emissions at glycol dehydrators where methane-rich sales-grade natural gas produced by the dehydrator would be readily available to supplement the flare stream.

\subsection{Future Recommendations}

There are several opportunities to extend and improve upon this research in the future. All of the tests performed in this research used a $50.8 \mathrm{~mm}$ diameter flare, and all but two cases were at a total flare gas flow rate of 75 SLPM. This would put the flares tested in this research in the "Turbulent buoyant - transition shear" regime as defined by Delichatsios [16]. Different nozzle diameters and flow rates could be used to tests flares in different aerodynamic regimes. Wind tunnel experiments considering the impacts of crosswind are also strongly recommended as crosswinds are known to reduce the effective combustion efficiency of flares [13]. 


\section{References}

[1] CAPP, "Control of Benzene Emissions from Glycol Dehydrators," Calgary, AB, 2006-0011, 2006.

[2] AER, "Directive 039: Revised Program to Reduce Benzene Emissions from Glycol Dehydrators,” Alberta Energy Regulator (AER), Calgary, AB, 2018.

[3] AER, "Upstream Petroleum Industry Flaring and Venting Report Industry Performance for Year Ending December 31, 2017,” Alberta Energy Regulator (AER), Calgary, AB, 2018.

[4] Canadian Council of Ministers of the Environment, "Canada-wide Standard for Benzene 2010 Final Report," pp. 1-12, 2012.

[5] U.S. EPA, "U.S. EPA - 2003 - Benzene - Integrated Risk Information System," 2003.

[6] Alberta Environment and Parks (AEP)., "Alberta Ambient Air Quality Objectives and Guidelines Summary,” 2017.

[7] S. Mokhatab, W. Poe, and J. Mak, Handbook of Natural Gas Transmission and Processing Principles and Practices, Third Edit. 2015.

[8] R. L. Pearce and C. R. Sivalls, "FUNDAMENTALS OF GAS DEHYDRATION DESIGN AND OPERATION WITH GLYCOL SOLUTIONS,” no. 1, 1984.

[9] AER, "Directive 060 (Effective 2020)," Alberta Energy Regulator (AER), Calgary, AB, 2018.

[10] ECCC, "Guide for Reporting to the National Pollutant Release Inventory (NPRI)," 2017. [Online]. Available:

https://www.canada.ca/content/dam/eccc/migration/main/inrp-npri/28c2417253cb-4307-8720-cb91 ee2a6069/2016-17-20guide-20for-20reporting-20-20en.pdf.

[11] ECCC, "National Pollutant Release Inventory (NPRI)," 2015. [Online]. Available: http://ec.gc.ca/inrp-npri/donnees-data/index.cfm?do=common\&common_query=3. [Accessed: 21-Apr-2017].

[12] Clearstone Engineering Ltd., "UOG Emissions Inventory Volume 2: Overview of CAC and Other Priority Substance Emission Inventory," Environment Canada, Gatineau, QC, 2014. 
[13] L. W. Kostiuk, M. R. Johnson, and G. P. Thomas, "University of Alberta Flare Research Project Final Report,” Edmonton, 2004.

[14] U.S. EPA, "U.S. EPA - 1998 - Locating and Estimating Air Emissions from Sources of Benzene," Reasearch Triangle Park. NC Off. Air Qual. Plan. Stand., no. September, 1998.

[15] J. H. Pohl and N. R. Soelberg, "Evaluation of the efficiency of industrial flares: Flare head design and gas composition," United States Environmental Protection Agency, Research Triangle Park, NC, EPA-600/2-85-106, 1985.

[16] M. A. Delichatsios, "Transition from momentum to buoyancy-controlled turbulent jet diffusion flames and flame height relationships," Combust. Flame, vol. 92, no. 4, pp. 349-364, Mar. 1993.

[17] J. D. N. McEwen and M. R. Johnson, "Black Carbon Particulate Matter Emission Factors for Buoyancy Driven Associated Gas Flares," J. Air Waste Manage. Assoc., vol. 62, no. 3, pp. 307-321, 2012.

[18] V. Ramanathan and G. Carmichael, "Global and regional climate changes due to black carbon," Nat. Geosci., vol. 1, no. 4, pp. 221-227, Mar. 2008.

[19] T. C. Bond et al., "Bounding the role of black carbon in the climate system: A scientific assessment," J. Geophys. Res. Atmos., vol. 118, no. 11, pp. 5380-5552, Jun. 2013.

[20] M. Sato et al., "Global atmospheric black carbon inferred from AERONET," Proc. Natl. Acad. Sci., vol. 100, no. 11, pp. 6319-6324, May 2003.

[21] M. Z. Jacobson, "Strong radiative heating due to the mixing state of black carbon in atmospheric aerosols," Nature, vol. 409, no. 6821, pp. 695-697, Feb. 2001.

[22] T. J. Grahame, R. Klemm, and R. B. Schlesinger, "Public health and components of particulate matter: The changing assessment of black carbon," J. Air Waste Manage. Assoc., vol. 64, no. 6, pp. 620-660, May 2014.

[23] C. D. Elvidge et al., "A Twelve Year Record of National and Global Gas Flaring Volumes Estimated Using Satellite Data: Final Report to the World Bank," 2007.

[24] C. D. Elvidge, M. Zhizhin, K. Baugh, F. Hsu, and T. Ghosh, "Methods for Global Survey of Natural Gas Flaring from Visible Infrared Imaging Radiometer Suite Data," Energies, vol. 9, no. 1, p. 14, Dec. 2015. 
[25] C. D. Elvidge et al., "A Fifteen Year Record of Global Natural Gas Flaring Derived from Satellite Data," Energies, vol. 2, no. 3, pp. 595-622, Aug. 2009.

[26] C. HF, "Mechanisms of soot nucleation in flames," Mech. soot nucleation flames a Crit. Rev., vol. 42, p. 215, 1981.

[27] J. H. Pohl, B. A. Tichenor, J. Lee, and R. Payne, "Combustion Efficiency of Flares," Combust. Sci. Technol., vol. 50, no. 4-6, pp. 217-231, Dec. 1986.

[28] M. R. Johnson, D. J. Wilson, and L. W. Kostiuk, "A fuel stripping mechanism for wake-stabilized jet diffusion flames in crossflow," Combust. Sci. Technol., vol. 169, no. 1, pp. 155-174, 2001.

[29] G. T. Kalghatgi, "Lift-off Heights and Visible Lengths of Vertical Turbulent Jet Diffusion Flames in Still Air," Combust. Sci. Technol., vol. 41, no. 1-2, pp. 17-29, Sep. 1984.

[30] W. Engewald and K. Dettmer-wilde, "Practical Gas Chromatography," 2014.

[31] RAE Systems Inc., The PID Handbook. 2013.

[32] J. C. Chow, J. G. Watson, D. Crow, D. H. Lowenthal, and T. Merrifield, "Comparison of IMPROVE and NIOSH Carbon Measurements," Aerosol Sci.

Technol., vol. 34, no. 1, pp. 23-34, Jan. 2001.

[33] B. M. Conrad and M. R. Johnson, "Split Point Analysis and Uncertainty Quantification of Thermal-Optical Organic/Elemental Carbon Measurements," $J$. Vis. Exp., no. 151, Sep. 2019.

[34] B. Efron, "Bootstrap Methods : Another Look at the Jackknife," Ann. Stat., 1979.

[35] K. Singh and M. Xie, "Bootstrap : A Statistical Method," pp. 1-14, 2010.

[36] M. R. Johnson, A. M. Jefferson, D. J. Corbin, and B. M. Conrad, "Field Measurements of Black Carbon Emissions from Flaring in Coca, Ecuador Interim Project Report I: Summary of Data Collected during Field Measurements," Carleton University Energy \& Emissions Research Lab., Ottawa, ON, 2015.

[37] D. J. Corbin and M. R. Johnson, "Detailed Expressions and Methodologies for Measuring Flare Combustion Efficiency, Species Emission Rates, and Associated Uncertainties," Ind. Eng. Chem. Res., vol. 53, no. 49, pp. 19359-19369, Dec. 2014.

[38] D. J. Corbin, "Methodology and Experiments to Determine Soot and NOx Yields 
from a Vertical Lab-Scale Flare Burning Alkane-Mixtures and Ethylene,” M.A.Sc. Thesis, Carleton University, 2014.

[39] B. M. Conrad, B. M. Crosland, A. M. Jefferson, and M. R. Johnson, "Measurements of Mass Absorption Cross-Section of Flare-Generated Black Carbon and Climatic Implications," in European Geophysical Union General Assembly, 2018.

[40] A. E. Karataş and Ö. L. Gülder, "Effects of carbon dioxide and nitrogen addition on soot processes in laminar diffusion flames of ethylene-air at high pressures," Fuel, vol. 200, pp. 76-80, 2017.

[41] M. R. Johnson and D. R. Tyner, "A Black Carbon Inventory for Gas Flaring in Alberta's Upstream Oil and Gas Sector,”2019, p. 21.

[42] Environment and Climate Change Canada, "Canada's Black Carbon Inventory Report 2013-2017,” 2019. 


\section{Appendix A: Supplementary Data}

Table A.1: Results summary for repeats of the M11 test

\begin{tabular}{|l|c|c|c|c|c|c|}
\hline Test & $\begin{array}{c}\text { Average } \\
\text { Benzene } \\
\text { Detected in } \\
\text { plume }[\mathrm{ppb}]\end{array}$ & $\begin{array}{c}\text { Ambient } \\
\text { Benzene in } \\
\text { Lab Air [ppb] }\end{array}$ & DRE (\%) & $\begin{array}{c}\text { Soot Yield } \\
{\left[\mathrm{g} / \mathrm{m}^{3}\right]}\end{array}$ & $\begin{array}{c}\text { Benzene } \\
\text { Injected } \\
{\left[\mathrm{g} / \mathrm{m}^{3}\right]}\end{array}$ & $\begin{array}{c}\text { Benzene } \\
\text { Yield } \\
{\left[\mathrm{mg} / \mathrm{m}^{3}\right]}\end{array}$ \\
\hline M11 (1) & $3.60 \pm 0.25$ & $0.75 \pm 0.05$ & $99.991 \pm 0.002$ & $6.232 \pm 0.542$ & 56.49 & $6.68 \pm 0.48$ \\
\hline M11 (2) & $3.27 \pm 0.24$ & $0.46 \pm 0.03$ & $99.991 \pm 0.002$ & $8.142 \pm 0.714$ & 56.49 & $6.48 \pm 0.46$ \\
\hline M11 (3) & $1.65 \pm 0.12$ & $0.16 \pm 0.01$ & $99.995 \pm 0.001$ & $7.380 \pm 0.672$ & 56.49 & $3.67 \pm 0.26$ \\
\hline M11 (4) & $3.21 \pm 0.23$ & $0.08 \pm 0.01$ & $99.990 \pm 0.002$ & $8.705 \pm 0.733$ & 56.49 & $7.19 \pm 0.52$ \\
\hline M11 (5) & $4.21 \pm 0.30$ & $0.96 \pm 0.07$ & $99.989 \pm 0.003$ & $7.594 \pm 0.627$ & 56.49 & $7.48 \pm 0.54$ \\
\hline M11 (6) & $2.75 \pm 0.19$ & $0.12 \pm 0.01$ & $99.990 \pm 0.002$ & $6.839 \pm 0.566$ & 56.49 & $7.03 \pm 0.50$ \\
\hline M11 (7) & $4.36 \pm 0.31$ & $0.73 \pm 0.05$ & $99.986 \pm 0.004$ & $8.329 \pm 0.682$ & 56.49 & $9.70 \pm 0.70$ \\
\hline M11 Precision & - & - & 0.0025 & - & - & 1.64 \\
\hline M11 (Avg) & - & - & $99.990 \pm 0.007$ & $6.232 \pm 0.542$ & 56.49 & $6.68 \pm 2.12$ \\
\hline
\end{tabular}


Table A.2: Experimental results summary, with precision error from repeated M11 measurements applied to DRE and benzene yield to estimate total uncertainty

\begin{tabular}{|c|c|c|c|c|c|c|}
\hline Test & \begin{tabular}{|c|} 
Average \\
Benzene \\
Detected in \\
plume [ppb]
\end{tabular} & $\begin{array}{c}\text { Ambient } \\
\text { Benzene in } \\
\text { Lab Air } \\
\text { [ppb] }\end{array}$ & DRE (\%) & $\begin{array}{l}\text { Soot Yield } \\
{\left[\mathrm{g} / \mathrm{m}^{3}\right]}\end{array}$ & $\begin{array}{c}\text { Benzene } \\
\text { Injected } \\
{\left[\mathrm{g} / \mathrm{m}^{3}\right]}\end{array}$ & $\begin{array}{c}\text { Benzene } \\
\text { Yield } \\
{\left[\mathrm{mg} / \mathrm{m}^{3}\right]}\end{array}$ \\
\hline M11 (Avg) & - & - & $\begin{array}{c}99.990 \pm \\
0.007\end{array}$ & $6.232 \pm 0.542$ & 56.49 & $6.68 \pm 2.12$ \\
\hline L11 & $0.95 \pm 0.07$ & $0.28 \pm 0.02$ & $\begin{array}{c}99.998 \pm \\
0.003 \\
\end{array}$ & $3.223 \pm 0.288$ & 45.59 & $1.39 \pm 0.35$ \\
\hline L11 (2) & $0.93 \pm 0.07$ & $0.12 \pm 0.01$ & $\begin{array}{c}99.997 \pm \\
0.003\end{array}$ & $3.427 \pm 0.282$ & 45.59 & $2.02 \pm 0.50$ \\
\hline H11 & $3.96 \pm 0.28$ & $0.47 \pm 0.03$ & $\begin{array}{c}99.991 \pm \\
0.003 \\
\end{array}$ & $13.419 \pm 1.127$ & 75.65 & $8.22 \pm 2.05$ \\
\hline H11 (2) & $4.08 \pm 0.29$ & $0.62 \pm 0.06$ & $\begin{array}{c}99.990 \pm \\
0.003\end{array}$ & $13.508 \pm 1.124$ & 75.65 & $9.17 \pm 2.14$ \\
\hline $\mathrm{M} 11+\mathrm{CH} 4 \mathrm{a}$ & $2.07 \pm 0.15$ & $0.96 \pm 0.07$ & $\begin{array}{c}99.995 \pm \\
0.003\end{array}$ & $6.382 \pm 0.546$ & 45.92 & $2.60 \pm 0.65$ \\
\hline $\mathrm{M} 11+\mathrm{CH} 4 \mathrm{~b}$ & $2.29 \pm 0.16$ & $0.62 \pm 0.04$ & $\begin{array}{c}99.991 \pm \\
0.003\end{array}$ & $4.570 \pm 0.416$ & 38.65 & $4.09 \pm 1.02$ \\
\hline $\mathrm{M} 11+\mathrm{C} 6 \mathrm{H} 6 \mathrm{a}$ & $4.72 \pm 0.33$ & $0.60 \pm 0.04$ & $\begin{array}{c}99.991 \pm \\
0.003 \\
\end{array}$ & $7.714 \pm 0.674$ & 83.91 & $9.77 \pm 2.43$ \\
\hline $\mathrm{M} 11+\mathrm{C} 6 \mathrm{H} 6 \mathrm{a}(2)$ & $5.00 \pm 0.35$ & $0.56 \pm 0.04$ & $\begin{array}{c}99.989 \pm \\
0.004\end{array}$ & $10.298 \pm 1.005$ & 83.91 & $\begin{array}{c}11.96 \pm \\
2.98\end{array}$ \\
\hline $\mathrm{M} 11+\mathrm{C} 6 \mathrm{H} 6 \mathrm{~b}$ & $5.19 \pm 0.37$ & $0.15 \pm 0.01$ & $\begin{array}{c}99.991 \pm \\
0.003\end{array}$ & $12.433 \pm 1.113$ & 111 & $\begin{array}{c}12.54 \pm \\
3.12\end{array}$ \\
\hline $\mathrm{M} 11+\mathrm{C} 6 \mathrm{H} 6 \mathrm{~b}(2)$ & $7.36 \pm 0.52$ & $0.15 \pm 0.01$ & $\begin{array}{c}99.986 \pm \\
0.004 \\
\end{array}$ & $12.494 \pm 1.042$ & 111 & $\begin{array}{c}19.45 \pm \\
4.85 \\
\end{array}$ \\
\hline $\mathrm{M} 11-\mathrm{H} 2 \mathrm{Oa}$ & $3.03 \pm 0.21$ & $0.14 \pm 0.01$ & $\begin{array}{c}99.991 \pm \\
0.003 \\
\end{array}$ & $8.431 \pm 0.797$ & 57.48 & $6.70 \pm 1.67$ \\
\hline M11-H2Ob & $3.37 \pm 0.24$ & $0.43 \pm 0.03$ & $\begin{array}{c}99.990 \pm \\
0.003 \\
\end{array}$ & $7.796 \pm 0.699$ & 58.14 & $6.97 \pm 1.74$ \\
\hline $\mathrm{M} 11+\mathrm{CO} 2 \mathrm{a}$ & $0.69 \pm 0.04$ & $0.31 \pm 0.02$ & $\begin{array}{c}99.999 \pm \\
0.003\end{array}$ & $4.800 \pm 0.423$ & 47.24 & $0.87 \pm 0.22$ \\
\hline $\mathrm{M} 11+\mathrm{CO} 2 \mathrm{~b}$ & $0.25 \pm 0.02$ & $0.10 \pm 0.01$ & $\begin{array}{c}99.999 \pm \\
0.003\end{array}$ & $0.568 \pm 0.049$ & 29.73 & $0.24 \pm 0.06$ \\
\hline $\mathrm{M} 11+\mathrm{CO} 2 \mathrm{c}$ & $0.66 \pm 0.05$ & $0.30 \pm 0.02$ & $\begin{array}{c}99.998 \pm \\
0.003\end{array}$ & N/A & 17.84 & $0.30 \pm 0.08$ \\
\hline $\mathrm{C} 6 \mathrm{H} 6+\mathrm{CO} 2 \mathrm{a}$ & $5.14 \pm 0.36$ & $1.11 \pm 0.08$ & $\begin{array}{c}99.992 \pm \\
0.004\end{array}$ & $7.773 \pm 0.652$ & 93.16 & $\begin{array}{c}10.10 \pm \\
2.52\end{array}$ \\
\hline $\mathrm{C} 6 \mathrm{H} 6+\mathrm{CO} 2 \mathrm{~b}$ & 0 & 0 & $\begin{array}{c}100.000 \pm \\
0.003\end{array}$ & $1.378 \pm 0.111$ & 58.14 & 0 \\
\hline $\mathrm{C} 6 \mathrm{H} 6+\mathrm{CO} 2 \mathrm{c}$ & $1.76 \pm 0.12$ & 0 & $\begin{array}{c}99.992 \pm \\
0.008\end{array}$ & $0.008 \pm 0.016$ & 35.02 & $4.15 \pm 1.03$ \\
\hline AB M9 & $0.33 \pm 0.02$ & $0.10 \pm 0.01$ & N/A & $0.604 \pm 0.052$ & 0 & $0.54 \pm 0.13$ \\
\hline EC O4 & $0.82 \pm 0.11$ & $0.15 \pm 0.02$ & $\mathrm{~N} / \mathrm{A}$ & $3.297 \pm 0.280$ & 0 & $1.48 \pm 0.37$ \\
\hline S-M11 & $3.25 \pm 0.23$ & $0.70 \pm 0.05$ & $\begin{array}{c}99.992 \pm \\
0.013 \\
\end{array}$ & $4.86 \pm 0.61$ & 98.45 & $9.06 \pm 2.16$ \\
\hline S-M11+C6H6 & $42.86 \pm 3.03$ & $0.70 \pm 0.05$ & $\begin{array}{c}99.933 \pm \\
0.220 \\
\end{array}$ & $14.81 \pm 1.93$ & 215.4 & $\begin{array}{c}150.29 \pm \\
35.89 \\
\end{array}$ \\
\hline
\end{tabular}


Table A.3: Simulated glycol dehydrator still gas compositions

\begin{tabular}{|l|l|l|l|l|l|l|l|l|}
\hline Composition Number & $\mathbf{1}$ & $\mathbf{2}$ & $\mathbf{3}$ & $\mathbf{4}$ & $\mathbf{5}$ & $\mathbf{6}$ & $\mathbf{7}$ & $\mathbf{8}$ \\
\hline Hydrogen & 0 & 0 & 0 & 0 & 0 & 0 & 0 & 0 \\
\hline Helium & 0.0002 & 0.0002 & 0 & 0 & 0.0006 & 0.0007 & 0.0002 & 0.0002 \\
\hline Nitrogen & 0 & 0 & 0.0059 & 0.002 & 0.0242 & 0.0253 & 0 & 0 \\
\hline CO2 & 0.4775 & 0.4544 & 0.0765 & 0.0298 & 0.0121 & 0.0065 & 0.3967 & 0.3753 \\
\hline H2S & 0 & 0 & 0 & 0 & 0 & 0 & 0 & 0 \\
\hline Methane & 0.2039 & 0.2374 & 0.6546 & 0.244 & 0.9287 & 0.9433 & 0.2783 & 0.2672 \\
\hline Ethane & 0.0905 & 0.0943 & 0.04 & 0.025 & 0.0135 & 0.0083 & 0.0909 & 0.0966 \\
\hline Propane & 0.0707 & 0.0755 & 0.0847 & 0.071 & 0.0127 & 0.0092 & 0.0806 & 0.0885 \\
\hline i-Butane & 0.0112 & 0.0115 & 0.0015 & 0.0016 & 0.0005 & 0.0005 & 0.0118 & 0.014 \\
\hline n-Butane & 0.0236 & 0.0223 & 0.0308 & 0.0277 & 0.0043 & 0.0036 & 0.0233 & 0.0274 \\
\hline i-Pentane & 0.006 & 0.0052 & 0.0025 & 0.0027 & 0.0007 & 0.0006 & 0.0058 & 0.0071 \\
\hline n-Pentane & 0.0056 & 0.0049 & 0.0246 & 0.0246 & 0.0026 & 0.002 & 0.0052 & 0.0063 \\
\hline Hexane & 0.0053 & 0.0046 & 0.0789 & 0.048 & 0 & 0 & 0.0049 & 0.0057 \\
\hline Heptane & 0.0007 & 0.0005 & 0 & 0.0365 & 0 & 0 & 0.0008 & 0.0009 \\
\hline Octane & 0 & 0 & 0 & 0.0848 & 0 & 0 & 0 & 0 \\
\hline Nonane & 0 & 0 & 0 & 0 & 0 & 0 & 0 & 0 \\
\hline Decane & 0 & 0 & 0 & 0 & 0 & 0 & 0 & 0 \\
\hline Cyclopentane & 0 & 0 & 0 & 0 & 0 & 0 & 0 & 0 \\
\hline Methylcyclohexane & 0.0018 & 0.0014 & 0 & 0.0453 & 0 & 0 & 0.0015 & 0.0017 \\
\hline Neohexane & 0 & 0 & 0 & 0 & 0 & 0 & 0 & 0 \\
\hline Cyclohexane & 0.0098 & 0.0081 & 0 & 0.021 & 0 & 0 & 0.008 & 0.009 \\
\hline 224-Trimethylpentane & 0 & 0 & 0 & 0 & 0 & 0 & 0 & 0 \\
\hline 124-Trimethylbenzene & 0 & 0 & 0 & 0 & 0 & 0 & 0 & 0 \\
\hline Benzene & 0.0215 & 0.0213 & 0 & 0.0472 & 0 & 0 & 0.03 & 0.0319 \\
\hline Toluene & 0.0043 & 0.0032 & 0 & 0.2744 & 0 & 0 & 0.0061 & 0.0066 \\
\hline Ethylbenzene & 0.0007 & 0 & 0 & 0 & 0 & 0 & 0.0008 & 0.0009 \\
\hline Xylenes & 0.0021 & 0 & 0 & 0 & 0 & 0 & 0.0024 & 0.0026 \\
\hline Methylcyclopentane & 0.0646 & 0.0552 & 0 & 0.0144 & 0 & 0 & 0.0527 & 0.058 \\
\hline & & & & & & & 0 \\
\hline
\end{tabular}


Table A.3: Simulated glycol dehydrator still gas compositions(continued)

\begin{tabular}{|l|l|l|l|l|l|l|l|l|}
\hline Composition Number & 9 & 10 & 11 & 12 & 13 & 14 & 15 & 16 \\
\hline Hydrogen & 0 & 0 & 0 & 0 & 0 & 0 & 0 & 0 \\
\hline Helium & 0 & 0 & 0.0002 & 0.0001 & 0.0002 & 0.0001 & 0.0002 & 0.0001 \\
\hline Nitrogen & 0.0008 & 0.0012 & 0 & 0 & 0 & 0 & 0 & 0 \\
\hline CO2 & 0.0118 & 0.02 & 0.3958 & 0.3878 & 0.4455 & 0.5685 & 0.4431 & 0.5647 \\
\hline H2S & 0 & 0 & 0 & 0 & 0 & 0 & 0 & 0 \\
\hline Methane & 0.0692 & 0.1003 & 0.2924 & 0.2887 & 0.1579 & 0.1235 & 0.1604 & 0.1254 \\
\hline Ethane & 0.0219 & 0.044 & 0.073 & 0.0838 & 0.2069 & 0.1655 & 0.2074 & 0.1665 \\
\hline Propane & 0.0882 & 0.1205 & 0.0704 & 0.0845 & 0.1187 & 0.0892 & 0.1187 & 0.0899 \\
\hline i-Butane & 0.0028 & 0.003 & 0.011 & 0.0135 & 0.0121 & 0.0088 & 0.012 & 0.0088 \\
\hline n-Butane & 0.0366 & 0.0481 & 0.0248 & 0.0305 & 0.0291 & 0.0209 & 0.029 & 0.021 \\
\hline i-Pentane & 0.0047 & 0.0061 & 0.0063 & 0.0073 & 0.0039 & 0.0028 & 0.0039 & 0.0028 \\
\hline n-Pentane & 0.0302 & 0.0424 & 0.0062 & 0.0074 & 0.0042 & 0.0029 & 0.0041 & 0.0029 \\
\hline Hexane & 0.0799 & 0.0924 & 0.0063 & 0.0071 & 0.0021 & 0.0016 & 0.002 & 0.0016 \\
\hline Heptane & 0.071 & 0.0658 & 0.001 & 0.0008 & 0.0002 & 0.0001 & 0.0002 & 0.0001 \\
\hline Octane & 0.1699 & 0.1052 & 0 & 0 & 0 & 0 & 0 & 0 \\
\hline Nonane & 0.0347 & 0.0168 & 0 & 0 & 0 & 0 & 0 & 0 \\
\hline Decane & 0 & 0 & 0 & 0 & 0 & 0 & 0 & 0 \\
\hline Cyclopentane & 0 & 0 & 0 & 0 & 0 & 0 & 0 & 0 \\
\hline Methylcyclohexane & 0.0545 & 0.0649 & 0.0025 & 0.0019 & 0.0004 & 0.0003 & 0.0004 & 0.0003 \\
\hline Neohexane & 0.001 & 0 & 0.0006 & 0 & 0 & 0 & 0 & 0 \\
\hline Cyclohexane & 0.0298 & 0.0419 & 0.0125 & 0 & 0.0022 & 0.0018 & 0.0022 & 0.0018 \\
\hline 224-Trimethylpentane & 0 & 0 & 0 & 0 & 0 & 0 & 0 & 0 \\
\hline 124-Trimethylbenzene & 0 & 0 & 0 & 0 & 0 & 0 & 0 & 0 \\
\hline Benzene & 0.0408 & 0.0523 & 0.0116 & 0.0171 & 0.0038 & 0.0029 & 0.0037 & 0.0029 \\
\hline Toluene & 0.094 & 0.0832 & 0.0046 & 0.0034 & 0.0006 & 0.0006 & 0.0006 & 0.0006 \\
\hline Ethylbenzene & 0.0313 & 0.0156 & 0.0007 & 0 & 0 & 0 & 0 & 0 \\
\hline Xylenes & 0.1036 & 0.0445 & 0.0019 & 0 & 0.0003 & 0.0002 & 0.0003 & 0.0002 \\
\hline Methylcyclopentane & 0.0234 & 0.0317 & 0.0783 & 0.0661 & 0.012 & 0.0103 & 0.0118 & 0.0102 \\
\hline & & & & & & & 0 \\
\hline
\end{tabular}


Table A.3: Simulated glycol dehydrator still gas compositions(continued)

\begin{tabular}{|l|l|l|l|l|l|l|l|l|}
\hline Composition Number & 17 & 18 & 19 & 20 & 21 & 22 & 23 & 24 \\
\hline Hydrogen & 0 & 0 & 0 & 0 & 0 & 0 & 0 & 0 \\
\hline Helium & 0.0002 & 0.0002 & 0.0002 & 0 & 0 & 0 & 0 & 0.0001 \\
\hline Nitrogen & 0 & 0 & 0 & 0.0004 & 0.0004 & 0.0001 & 0.0001 & 0.0007 \\
\hline CO2 & 0.5726 & 0.5807 & 0.5909 & 0.0817 & 0.0562 & 0.1492 & 0.1608 & 0.1124 \\
\hline H2S & 0 & 0 & 0 & 0 & 0 & 0 & 0 & 0 \\
\hline Methane & 0.1433 & 0.1361 & 0.1339 & 0.1448 & 0.1297 & 0.1903 & 0.213 & 0.7463 \\
\hline Ethane & 0.1731 & 0.1744 & 0.1747 & 0.1187 & 0.091 & 0.0062 & 0.0071 & 0.0363 \\
\hline Propane & 0.0749 & 0.0735 & 0.068 & 0.197 & 0.1791 & 0.0025 & 0.0027 & 0.0051 \\
\hline i-Butane & 0.0067 & 0.0064 & 0.0057 & 0.0029 & 0.0032 & 0.0002 & 0.0002 & 0.0004 \\
\hline n-Butane & 0.0139 & 0.0134 & 0.0118 & 0.0674 & 0.0713 & 0.0006 & 0.0007 & 0.0005 \\
\hline i-Pentane & 0.0017 & 0.0016 & 0.0014 & 0.005 & 0.0064 & 0.0001 & 0.0001 & 0.0001 \\
\hline n-Pentane & 0.0015 & 0.0014 & 0.0012 & 0.0429 & 0.0527 & 0.0001 & 0.0001 & 0 \\
\hline Hexane & 0.0008 & 0.0008 & 0.0007 & 0.0201 & 0.09 & 0.0003 & 0.0003 & 0.0002 \\
\hline Heptane & 0.0001 & 0.0001 & 0.0001 & 0.0258 & 0.0423 & 0.0008 & 0.0008 & 0.0003 \\
\hline Octane & 0 & 0 & 0 & 0.0323 & 0.0437 & 0.0025 & 0.0024 & 0.0007 \\
\hline Nonane & 0 & 0 & 0 & 0.0002 & 0 & 0.0057 & 0.0054 & 0.0013 \\
\hline Decane & 0 & 0 & 0 & 0.0002 & 0 & 0.0112 & 0.0106 & 0.0022 \\
\hline Cyclopentane & 0 & 0 & 0 & 0 & 0 & 0 & 0 & 0 \\
\hline Methylcyclohexane & 0.0002 & 0.0002 & 0.0002 & 0.0278 & 0.0181 & 0.0097 & 0.0092 & 0.0017 \\
\hline Neohexane & 0 & 0 & 0 & 0.0021 & 0 & 0.0003 & 0.0003 & 0.0001 \\
\hline Cyclohexane & 0.0011 & 0.0011 & 0.0011 & 0.0193 & 0.0257 & 0.0021 & 0.0022 & 0.0011 \\
\hline 224-Trimethylpentane & 0 & 0 & 0 & 0.0003 & 0 & 0.0001 & 0.0001 & 0 \\
\hline 124-Trimethylbenzene & 0 & 0 & 0 & 0.002 & 0 & 0.2055 & 0.1909 & 0.0211 \\
\hline Benzene & 0.0023 & 0.0024 & 0.0024 & 0.0845 & 0.1009 & 0.0565 & 0.0555 & 0.0271 \\
\hline Toluene & 0.0005 & 0.0005 & 0.0005 & 0.086 & 0.0719 & 0.0624 & 0.0601 & 0.0242 \\
\hline Ethylbenzene & 0 & 0 & 0 & 0.0046 & 0 & 0.0649 & 0.0617 & 0 \\
\hline Xylenes & 0 & 0 & 0 & 0.0225 & 0 & 0.2275 & 0.2145 & 0.0177 \\
\hline Methylcyclopentane & 0.0072 & 0.0073 & 0.0074 & 0.0117 & 0.0174 & 0.0011 & 0.0011 & 0.0002 \\
\hline & & & & & & & \\
\hline
\end{tabular}


Table A.3: Simulated glycol dehydrator still gas compositions(continued)

\begin{tabular}{|l|l|l|l|l|l|l|l|l|}
\hline Composition Number & 25 & 26 & 27 & 28 & 29 & 30 & 31 & 32 \\
\hline Hydrogen & 0 & 0.0001 & 0.0001 & 0 & 0 & 0.0001 & 0.0001 & 0 \\
\hline Helium & 0.0001 & 0 & 0 & 0 & 0 & 0.0002 & 0.0003 & 0 \\
\hline Nitrogen & 0.0008 & 0.0007 & 0.0007 & 0.0009 & 0.0009 & 0.0055 & 0.0063 & 0.0003 \\
\hline CO2 & 0.06 & 0.0681 & 0.0939 & 0.1061 & 0.0923 & 0.3303 & 0.2649 & 0.9253 \\
\hline H2S & 0 & 0 & 0 & 0 & 0 & 0.0014 & 0.0008 & 0.0053 \\
\hline Methane & 0.8587 & 0.8474 & 0.7905 & 0.8542 & 0.8656 & 0.6615 & 0.7258 & 0.0629 \\
\hline Ethane & 0.0329 & 0.0142 & 0.0143 & 0.0135 & 0.0132 & 0.0008 & 0.0012 & 0.0005 \\
\hline Propane & 0.0034 & 0.0015 & 0.0016 & 0.0021 & 0.002 & 0.0001 & 0 & 0 \\
\hline i-Butane & 0.0004 & 0.0002 & 0.0002 & 0.0003 & 0.0003 & 0 & 0 & 0 \\
\hline n-Butane & 0.0003 & 0.0003 & 0.0003 & 0.0003 & 0.0003 & 0.0001 & 0 & 0 \\
\hline i-Pentane & 0.0001 & 0.0001 & 0.0001 & 0.0001 & 0.0001 & 0.0001 & 0 & 0 \\
\hline n-Pentane & 0 & 0 & 0 & 0 & 0 & 0 & 0 & 0 \\
\hline Hexane & 0.0001 & 0.0001 & 0.0001 & 0.0001 & 0.0001 & 0 & 0 & 0 \\
\hline Heptane & 0.0001 & 0.0001 & 0.0002 & 0.0001 & 0.0001 & 0 & 0 & 0 \\
\hline Octane & 0.0003 & 0.0003 & 0.0004 & 0.0002 & 0.0002 & 0 & 0 & 0 \\
\hline Nonane & 0.0006 & 0.0006 & 0.0009 & 0.0005 & 0.0005 & 0 & 0.0002 & 0.0021 \\
\hline Decane & 0.0012 & 0.0011 & 0.0017 & 0.0008 & 0.0008 & 0 & 0.0004 & 0.0035 \\
\hline Cyclopentane & 0 & 0 & 0 & 0 & 0 & 0 & 0 & 0 \\
\hline Methylcyclohexane & 0.0008 & 0.0012 & 0.0022 & 0.0006 & 0.0006 & 0 & 0 & 0 \\
\hline Neohexane & 0.0001 & 0 & 0 & 0 & 0 & 0 & 0 & 0 \\
\hline Cyclohexane & 0.0004 & 0.0003 & 0.0006 & 0.0004 & 0.0004 & 0 & 0 & 0 \\
\hline 224-Trimethylpentane & 0 & 0 & 0 & 0 & 0 & 0 & 0 & 0 \\
\hline 124-Trimethylbenzene & 0.0094 & 0.0232 & 0.0254 & 0.0048 & 0.0061 & 0 & 0 & 0 \\
\hline Benzene & 0.0115 & 0.0071 & 0.0163 & 0.0039 & 0.0039 & 0 & 0 & 0 \\
\hline Toluene & 0.0107 & 0.0076 & 0.0155 & 0.0064 & 0.007 & 0 & 0 & 0 \\
\hline Ethylbenzene & 0 & 0 & 0 & 0 & 0 & 0 & 0 & 0 \\
\hline Xylenes & 0.0079 & 0.0257 & 0.0347 & 0.0043 & 0.0052 & 0 & 0 & 0 \\
\hline Methylcyclopentane & 0.0001 & 0.0001 & 0.0002 & 0.0002 & 0.0002 & 0 & 0 & 0 \\
\hline & & & & & & & 0 \\
\hline
\end{tabular}


Table A.3: Simulated glycol dehydrator still gas compositions(continued)

\begin{tabular}{|l|l|l|l|l|l|l|l|l|}
\hline Composition Number & 33 & 34 & 35 & 36 & 37 & 38 & 39 & 40 \\
\hline Hydrogen & 0 & 0 & 0 & 0 & 0 & 0 & 0 & 0 \\
\hline Helium & 0 & 0 & 0 & 0 & 0.0002 & 0.0002 & 0 & 0 \\
\hline Nitrogen & 0.0003 & 0.0001 & 0.0001 & 0.0002 & 0 & 0 & 0.002 & 0.002 \\
\hline CO2 & 0.9263 & 0.1066 & 0.0979 & 0.1797 & 0.4544 & 0.4611 & 0.0298 & 0.03 \\
\hline H2S & 0.0064 & 0 & 0 & 0 & 0 & 0 & 0 & 0 \\
\hline Methane & 0.0662 & 0.1931 & 0.1804 & 0.1628 & 0.2374 & 0.2372 & 0.244 & 0.2453 \\
\hline Ethane & 0.0004 & 0.0347 & 0.032 & 0.0248 & 0.0943 & 0.0936 & 0.025 & 0.0253 \\
\hline Propane & 0.0001 & 0.0203 & 0.0189 & 0.0213 & 0.0755 & 0.0748 & 0.071 & 0.0711 \\
\hline i-Butane & 0 & 0.0011 & 0.001 & 0.0006 & 0.0115 & 0.0113 & 0.0016 & 0.0016 \\
\hline n-Butane & 0.0002 & 0.0056 & 0.0052 & 0.0065 & 0.0223 & 0.0217 & 0.0277 & 0.0277 \\
\hline i-Pentane & 0 & 0.0014 & 0.0013 & 0.0009 & 0.0052 & 0.005 & 0.0027 & 0.0027 \\
\hline n-Pentane & 0 & 0.0046 & 0.0043 & 0.0058 & 0.0049 & 0.0047 & 0.0246 & 0.0245 \\
\hline Hexane & 0 & 0.0093 & 0.0087 & 0.0087 & 0.0046 & 0.0043 & 0.048 & 0.0478 \\
\hline Heptane & 0 & 0.0519 & 0.0486 & 0.0424 & 0.0005 & 0.0005 & 0.0365 & 0.0363 \\
\hline Octane & 0 & 0.1428 & 0.1343 & 0.071 & 0 & 0 & 0.0848 & 0.0844 \\
\hline Nonane & 0 & 0.0024 & 0.0023 & 0.0035 & 0 & 0 & 0 & 0 \\
\hline Decane & 0 & 0.004 & 0.0041 & 0.0061 & 0 & 0 & 0 & 0 \\
\hline Cyclopentane & 0 & 0 & 0 & 0 & 0 & 0 & 0 & 0 \\
\hline Methylcyclohexane & 0 & 0.0587 & 0.0551 & 0.0483 & 0.0014 & 0.0014 & 0.0453 & 0.0452 \\
\hline Neohexane & 0 & 0.0009 & 0.0008 & 0.0003 & 0 & 0 & 0 & 0 \\
\hline Cyclohexane & 0 & 0.0336 & 0.0313 & 0.0201 & 0.0081 & 0.0078 & 0.021 & 0.021 \\
\hline 224-Trimethylpentane & 0 & 0.0003 & 0.0002 & 0.0003 & 0 & 0 & 0 & 0 \\
\hline 124-Trimethylbenzene & 0 & 0.0058 & 0.0073 & 0.0329 & 0 & 0 & 0 & 0 \\
\hline Benzene & 0 & 0.1191 & 0.13 & 0.0854 & 0.0213 & 0.0204 & 0.0472 & 0.0473 \\
\hline Toluene & 0 & 0.1513 & 0.1752 & 0.1431 & 0.0032 & 0.0031 & 0.2744 & 0.2733 \\
\hline Ethylbenzene & 0 & 0.0062 & 0.0077 & 0.0301 & 0 & 0 & 0 & 0 \\
\hline Xylenes & 0 & 0.0321 & 0.0398 & 0.0961 & 0 & 0 & 0 & 0 \\
\hline Methylcyclopentane & 0 & 0.014 & 0.0131 & 0.0091 & 0.0552 & 0.053 & 0.0144 & 0.0144 \\
\hline & & & & & & & 0 \\
\hline
\end{tabular}


Table A.3: Simulated glycol dehydrator still gas compositions(continued)

\begin{tabular}{|l|l|l|l|l|l|l|l|l|}
\hline Composition Number & 41 & 42 & 43 & 44 & 45 & 46 & 47 & 48 \\
\hline Hydrogen & 0 & 0 & 0 & 0 & 0 & 0 & 0 & 0 \\
\hline Helium & 0.0007 & 0.0006 & 0.0002 & 0.0003 & 0 & 0.0001 & 0.0001 & 0.0001 \\
\hline Nitrogen & 0.0253 & 0.0242 & 0 & 0 & 0.0012 & 0 & 0 & 0 \\
\hline CO2 & 0.0065 & 0.0113 & 0.3753 & 0.2805 & 0.02 & 0.3878 & 0.3878 & 0.5685 \\
\hline H2S & 0 & 0 & 0 & 0 & 0 & 0 & 0 & 0 \\
\hline Methane & 0.9433 & 0.9297 & 0.2672 & 0.2798 & 0.1003 & 0.2887 & 0.2887 & 0.1235 \\
\hline Ethane & 0.0083 & 0.0135 & 0.0966 & 0.0958 & 0.044 & 0.0838 & 0.0838 & 0.1655 \\
\hline Propane & 0.0092 & 0.0125 & 0.0885 & 0.08 & 0.1205 & 0.0845 & 0.0845 & 0.0892 \\
\hline i-Butane & 0.0005 & 0.0005 & 0.014 & 0.0149 & 0.003 & 0.0135 & 0.0135 & 0.0088 \\
\hline n-Butane & 0.0036 & 0.0042 & 0.0274 & 0.034 & 0.0481 & 0.0305 & 0.0305 & 0.0209 \\
\hline i-Pentane & 0.0006 & 0.0007 & 0.0071 & 0.0141 & 0.0061 & 0.0073 & 0.0073 & 0.0028 \\
\hline n-Pentane & 0.002 & 0.0025 & 0.0063 & 0.0126 & 0.0424 & 0.0074 & 0.0074 & 0.0029 \\
\hline Hexane & 0 & 0 & 0.0057 & 0.0197 & 0.0924 & 0.0071 & 0.0071 & 0.0016 \\
\hline Heptane & 0 & 0 & 0.0009 & 0.001 & 0.0658 & 0.0008 & 0.0008 & 0.0001 \\
\hline Octane & 0 & 0 & 0 & 0 & 0.1052 & 0 & 0 & 0 \\
\hline Nonane & 0 & 0 & 0 & 0 & 0.0168 & 0 & 0 & 0 \\
\hline Decane & 0 & 0 & 0 & 0 & 0 & 0 & 0 & 0 \\
\hline Cyclopentane & 0 & 0 & 0 & 0 & 0 & 0 & 0 & 0 \\
\hline Methylcyclohexane & 0 & 0 & 0.0017 & 0 & 0.0649 & 0.0019 & 0.0019 & 0.0003 \\
\hline Neohexane & 0 & 0 & 0 & 0 & 0 & 0 & 0 & 0 \\
\hline Cyclohexane & 0 & 0 & 0.009 & 0 & 0.0419 & 0 & 0 & 0.0018 \\
\hline 224-Trimethylpentane & 0 & 0 & 0 & 0.0004 & 0 & 0 & 0 & 0 \\
\hline 124-Trimethylbenzene & 0 & 0 & 0 & 0 & 0 & 0 & 0 & 0 \\
\hline Benzene & 0 & 0 & 0.0319 & 0.1296 & 0.0523 & 0.0171 & 0.0171 & 0.0029 \\
\hline Toluene & 0 & 0 & 0.0066 & 0.0292 & 0.0832 & 0.0034 & 0.0034 & 0.0006 \\
\hline Ethylbenzene & 0 & 0 & 0.0009 & 0.0012 & 0.0156 & 0 & 0 & 0 \\
\hline Xylenes & 0 & 0 & 0.0026 & 0.0069 & 0.0445 & 0 & 0 & 0.0002 \\
\hline Methylcyclopentane & 0 & 0 & 0.058 & 0 & 0.0317 & 0.0661 & 0.0661 & 0.0103 \\
\hline & & & & & & & 0 \\
\hline
\end{tabular}


Table A.3: Simulated glycol dehydrator still gas compositions(continued)

\begin{tabular}{|l|l|l|l|l|l|l|l|l|}
\hline Composition Number & 49 & 50 & 51 & 52 & 53 & 54 & 55 & 56 \\
\hline Hydrogen & 0 & 0 & 0 & 0 & 0 & 0 & 0 & 0 \\
\hline Helium & 0.0001 & 0.0001 & 0.0001 & 0.0001 & 0 & 0 & 0 & 0 \\
\hline Nitrogen & 0 & 0 & 0 & 0 & 0.0004 & 0.0003 & 0.0001 & 0.0002 \\
\hline CO2 & 0.5647 & 0.5824 & 0.5938 & 0.5905 & 0.0562 & 0.0508 & 0.1608 & 0.5462 \\
\hline H2S & 0 & 0 & 0 & 0 & 0 & 0 & 0 & 0 \\
\hline Methane & 0.1254 & 0.1207 & 0.1184 & 0.1181 & 0.1297 & 0.1095 & 0.213 & 0.4176 \\
\hline Ethane & 0.1665 & 0.1634 & 0.1625 & 0.163 & 0.091 & 0.0796 & 0.0071 & 0.0248 \\
\hline Propane & 0.0899 & 0.0832 & 0.0777 & 0.0795 & 0.1791 & 0.1536 & 0.0027 & 0.0084 \\
\hline i-Butane & 0.0088 & 0.0082 & 0.0075 & 0.0078 & 0.0032 & 0.0032 & 0.0002 & 0.0005 \\
\hline n-Butane & 0.021 & 0.0182 & 0.0166 & 0.0171 & 0.0713 & 0.0609 & 0.0007 & 0.0019 \\
\hline i-Pentane & 0.0028 & 0.0025 & 0.0023 & 0.0023 & 0.0064 & 0.0062 & 0.0001 & 0.0004 \\
\hline n-Pentane & 0.0029 & 0.0024 & 0.0021 & 0.0022 & 0.0527 & 0.0507 & 0.0001 & 0 \\
\hline Hexane & 0.0016 & 0.0014 & 0.0012 & 0.0013 & 0.09 & 0.0802 & 0.0003 & 0 \\
\hline Heptane & 0.0001 & 0.0001 & 0.0001 & 0.0001 & 0.0423 & 0.0406 & 0.0008 & 0 \\
\hline Octane & 0 & 0 & 0 & 0 & 0.0437 & 0.0559 & 0.0024 & 0 \\
\hline Nonane & 0 & 0 & 0 & 0 & 0 & 0.007 & 0.0054 & 0 \\
\hline Decane & 0 & 0 & 0 & 0 & 0 & 0.0073 & 0.0106 & 0 \\
\hline Cyclopentane & 0 & 0 & 0 & 0 & 0 & 0 & 0 & 0 \\
\hline Methylcyclohexane & 0.0003 & 0.0003 & 0.0003 & 0.0003 & 0.0181 & 0.031 & 0.0092 & 0 \\
\hline Neohexane & 0 & 0 & 0 & 0 & 0 & 0.0025 & 0.0003 & 0 \\
\hline Cyclohexane & 0.0018 & 0.0017 & 0.0017 & 0.0017 & 0.0257 & 0.0256 & 0.0022 & 0 \\
\hline 224-Trimethylpentane & 0 & 0 & 0 & 0 & 0 & 0.0003 & 0.0001 & 0 \\
\hline 124-Trimethylbenzene & 0 & 0 & 0 & 0 & 0 & 0 & 0.1909 & 0 \\
\hline Benzene & 0.0029 & 0.0041 & 0.0042 & 0.0042 & 0.1009 & 0.1017 & 0.0555 & 0 \\
\hline Toluene & 0.0006 & 0.0007 & 0.0007 & 0.0007 & 0.0719 & 0.0846 & 0.0601 & 0 \\
\hline Ethylbenzene & 0 & 0 & 0 & 0 & 0 & 0 & 0.0617 & 0 \\
\hline Xylenes & 0.0002 & 0.0003 & 0.0003 & 0.0003 & 0 & 0.0336 & 0.2145 & 0 \\
\hline Methylcyclopentane & 0.0102 & 0.0104 & 0.0106 & 0.0107 & 0.0174 & 0.015 & 0.0011 & 0 \\
\hline & & & & & & & 0 \\
\hline
\end{tabular}


Table A.3: Simulated glycol dehydrator still gas compositions(continued)

\begin{tabular}{|l|l|l|l|l|l|l|l|l|}
\hline Composition Number & 57 & 58 & 59 & 60 & 61 & 62 & 63 & 64 \\
\hline Hydrogen & 0 & 0 & 0 & 0.0001 & 0 & 0 & 0 & 0 \\
\hline Helium & 0.0001 & 0.0001 & 0 & 0 & 0 & 0 & 0 & 0 \\
\hline Nitrogen & 0.0008 & 0.0009 & 0.0006 & 0.0007 & 0.0007 & 0.0009 & 0.0008 & 0.0003 \\
\hline CO2 & 0.06 & 0.0562 & 0.0847 & 0.0939 & 0.0936 & 0.0923 & 0.0955 & 0.9263 \\
\hline H2S & 0 & 0 & 0 & 0 & 0 & 0 & 0 & 0.0064 \\
\hline Methane & 0.8587 & 0.9013 & 0.8961 & 0.7905 & 0.8867 & 0.8656 & 0.8877 & 0.0662 \\
\hline Ethane & 0.0329 & 0.0366 & 0.0162 & 0.0143 & 0.017 & 0.0132 & 0.0129 & 0.0004 \\
\hline Propane & 0.0034 & 0.0038 & 0.0017 & 0.0016 & 0.0015 & 0.002 & 0.002 & 0.0001 \\
\hline i-Butane & 0.0004 & 0.0006 & 0.0004 & 0.0002 & 0.0002 & 0.0003 & 0.0003 & 0 \\
\hline n-Butane & 0.0003 & 0.0004 & 0.0003 & 0.0003 & 0.0002 & 0.0003 & 0.0003 & 0.0002 \\
\hline i-Pentane & 0.0001 & 0.0001 & 0.0001 & 0.0001 & 0.0001 & 0.0001 & 0.0001 & 0 \\
\hline n-Pentane & 0 & 0 & 0 & 0 & 0 & 0 & 0.0003 & 0 \\
\hline Hexane & 0.0001 & 0 & 0 & 0.0001 & 0 & 0.0001 & 0 & 0 \\
\hline Heptane & 0.0001 & 0 & 0 & 0.0002 & 0 & 0.0001 & 0 & 0 \\
\hline Octane & 0.0003 & 0 & 0 & 0.0004 & 0 & 0.0002 & 0 & 0 \\
\hline Nonane & 0.0006 & 0 & 0 & 0.0009 & 0 & 0.0005 & 0 & 0 \\
\hline Decane & 0.0012 & 0 & 0 & 0.0017 & 0 & 0.0008 & 0 & 0 \\
\hline Cyclopentane & 0 & 0 & 0 & 0 & 0 & 0 & 0 & 0 \\
\hline Methylcyclohexane & 0.0008 & 0 & 0 & 0.0022 & 0 & 0.0006 & 0 & 0 \\
\hline Neohexane & 0.0001 & 0 & 0 & 0 & 0 & 0 & 0 & 0 \\
\hline Cyclohexane & 0.0004 & 0 & 0 & 0.0006 & 0 & 0.0004 & 0 & 0 \\
\hline 224-Trimethylpentane & 0 & 0 & 0 & 0 & 0 & 0 & 0 & 0 \\
\hline 124-Trimethylbenzene & 0.0094 & 0 & 0 & 0.0254 & 0 & 0.0061 & 0 & 0 \\
\hline Benzene & 0.0115 & 0 & 0 & 0.0163 & 0 & 0.0039 & 0 & 0 \\
\hline Toluene & 0.0107 & 0 & 0 & 0.0155 & 0 & 0.007 & 0 & 0 \\
\hline Ethylbenzene & 0 & 0 & 0 & 0 & 6 & 0 & 0 & 0 \\
\hline Xylenes & 0.0079 & 0 & 0 & 0.0347 & 0 & 0.0052 & 0 & 0 \\
\hline Methylcyclopentane & 0.0001 & 0 & 0 & 0.0002 & 0 & 0.0002 & 0 & 0 \\
\hline & & & & & & 0 & 0 \\
\hline
\end{tabular}


Table A.3: Simulated glycol dehydrator still gas compositions(continued)

\begin{tabular}{|l|l|l|l|l|}
\hline Composition Number & 65 & 66 & 67 & 68 \\
\hline Hydrogen & 0.0003 & 0 & 0 & 0 \\
\hline Helium & 0.0002 & 0 & 0 & 0 \\
\hline Nitrogen & 0.0066 & 0.0001 & 0.0002 & 0.0002 \\
\hline CO2 & 0.3318 & 0.0979 & 0.1214 & 0.1797 \\
\hline H2S & 0.0017 & 0 & 0 & 0 \\
\hline Methane & 0.6583 & 0.1804 & 0.2233 & 0.1628 \\
\hline Ethane & 0.0008 & 0.032 & 0.04 & 0.0248 \\
\hline Propane & 0.0001 & 0.0189 & 0.023 & 0.0213 \\
\hline i-Butane & 0.0001 & 0.001 & 0.0013 & 0.0006 \\
\hline n-Butane & 0.0001 & 0.0052 & 0.0063 & 0.0065 \\
\hline i-Pentane & 0 & 0.0013 & 0.0015 & 0.0009 \\
\hline n-Pentane & 0 & 0.0043 & 0.0051 & 0.0058 \\
\hline Hexane & 0 & 0.0087 & 0.0102 & 0.0087 \\
\hline Heptane & 0 & 0.0486 & 0.0559 & 0.0424 \\
\hline Octane & 0 & 0.1343 & 0.1493 & 0.071 \\
\hline Nonane & 0 & 0.0023 & 0.0024 & 0.0035 \\
\hline Decane & 0 & 0.0041 & 0.0037 & 0.0061 \\
\hline Cyclopentane & 0 & 0 & 0 & 0 \\
\hline Methylcyclohexane & 0 & 0.0551 & 0.0605 & 0.0483 \\
\hline Neohexane & 0 & 0.0008 & 0.001 & 0.0003 \\
\hline Cyclohexane & 0 & 0.0313 & 0.036 & 0.0201 \\
\hline 224-Trimethylpentane & 0 & 0.0002 & 0.0003 & 0.0003 \\
\hline 124-Trimethylbenzene & 0 & 0.0073 & 0.0039 & 0.0329 \\
\hline Benzene & 0 & 0.13 & 0.0974 & 0.0854 \\
\hline Toluene & 0 & 0.1752 & 0.1153 & 0.1431 \\
\hline Ethylbenzene & 0 & 0.0077 & 0.0044 & 0.0301 \\
\hline Xylenes & 0 & 0.0398 & 0.0226 & 0.0961 \\
\hline Methylcyclopentane & 0 & 0.0131 & 0.0153 & 0.0091 \\
\hline & & & & \\
\hline
\end{tabular}




\section{Appendix B: Supporting Calculations}

To validate the assumption that the mass of $\mathrm{BC}$ is negligible for the DRE calculation, we will compare the mass of carbon dioxide produced and the mass of $\mathrm{BC}$ produced in the case with the highest BC yield H11 (2). The BC measured from this test was $13.508 \pm 1.124 \mathrm{~g} / \mathrm{m}^{3}$ and we will calculate the emission factor of carbon dioxide $E F_{\mathrm{CO}_{2}}$.

$$
\begin{gathered}
E F_{C O_{2}}=\frac{\left(X_{C O_{2}, p}-X_{C O_{2}, \infty}\right) \dot{n}_{p} M_{C O_{2}}}{60 Q_{F G}} \\
E F_{C O_{2}}=\frac{\left(3.974 \times 10^{-3}-4.729 \times 10^{-4}\right) 042478 \times 44.01}{60 \times 75} \\
E F_{C O_{2}}=5235.6 \frac{\mathrm{g}}{\mathrm{m}^{3}}
\end{gathered}
$$

When comparing the mass of $\mathrm{BC}$ produced per cubic meter of flare gas to the emission factor of carbon dioxide, $\mathrm{BC}$ is only $0.0026 \%$ of the mass of carbon dioxide. This means that all other test cases would be even lower, and that for this research the assumption of the mass of $\mathrm{BC}$ is negligible when calculating the $\mathrm{DRE}$ of benzene.

To validate the assumption that $M_{\infty}=M_{p}$, we will look at the test case with the lowest duct dilution factor $\mathrm{C}_{6} \mathrm{H}_{6}+\mathrm{CO}_{2}$. We will begin by calculating DRE with the assumption that $M_{\infty}=M_{p}$, starting by calculating $A$.

$$
\begin{gathered}
A=X_{C O, p}-X_{C O, \infty}+X_{C H_{4}, p}-X_{C_{4}, \infty}+\# C_{C_{6} H_{6}}\left(X_{C_{6} H_{6}, p}-X_{C_{6} H_{6}, \infty}\right) \\
A=9.664 \times 10^{-7}-0+4.930 \times 10^{-6}-4.388 \times 10^{-6}+6\left(1.76 \times 10^{-9}-0\right) \\
A=1.533 \times 10^{-6}
\end{gathered}
$$

Using (3.4) and calculating $D$ :

$$
\begin{gathered}
D=X_{C O, p}+X_{C H_{4}, p}+\# C_{C_{6} H_{6}} X_{C_{6} H_{6}, p} \\
D=9.664 \times 10^{-7}+4.930 \times 10^{-6}+6\left(1.76 \times 10^{-9}\right) \\
D=6.060 \times 10^{-6}
\end{gathered}
$$

Using Equation (3.5) to calculate $E$. 


$$
\begin{gathered}
E=X_{C O, \infty}+X_{C_{4}, \infty}+\# C_{C_{6} H_{6}} X_{C_{6} H_{6}, \infty} \\
E=0+4.388 \times 10^{-6}+6(0) \\
E=4.527 \times 10^{-6}
\end{gathered}
$$

Lastly, we can substitute $A, D, E$, and all known variables into (3.2) to calculate DRE:

$$
\begin{aligned}
& D R E_{C_{6} H_{6}}=\left[1-\frac{\left(x\left(X_{C_{x} H_{y}, F G}\right)+X_{C O_{2} . F G}\right)\left(X_{C_{6} H_{6}, p}-X_{C_{6} H_{6}, \infty}\right)}{\left(X_{i, F G}\right)\left(X_{C_{2} \cdot p}-X_{C_{2} \cdot \infty}+A\right)}\right. \\
& \left.+\frac{\left(X_{C_{6} H_{6}, \infty}\left(X_{C_{2} . p}+D\right)-X_{C_{6} H_{6}, p}\left(X_{C_{2} \cdot \infty}+E\right)\right) \frac{\dot{m}_{F G}}{M_{\infty}}}{\left(X_{C_{6} H_{6}, F G}\right)\left(X_{C O_{2} . p}-X_{C O_{2} . \infty}+A\right)}\right] \\
& D R E_{C_{6} H_{6}} \\
& =\left[1-\frac{(1.334(0.2677)+0.70)\left(1.76 \times 10^{-9}-0\right)}{(0.0171)\left(4.15 \times 10^{-6}-0+3.20 \times 10^{-6}\right)}\right. \\
& \left.+\frac{\left(0.75 \times 10^{-9}\left(4.15 \times 10^{-6}+1.01 \times 10^{-5}\right)-3.60 \times 10^{-9}\left(0+6.88 \times 10^{-6}\right)\right) \frac{0.001867}{28.84}}{(0.0171)\left(4.15 \times 10^{-6}-0+3.20 \times 10^{-6}\right)}\right] \\
& D R E_{C_{6} H_{6}}=0.99990
\end{aligned}
$$

Next we repeat the calculation for DRE using the molar mass of the idealized combustion products $M_{p}$, which has a value of $29.95 \frac{\mathrm{kg}}{\mathrm{kmol}}$. The values of $A, D$, and $E$ all remain the same for this calculation, so we can substitute them directly into (3.2). 


$$
\begin{aligned}
D R E_{C_{6} H_{6}}= & {\left[\begin{array}{l}
1-\frac{\left(x\left(X_{C_{x} H_{y}, F G}\right)+X_{C O_{2} \cdot F G}\right)\left(X_{C_{6} H_{6}, p}-X_{C_{6} H_{6}, \infty}\right)}{\left(X_{i, F G}\right)\left(X_{C O_{2} \cdot p}-X_{C O_{2} \cdot \infty}+A\right)} \\
+\frac{\left(X_{C_{6} H_{6}, \infty}\left(X_{C O_{2} \cdot p}+D\right)-X_{C_{6} H_{6}, p}\left(X_{C O_{2} \cdot \infty}+E\right)\right) \frac{\dot{m}_{F G}}{M_{\mathrm{p}}}}{\left(X_{C_{6} H_{6}, F G}\right)\left(X_{C O_{2} \cdot p}-X_{C O_{2} \cdot \infty}+A\right)}
\end{array}\right] }
\end{aligned}
$$

$$
\begin{aligned}
& D R E_{C_{6} H_{6}} \\
& =\left[1-\frac{(1.334(0.2677)+0.70)\left(1.76 \times 10^{-9}-0\right)}{(0.0171)\left(4.15 \times 10^{-6}-0+3.20 \times 10^{-6}\right)}\right. \\
& \left.+\frac{\left(0.75 \times 10^{-9}\left(4.15 \times 10^{-6}+1.01 \times 10^{-5}\right)-3.60 \times 10^{-9}\left(0+6.88 \times 10^{-6}\right)\right) \frac{0.001867}{29.95}}{(0.0171)\left(4.15 \times 10^{-6}-0+3.20 \times 10^{-6}\right)}\right] \\
& \operatorname{DRE}_{C_{6} H_{6}}=\mathbf{0 . 9 9 9 9 0}
\end{aligned}
$$

As can be observed from the calculations DRE remains the same in either case, therefore the assumption is valid. 